\title{
CHARACTERISTICS OF HIGH-PERFORMING CALIFORNIA CHARTER SCHOOLS SERVING LOW-INCOME MINORITY STUDENTS
}

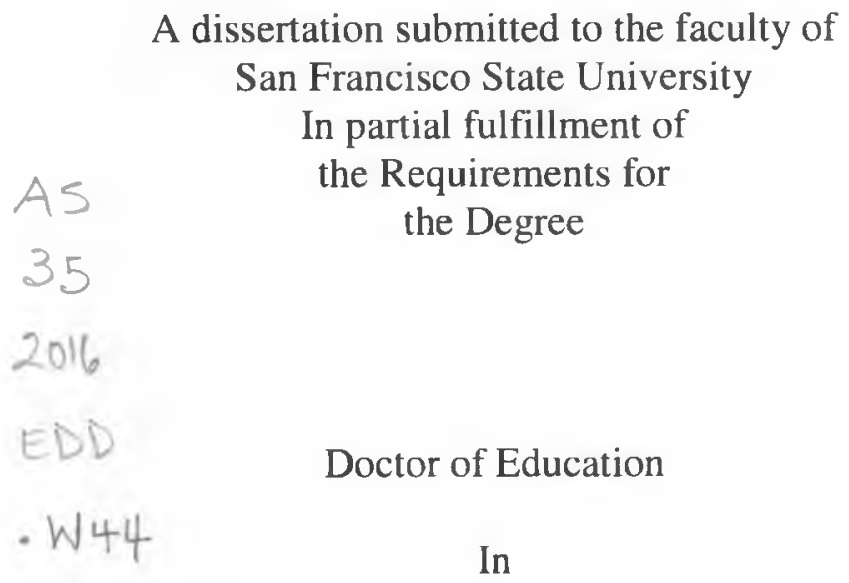

Educational Leadership

by

Timothy L. Weekes

San Francisco, California

May 2016 
Copyright by

Timothy L. Weekes

2016 


\section{CERTIFICATION OF APPROVAL}

I certify that I have read Characteristics of High-Performing California Charter Schools Serving Minority and Low-income Students by Timothy L. Weekes, and that in my opinion this work meets the criteria for approving a thesis submitted in partial fulfillment of the requirement for the degree Doctor of Education at San Francisco State University.
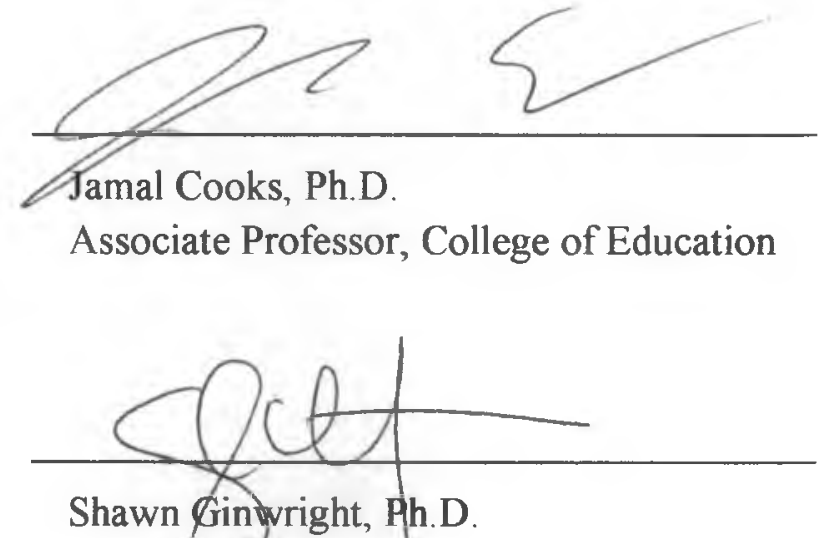

Associate Professor of Ethnic Studies

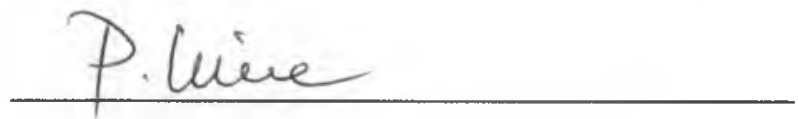

Patricia Irvine Ph.D.

Associate Dean, College of Education and

Allied Studies 


\section{CHARACTERISTICS OF HIGH-PERFORMING CALIFORNIA CHARTER SCHOOLS SERVING UNDER-REPRESENTED MINORITY STUDENTS}

Timothy L. Weekes

San Francisco, California 2016

Since the establishment of the first public charter school in 1991, the number of public charters has grown to more than 6,400 schools serving over 2.5 million students in the U.S. As their numbers continue to grow, charters are becoming responsible for educating a disproportionately larger percentage of our under-represented minority (URM) and lowincome students.

This study investigated three high-performing urban charter schools to explore the performance characteristics that specifically support the academic achievement of URM and low-income students. It was found that at all three schools: teachers and administrators had high-expectations for student achievement; the curriculum was internally developed to meet the needs of the students; and teacher engaged in culturally responsive instructional practices.

I certify that the Abstract is a correct representation of the content of this dissertation.
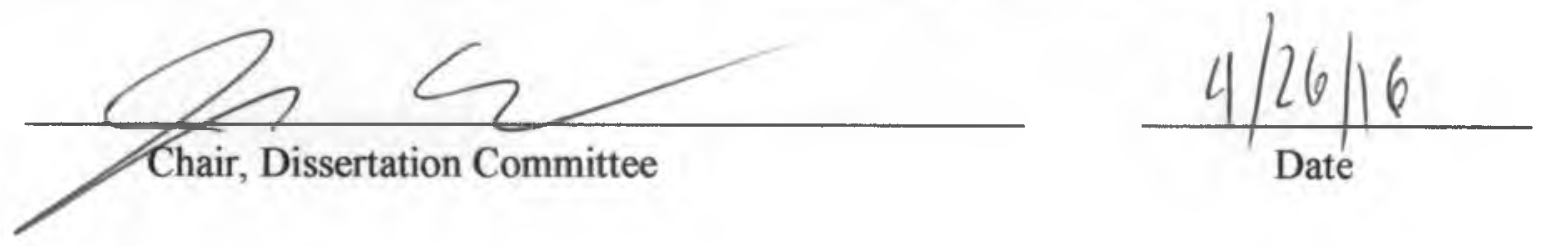


\section{ACKNOWLEDGEMENTS}

I want to thank my dissertation chair, Dr. Jamal Cooks, for his support and guidance throughout this process. Additionally, I would like to thank my amazing dissertation committee, Dr. Shawn Ginwright and Dr. Patricia Irvine, for their invaluable insight and direction. And finally, I would like to thank the Educational Leadership Program

Director, Dr. Robert Gabriner, and all the amazing professors who challenged me and motivated me to finish this monumental achievement. 


\section{TABLE OF CONTENTS}

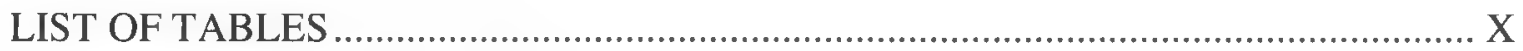

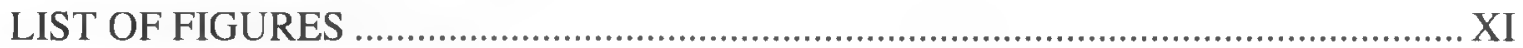

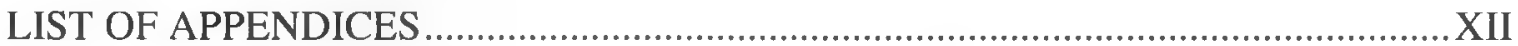

CHAPTER ONE ...................................... ERROR! BOOKMARK NOT DEFINED.

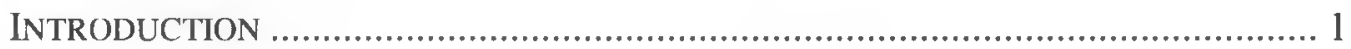

RESEARCH QUESTIONS AND DESIGN .................................................. 4

THEORETICAL FRAMEWORK ................................................................. 6

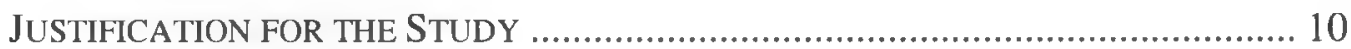

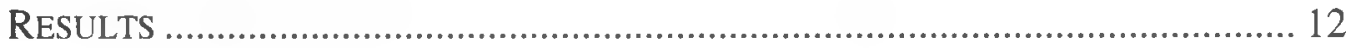

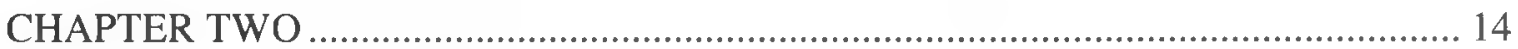

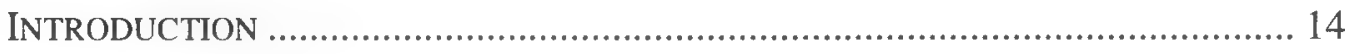

SCOPE AND SEARCH CRITERIA .............................................................. 15

Charter SchoOl History ANd GrowTH ........................................... 15

Charter School Demographics Characteristics................................. 21

Charter School AchiEvement ................................................... 27

CHAPTER THREE

ERROR! BOOKMARK NOT DEFINED.

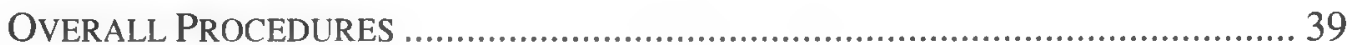

Sample Selection......................................................................... 40

vii 
Role of the Researcher ................................................................... 43

Data Collection ......................................................................... 43

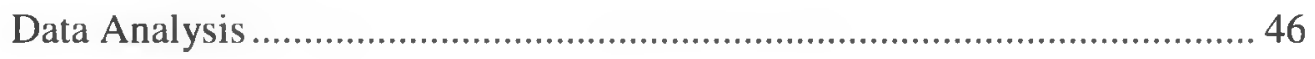

CHAPTER FOUR

ERROR! BOOKMARK NOT DEFINED.

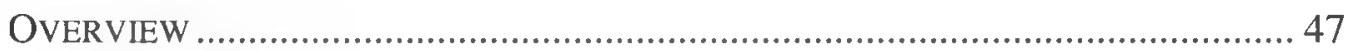

SCHOOL \#1: DESTINY PubLIC SCHOOL (DPS) ............................................. 49

The Destiny Public School Culture...................................................... 50

The Destiny Public School Classroom ................................................... 54

SCHOOL \#2: BeLIEVE IN Me ACAdEMy (BIM) ............................................. 59

The Believe In Me Academy Culture .................................................6 60

The Believe In Me Academy Classroom ............................................. 64

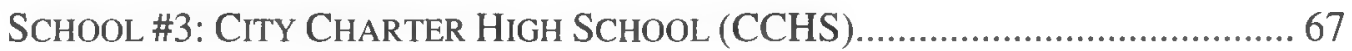

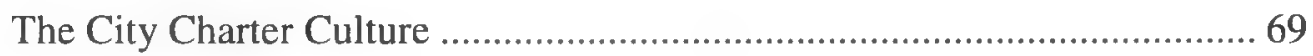

The City Charter Classroom .................................................... 73

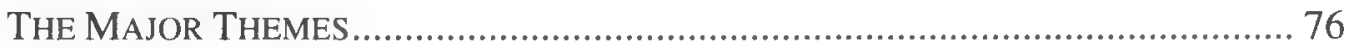

High EXPECTATIONS WITH SUPPORT ................................................. 77

College Going Culture with Commitment and Support ........................... 78 
Four-Year Cohort Advisory, Student Support and Development Model ..... 93

Internally DeVEloPed, Culturally ReleVAnt CURRICUlum .................... 97

DifFerentiated, Culturally Responsive Instructional Practices..... 107

CHAPTER FIVE ERROR! BOOKMARK NOT DEFINED.

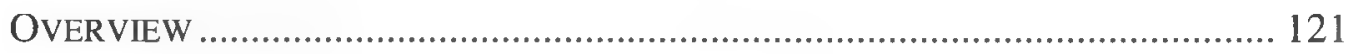

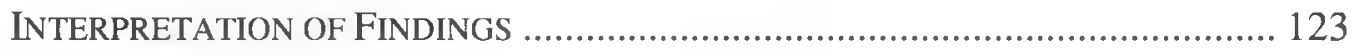

EDUCATIONAL EQUITY IMPLICATIONS .......................................................... 130

RECOMMENDATIONS FOR PRACTICE ………………….............................. 132

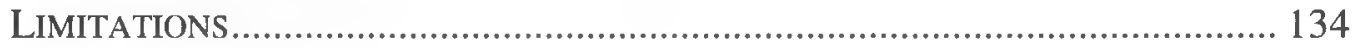

RECOMMENDATIONS FOR FURTHER STUDY …………................................. 134

REFLECTIONS ON THE RESEARCH PROCESS.................................................... 135

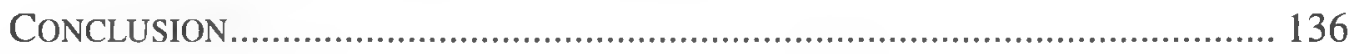

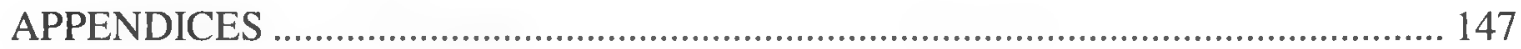




\section{LIST OF TABLES}

Table

Page

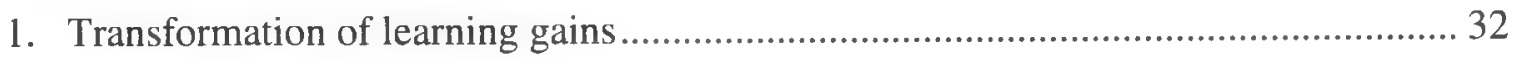

2. School demographics and performance ..................................................................... 42

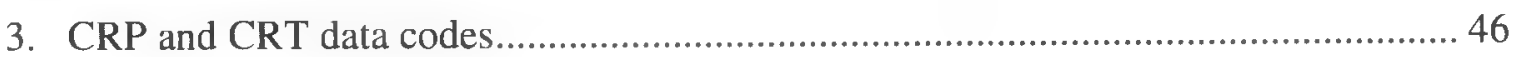




\section{LIST OF FIGURES}

1. Theoretical Framework ........................................................................................... 9 


\section{LIST OF APPENDICES}

Appendix $\quad$ Page

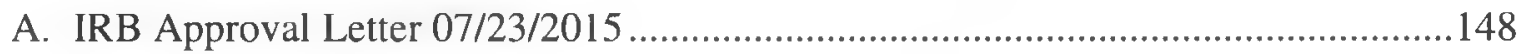

B. Counselor interview questions ............................................................. 149

C. Teacher interview questions .................................................................. 150

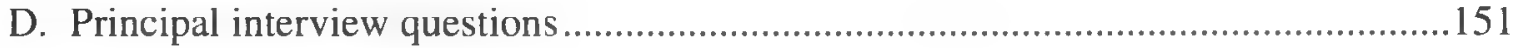

E. Classroom observation template ............................................................ 152

F. Split page observation template .............................................................. 154

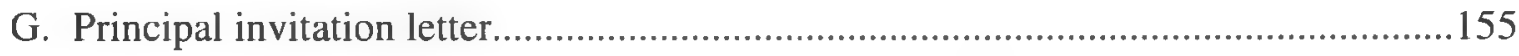

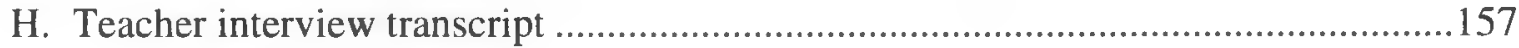

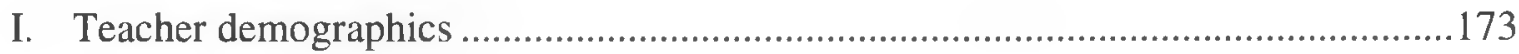




\section{Chapter One}

\section{Introduction}

Over the past two decades, charter schools have been the fastest growing segment in the U.S. public education system (Zimmer, Gill, Booker, Lavertu, \& Witte, 2012). Since the establishment of the first public charter school in Minnesota in 1991, the number of public charters has grown to more than 6,400 schools. Between 1999 and 2014 , the number of students enrolled in U.S. public charters increased from 300,000 to over 2.5 million. During that same period, the percentage of U.S. public school students enrolled in charter schools has grown from $0.7 \%$ to $4.2 \%$ (U.S. Department of Education, 2014).

Charter schools are publicly funded schools that operate outside of the direct control of conventional school districts and are under the authority of a charter-granting public body. As such, they are not directly controlled by the multiple layers of management governing our public school system. This increased autonomy allows for increased site-based decision making and the ability to respond quickly to the specific needs of the school.

Supporters had hoped that greater autonomy would allow charter schools to cut through much of the bureaucratic red tape and foster innovative reforms, provide families 
with additional school choices, and promote healthy competition, all of which would lead to increased student achievement (Bulkley \& Fisler, 2003; Zimmer et al., 2012). Critics contend that charter schools siphon away scarce financial resources from local traditional public schools (TPS), which can lead to re-segregation and rob TPS of their most promising and motivated students and teachers (Lacireno-Paquet, Holyoke, Moser, \& Henig, 2002; Zimmer et al., 2012).

Nevertheless, for some advocates, charter schools were seen as one possible solution to the achievement gap, especially in high-poverty urban areas (Zimmer \& Buddin, 2006b). Consequently, in recent years, research studies analyzing charter school performance have proliferated (Betts \& Tang, 2011; Buddin \& Zimmer, 2005; Cremata et al., 2013; Hill, Angel, \& Christensen, 2006; Winters, 2012; Zimmer \& Buddin, 2006a, 2006b; Zimmer et al., 2012). The overall findings of these studies have shown mixed results for charter school performance. Using student and district level assessment data to measure student achievement, these studies found that a small percentage of charters outperform TPS, a majority of charters are on par with TPS, and some charters perform far worse than TPS. A study of urban charter schools found that inner-cities charters outperform their TPS peers by a two to one margin when it comes to increasing the achievement of low-income and minority students (CREDO, 2105). 
Betts and Tang (2011) have argued that the mixed results may be due to the inconsistency and complexity involved in the research designs used to compare charter schools with traditional public schools (TPS). Others have concluded that the discrepancies may be the product of the varying state regulatory environments in which charter schools operate (Zimmer et al., 2012). The educational problem we face is that charter schools continue to educate an increasing proportion of the nation's public school students, especially those living in urban environments; however, we do not have a clear understanding of the factors that can lead to success for some charters and failure for others.

\section{Operational Definition of Key Terms}

Underrepresented Minorities (URMs): students who categorize themselves as African American (Black), Latino, or American Indian. This term has been selected because California institutions of higher education currently use it when referencing issues related to the achievement gap (Stulberg \& Weinberg, 2011).

Public Charter School: a publicly funded school operated by a group or organization that is under contract or charter with the state or other local jurisdiction (U.S. Department of Education, 2014). 


\section{Research Questions and Design}

The purpose of this study is to describe the primary performance characteristics of three high-performing California charter schools serving a majority of Under-represented minority (URM) and low-income students. Such schools are commonly referred to as high-needs schools (Klar \& Brewer, 2013). This study can provide deeper insight into the factors supporting the achievement of high-needs, high-performing California charter schools. Ultimately, the study's findings identify replicable practices that other public schools, serving similar student populations, can adopt to help increase student achievement.

This study sought to answer the following research question:

What are the primary performance characteristics of high-performing California charter schools serving low-income, underrepresented minority students?

To answer this question, the study employed a comparative, multi-case study analysis (Merriam, 1991) of three high-performing California charter schools. The charter schools were selected from a public national ranking report (U.S. News \& World Report, 2015). Each case was bound (Miles, Huberman, \& Saldaña, 2013) by the requirements that the schools selected for analysis must serve a majority of students classified as underrepresented minorities and as recipients of free or reduced lunch. Each school (i.e., 
case) was analyzed using an interpretive case study (Merriam, 1991) that included principal and teacher interviews and classroom observations.

Interpretive case studies are designed to illustrate or support theoretical assumptions made prior to gathering data (Merriam, 1991). The analytical approach used in this type of case study is inductive, and the outcomes of the analysis can range from thick, rich descriptions of each school's performance to the construction of a new theory illuminating the phenomenon of charter school student achievement.

Principal interviews were used to inquire about teacher recruitment, development, and retention; resource allocation; data-driven instruction; parent outreach; and school culture. Teacher interviews were used to inquire about curriculum, instructional practices, school culture, and student expectations. Classroom observations were used to investigate teaching practices, formative assessment strategies, and student expectations. A limited amount of document analysis determined the extent to which the characteristics and practices supporting student achievement were recorded in the school artifacts. These data sources, when available, were used to triangulate the findings from the principal and teacher interview. 


\section{Theoretical Framework}

The perspective used to frame this study is taken from the frameworks of culturally relevant pedagogy (CRP) (Ladson-Billings, 1995) and culturally responsive teaching (CRT) (Gay, 2002). Blended together, these two frameworks provide a theoretical lens with which to objectively investigate the characteristics of schools serving a majority of underrepresented minority students.

Ladson-Billings (2009) defined culturally relevant pedagogy as one "that empowers students intellectually, socially, emotionally, and politically using cultural referents to impart knowledge, skills, and attitudes" (pp. 16-17). Ladson-Billings (Ladson-Billings, 1995) described culturally relevant pedagogy as a "pedagogy of opposition not unlike critical pedagogy but specifically committed to collective, not merely individual, empowerment” (p. 160). Ladson-Billings (1995) additionally described a framework for culturally relevant pedagogy that encompassed the following three components.

Educators engaging in culturally relevant pedagogy think in terms of long-term academic achievement and not merely end-of-year tests. After advocates of culturally relevant pedagogy began to equate student achievement with standardized test scores, Ladson-Billings (2006) clarified her intent: “"student learning'-what it is that students 
actually know and are able to do as a result of pedagogical interactions with skilled teachers" (p. 34).

Culturally relevant pedagogues also focus on cultural competence, which "refers to helping students to recognize and honor their own cultural beliefs and practices while acquiring access to the wider culture, where they are likely to have a chance of improving their socioeconomic status and making informed decisions about the lives they wish to lead"' (Ladson-Billings, 2006, p. 36). They understand that students must learn to successfully make the transition between home and school, and teachers must find ways to equip students with the knowledge and socio-emotional skills needed to succeed in a school system that has historically oppressed them.

Culturally relevant pedagogues seek to develop sociopolitical consciousness, which requires teachers to find ways for "students to recognize, understand, and critique current and social inequalities" (Ladson-Billings, 1995b, p. 476).

Gay (2010) defined culturally responsive teaching as "using the cultural knowledge, prior experiences, frames of reference, and performance styles of ethnically diverse students to make learning encounters more relevant to and effective for them" (p. 31). There are six basic dimensions to culturally responsive teaching: (a) empowering students socially and academically by setting high expectations and committing to every 
student's success; (b) being multidimensional and engaging students' cultural knowledge, experiences, contributions, and perspectives; (c) validating the culture of every student by bridging gaps between school and home by using diversified instructional strategies and culturally relevant curricula; (d) being holistic as they seek to educate the whole child, socially, emotionally, and politically; (e) transforming schools by using students' prior knowledge to drive instruction, assessment, and curriculum design; and (f) being emancipatory and liberating from oppressive educational practices and ideologies as they lift "the veil of presumed absolute authority from conceptions of scholarly truth typically taught in schools" (Gay, 2002, p. 38).

As a theoretical framework, the works of Ladson-Billings (1995a, 1995b, 2009) and Gay $(2002,2010)$ represent two related but distinct perspectives from which to view the characteristics of the schools investigated in this study. Ladson-Billings' focus on pedagogy describes the attitudes and mindsets culturally relevant teachers adopt when designing curricula and assessments and planning lessons. Gay's focus on teaching describes the competencies and methodologies underlying what a teacher does in a culturally responsive classroom. An illustration of this framework is included in Figure 1. 


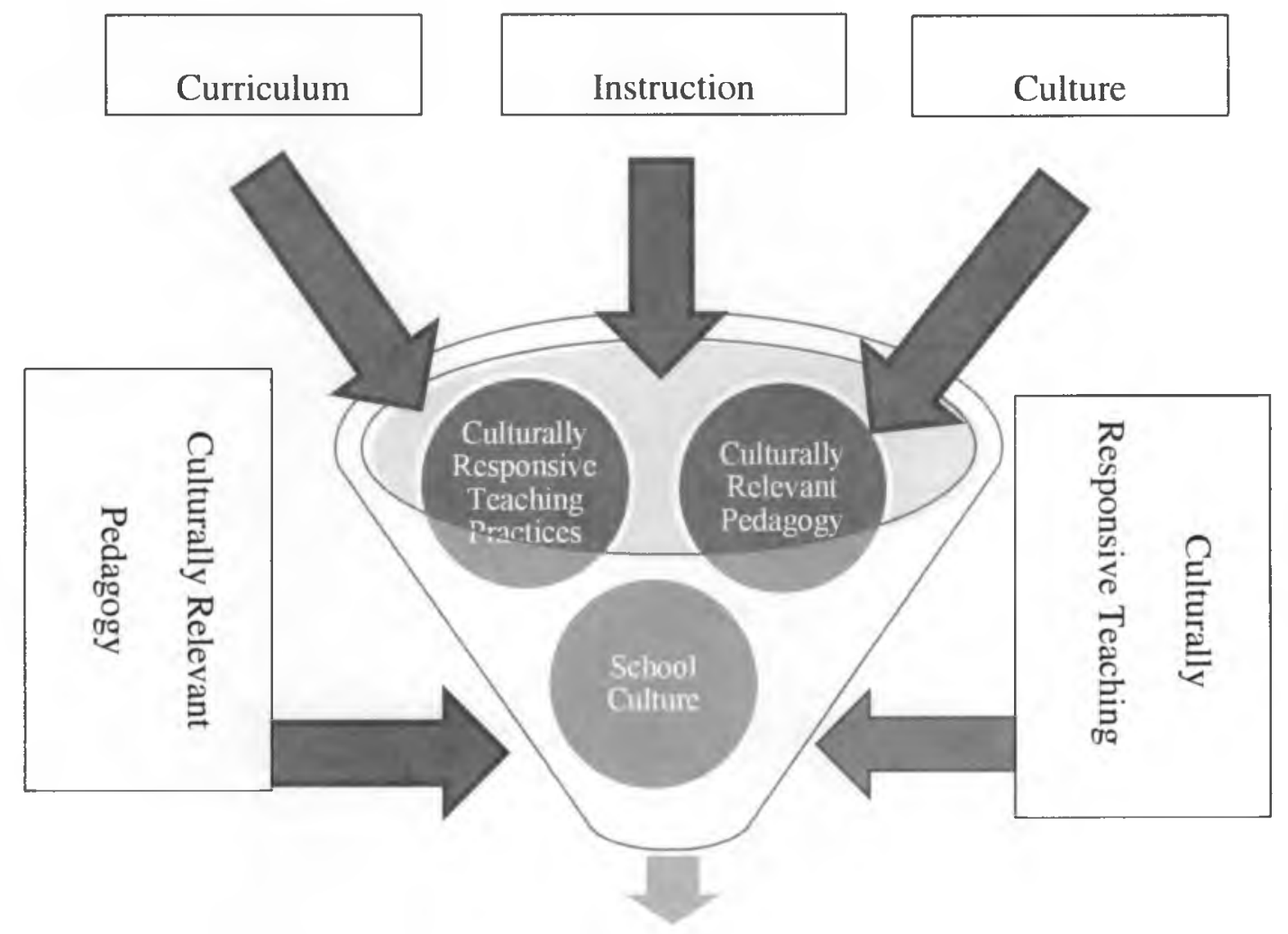

Characteristics, Practices, Culture

Figure 1. Theoretical Framework

The three components of culturally relevant pedagogy and the six dimensions of culturally responsive teaching were operationalized into a number of data codes, which are explained in more detail in chapter three. These codes were used during the first and 
second round of hypothesis coding (Miles et al., 2013) in order to find common themes across each of the three schools investigated in this study.

The theoretical frameworks of culturally relevant education and culturally responsive teaching were used as lens to focus the investigation on those characteristics of each school that were related to the school's curriculum, instructional practices, and culture. These three characteristics represented are considered four of three foundational pillars of culturally responsive teaching. By using these frameworks as conceptual lenses, the researcher was able to objectively investigate the three schools and mitigate much of his personal research bias. By analyzing each school curricula, instructional practices, and culture through these lenses, he was able to open-mindedly observe what he believed are foundational characteristics supporting each school's achievement.

\section{Justification for the Study}

Charter schools are a small but growing element in the U.S. public education landscape. As their numbers continue to grow, they disproportionately become more responsible for educating a larger proportion of our children in poverty and of our Black and Hispanic students (Cremata et al., 2013; Lacireno-Paquet et al., 2002). As this trend continues, the need for rich, descriptive research explaining charters' distinctiveness will 
become essential to an informed discussion about the role charter schools could play in closing the achievement gap in California.

Only Arizona (13\%) has higher concentrations of public school students attending charter schools than California (8\%) (National Center for Education Statistics, 2015). In the fall of 2014, California had more than a half million students attending the largest number of charter schools $(1,184)$ in the nation. In that same year, 87 new public charter schools opened in California (California Charter Schools Association, 2106), making California the fastest growing charter school state in the nation.

What also makes California so important to the charter school debate is the broad array of charters operating within the state. Some California charter schools are "conversions" and others are "startups" charters. Moreover, California charters also use two distinct instructional approaches. Most charters utilize a traditional classroom setting, but others use non-classroom approaches such as homeschooling, independent study, and online learning (Zimmer \& Buddin, 2006a).

Much of the charter school research conducted both nationally and in California has focused on comparing the achievement of charter school students to those attending TPS. However, the findings from these studies have shown mixed results, and in a number of cases, the methodology and findings have been questioned due to concerns 
about validity and reliability (Betts \& Tang, 2011). The proposed study seeks to add to the current body of research on charter school performance by identifying and describing the most salient performance characteristics across three high-performing California charter schools serving a majority of URM students. The equity and leadership implications of this study are grounded in the anticipated transferability of the study's findings to support the replication of high-performing charters that are designed to serve minority and low-income students.

\section{Results}

Three common themes emerged from the analysis as primary characteristics supporting student achievement across the three schools. Each school had a culture of high expectations that was reinforced by a number of academic support programs and strategies. The teachers and administrators also displayed a strong commitment to help students succeed. A lead content teacher or team of teachers internally developed the majority of the curricula taught at the schools. It was often designed with very high levels of rigor and included scaffolds at accommodate students with varying levels of prior knowledge and skills. The instructional practices used by many of the teachers were engaging and multi-dimensional. These practices involved the use of multiple teaching 
modalities and typically incorporated some type of collaborative learning approach into every lesson. 


\section{Chapter Two}

\section{Introduction}

Since charter schools were first conceived in the mid-1970s and later, formally proposed by then-president of the American Federation of Teachers in the late 1980s, they were intended to be structurally and philosophically different from traditional public schools. However, since the first charter school opened in 1991, charters have been embroiled in controversies regarding the following: their mixed record of student achievement; their use or misuse of financial and human capital; and the effects they are believed to have on the traditional public schools from which they draw their students and teachers.

The purpose of this literature review is to discuss a number of published studies about the genesis and evolution of the U.S. charter school sector. In doing so, this review will examine the findings from a number of empirical charter school achievement studies and offer a critique of the methodologies used in their research. Finally, this review will deliberate the findings from a number of achievement studies that support the notion of charter schools outperforming traditional public schools (TPS) when it comes to educating urban, low-income, minority, and English Language Learner (ELL) students in math and reading. 


\section{Scope and Search Criteria}

The scope of literature reviewed for this study includes peer-reviewed articles found using ERIC (EBSCO) and Google Scholar. The keywords used in the literature search were: ("CHARTER SCHOOL" and "ACHIEVEMENT"), ("CHARTER SCHOOL" and "HISTORY"), and ("CHARTER SCHOOL" and "MINORITY").

Snowball sampling was used to find additional relevant articles from the references in the sources retrieved using the above search criteria. Finally, more recent studies were found by scanning the table of contents in the most recent issue of the Journal for School Choice for relevant articles.

This literature review will focus on studies related to the following three categories:

- charter school history and growth,

- charter school demographics and characteristics, and

- charter school achievement.

\section{Charter School History and Growth}

Charter schools were initially conceived by Ray Budd, a former high school teacher and principal from East Lansing, Michigan (Kolderie, 2005). In 1974, Budd was 
teaching educational administration at the University of Massachusetts when he presented his ideas for the reorganization of school districts in a paper he titled "Education by Charter" (Kolderie, 2005). The paper did not receive much attention at the time, however, and it was shelved as he pursued an array of in-service training opportunities at local schools (Kolderie, 2005). Then, in the 1980s, came the report: Nation at Risk. Suddenly, the prospect implementing a radical school-restructuring scheme became more feasible. Budd "dusted off" his paper and had it published in The Regional Laboratory for Educational Improvement of the Northeast \& Islands (Budde, 1988). He distributed the paper widely and even sent a copy to then-president George H.W. Bush; however, there was still little interest in his ideas about school restructuring by charter.

The charter school concept finally gained some national attention in 1988 when Albert Shanker, then-president of the American Federation of Teachers (AFT), endorsed the charter school concept during a National Press Club speech in Washington, D.C. Shanker had been impressed by a model school he observed in the fall of 1987 during a visit to West Germany. The trip was part of an ongoing exchange program between the AFT and the GEW, the teachers' union of the Federal Republic of Germany.

The school he visited was the Holweide Comprehensive School in Cologne. Unlike most other European schools of that time, Holweide had a broad diversity of 
students similar to the diversity found in many U.S. public schools (Shanker, 1988). The students at the Holweide School included children of Turkish, Moroccan, and other foreign origins as "guest workers" from a broad range of linguistic and cultural backgrounds. Moreover, many of the native German children attending the school came from poor and broken homes. However, unlike other German schools where children were tracked according to "ability," Holweide had a mixture of students in each classroom, many of whom had already been identified by national exams as not being "college material" (Shanker, 1988). Shanker was impressed by the school's results and subsequently proposed a model for new teacher-led schools based on a combination of some of the characteristics he observed at the Holweide School and some of the concepts proposed by Budd in his paper on school restructuring by charter.

Shanker (1988) argued that the poor results produced by U.S. public schools were the direct result "of a bureaucratic, hierarchical, and factory-like structure of schooling that had remained virtually unchanged for 150 years; this structure's organization and assumptions essentially precluded all but one way of teaching (mainly lecturing) and all but one way of learning (mainly by listening and reading)" (1988, p. 92). Shanker proposed restructuring school districts by creating a policy that would allow teachers to "develop a proposal for how they could better educate youngsters and then 
give them a 'charter' to implement that proposal" (1988, p. 97). According to Shanker's plan for restructuring school districts by charter, teachers could submit their proposal for a school charter through the existing request for proposal (RFP) process.

To be considered, the RFP had to thoroughly address the following eight items:

(a) how the school would be organized to ensure that all students had equal access to worthwhile and useful knowledge based on high standards, recognizing that children learn in different ways and at different rates; (b) how students would be engaged as active workers in creating knowledge rather than being treated as passive recipients of information; (c) how the curriculum would support the use of multiple instructional strategies which included integration of audio, video, dance, drama, and manipulatives into classroom activities; (d) how the school would support a collegial and cooperative atmosphere among teachers and students and "ensure a continuity of learning and social relationships between teachers and students, for example, by teams of teachers and students working together for more than one year" (1988, p. 99); (e) how the school would actively involve parents and the larger community in the education of students in a plan for shared decision making; (f) how best practices about learning and teaching would be sought and applied to how the school will organize itself as a center of inquiry; (g) a commitment to publicize the school's failures as well as successes so other schools 
could adopt successful strategies and avoid potential pitfalls; and (h) an evaluation plan that set high standards for what students should learn and the ways they would be asked to demonstrate their accomplishments. Shanker realized that this list was by no means an exhaustive catalog of requirements for a complete charter school proposal; nevertheless, he did believe that this list could provide a solid foundation for a school capable of meeting the academic and socio-emotional needs of many public school students, and it ultimately became the foundation for the legislation that lead to the creation of the first charter school in 1991 (Kolderie, 2005).

Not long after Shanker's National Press Club Speech, the school choice movement of the early 1990 s began to gain momentum, supported in part by the burgeoning "White flight" of that period (Renzulli \& Evans, 2005). The first charter school authorization law was passed in Minnesota in 1991 (Toma \& Zimmer, 2012). Implementation of the Minnesota legislation, based largely on Shanker's proposal (Kolderie, 2005), was initiated by a study committee of the Citizen League, chaired by then-CEO of Cray Computer, John Wallegan (Kolderie, 2005). State Senator Ember Reichgott and Representative Ken Nelson subsequently adopted the legislative initiative. A compromised version of the legislation passed with the help of Representative Becky Kelso and was signed into law by Governor Arne Carlson in 1991. 
In summary, the charter school concept was first mentioned in writing in the early 1970s by Ray Budd (1988) and later championed by then AFT president, Albert Shanker (1988), in the late 1980s. However, it was not until the pro-choice school movement achieved some measure of social and political momentum, during the "White flight" of early 1990s (Renzulli \& Evans, 2005), that the first public charter schools begin to emerge.

In 1992, California became the second state in the union to pass charter school legislation (Buddin \& Zimmer, 2005). The subsequent growth in California charter schools has outpaced every other state in the union except Arizona. In 2005, California had just over 550 charter schools serving approximately 210,000 public school students (Zimmer \& Buddin, 2006a). By 2015, California had the largest number of charter schools in the country, with 1,230 schools serving over half a million public charter school students (California Charter Schools Association, 2106). Approximately 8\% of all California public school students attend a charter school, second only to Arizona where charter schools educate roughly $14 \%$ of all public school students (National Center for Education Statistics, 2015).

As of 2013, all but eight states had passed legislation allowing the formation of charter schools (Cremata et al., 2013) and nationwide, charter schools educate slightly 
more than $6 \%$ of the total public school student population. Charters may be responsible for educating a small fraction of our nation's public school students; however, a closer inspection of charter school demographics and characteristics highlight some interesting differences that warrant further discussion.

\section{Charter School Demographics Characteristics}

All charter schools are founded as either "startups" or "conversions." Conversions are charter schools that previously existed as traditional public schools, and they very often retain their existing facilities, faculty, and students throughout the conversion process. In a case study of nine California charter schools including both conversions and startups, Zimmer et al. (1999) suggested that most conversions became charter schools to reduce the level of bureaucracy from the districts and to change specific educational programs. In some cases, the conversion schools indicated that they did not like a particular mandated curriculum program, and this was a major motivation for the conversion. Startups, on the other hand, are completely new entities that attain facilities, faculty, and students during their creation. Typically, charters employ one of two distinct instructional approaches. Most charters utilize a traditional classroom setting, but others use non-classroom approaches such as homeschooling, independent study, and online learning, and some use a hybrid blend both approaches (Zimmer \& Buddin, 2006a). 
In California, Buddin \& Zimmer (2005) found that startup charter schools "were often initiated to create a new holistic approach to schooling" (2005, p. 352). This holistic approach in many ways resembles a number of the items originally proposed by Albert Shanker (1988) in the late 1980s. Furthermore, some charter schools in California solely rely on traditional classroom settings ( $17 \%$ of elementary and $41 \%$ of secondary), while others make extensive use of non-classroom settings, such as homeschooling, independent study, and distance learning (2005). Nationally, non-classroom-based students have much higher SES than students in classroom-based charters. However, on average, the test scores for non-classroom-based charter students are lower than they are for their classroom-based peers (2005).

Nationally, U.S. charter schools educate a larger percentage of students in poverty than traditional public schools (53\% vs. $48 \%$ ) and a larger proportion of charter school students are Black (29\% vs. $16 \%$ ) and Hispanic ( $27 \%$ vs. $23 \%$ ) compared to the students attending all U.S. public schools (Cremata et al., 2013; Lacireno-Paquet et al., 2002). Additionally, charter schools are becoming increasingly more concentrated in urban areas (CREDO, 2105) and have consequently taken on a greater responsibility for educating a larger proportion of the nation's inner-city public school students. Due to the high concentration of charter schools in urban areas and the disproportionately high numbers 
of Black, Hispanic, and low socio-economic status (SES) students attending them, an investigation of the characteristics supporting student achievement in charters could offer a significant contribution to a discussion of the role charter schools could play in the student achievement of under-represented minority (URM) and low SES students.

Charter schools, as they were initially proposed (Shanker, 1988), were intended to be inherently different from traditional public schools (TPS). For this reason, Wei, Patel, and Young (2014) believe that a better understanding of the differences between the two can help identify those factors influencing student achievement in charters.

Advocates believed charter schools could offer families greater school choice and that charters' higher levels of flexibility and autonomy would allow them to create better matches between students' educational needs and charter school services (Toma \& Zimmer, 2012). Charter proponents also had hoped that the flatter organization structure of charter schools would allow teachers to play a more active role in school-level decision making and offer them more opportunities for school leadership (Kahlenberg \& Potter, 2015).

One issue that has been a primary point of contention is the high teacher turnover rate in charter schools. In the 2012-2013 school year, the annual teacher turnover rate in charters was estimated to be $17 \%$ higher than in traditional district schools (Kahlenberg 
\& Potter, 2015). In a recent review of a nationally representative range of teacher retention studies, Torres and Oluwole (2015) found that the teacher turnover rates for some charter schools was 1.5 to 2.5 times that of traditional public schools.

Wei et al. (2014) argue that the higher teacher turnover in charters is due in part to the fact that charter schools tend to hire younger, less-experienced teachers who have usually graduated from highly competitive or selective colleges. Because of their aboveaverage educational backgrounds and the broad array of employment opportunities available to them, these younger teachers are less likely to remain interested in the teaching profession beyond a few years, and this may significantly contribute to the high turnover in charter school teachers.

Toma and Zimmer (2012), on the other hand, proposed that low unionization in charter schools and the resulting at-will nature of charter school teachers' contracts are the most significant factors explaining the high teacher turnover. Torres and Oluwole (2015) estimated that "roughly $12 \%$ of a charter schools have collective bargaining agreements" (2015, p. 504). Resultantly, "studies over the last two decades found that dissatisfaction with salary, benefits, job security, and teacher burnout associated with long working hours are among the most significant reasons teachers leave charters" (2015, p. 506). The issues regarding dissatisfaction with salaries and long working hours 
may support the conclusions of Reed and Rose (2015) that California charters spend less per pupil on instructional related expenses than TPS.

Torres and Oluwole (2015) found instances of charter management organization (CMO) teachers working 60-80 hours a week. The ability to offer a longer school day and school year that are considered critical to success of some charter schools may be one of the reasons why many charter managements organization are resistant to unionization (Torres \& Oluwole, 2015). An analysis of 506 California collective bargaining agreements (CBA) from 2008-2009 found that $63 \%$ of these agreements specified the amount of time teachers must work each day, $93 \%$ had provisions that required teachers receive extra compensation for an increased workload, and most regulated the conditions for assignment and transfer of staff, Strunk (as citied in Torres \& Oluwole, 2015). Based on this analysis, it is apparent that many CMO charters would have had substantially higher instructional costs had their teachers been represented by a CBA similar to those that existed in California in 2008.

On the other hand, many charter school teachers reported experiencing a more supportive teaching environment where most staff had higher expectations of students compared with traditional public school teachers. They also reported feeling a greater sense of responsibility for student learning and perceiving higher levels of student 
engagement (Wei et al., 2014). In the 2004 Schools and Staffing Survey (SASS), charter schools teachers also reported higher levels of distributed leadership and more opportunities for leadership roles than their traditional public school counterparts (Wei et al., 2014). This is not surprising in light of Kahlenberg \& Potter's (2015) finding that "charter schools were originally proposed as vehicles to give teachers more leadership opportunities" (2015, p. 1). Additionally, Wei et al. (2014) found that charter school teachers felt a stronger sense of collaborative effort than teachers in traditional public schools. These findings are congruent with the results of Maas and Lake (2015). Their review of research on the common characteristics of effective charter and traditional public schools revealed that some effective school "common characteristics are: a focus on a shared sense of purpose and mission that emphasizes academic performance, ... collaboration, extensive teacher coaching within the school, increased instructional time, and a culture of high expectations" (2015, p. 169).

One of the criticisms often made about charter schools is that, through the process of school choice, they can lead to racial re-segregation of students (Bifulco \& Ladd, 2007). Nationwide, Lacireno-Paquet et al. (2002), Renzulli and Evans (2005), and Zimmer and Buddin (2006a) found evidence of racially-segregated charter schools in a number of states. In California, Lacireno-Paquet et al. (2002) uncovered significant levels 
of racial segregation when disaggregating schools by performance level but only limited segregation when charters were categorized by curricular focus. On the other hand, in Arizona, Lacireno-Paquet et al.(2002) reported that charter schools in Phoenix and neighboring towns were segregated by curricular focus. Phoenix-area charters that focused on vocational education were predominately Hispanic, while charters designated as college-preparatory academies were predominately White. In North Carolina, Zimmer and Buddin (2006a) found that Black students were more likely to move to charter schools with higher concentrations of Black students than their exiting school. While there is evidence supporting the existence of racial and ethnic segregation in charter schools, the key question is the following: what impact, if any, does the issue of charter school segregation have on student achievement?

\section{Charter School Achievement}

Overall, the research on charter school achievement revealed mixed results amid reports of some charters registering positive impacts on student achievement, others having no effect at all, and still others negatively impacting student outcomes. Some of the major issues highlighted with many charter school performance studies regard the internal and external validity of the research designs used to measure the highly complex phenomenon of charter school performance (Maul \& McClelland, 2013). 
Most charter school performance studies use one of three performance modeling approaches in their design. These approaches include: (a) the lottery based method, (b) the student fixed-effect model, and (c) propensity score matching. Each of these approaches has a number of inherent limitations and is capable of producing significantly different results, given identical student, district, or state level assessment data (Betts \& Tang, 2011).

The most commonly used charter school achievement research designs are based on the fixed-effect approach (Betts \& Tang, 2011). These designs are inherently the least complex and the most commonly used because they eliminate the need to identify a control group of comparable traditional public school students. By comparing the growth of the student while in enrolled in a charter school to the growth for the same student during the years not enrolled in charter school, this approach employs a before and after comparative analysis of each student's performance (Toma \& Zimmer, 2012). The primary limitation of this approach stems from the need for a sample of students who have switched from a traditional public school to a charter school or vice-versa. This is often not the case for elementary charter school students, many of whom start in charters and do not switch. This shortcoming of fixed-effect studies brings up a number of 
concerns regarding external validity of the research design, especially at the elementaryschool level.

The second most commonly used achievement comparison models rely on the lottery-based approach. Studies employing this approach used the winners and losers of oversubscribed charters to randomly select students into a treatment (charter) or control (traditional public school) groups. Zimmer et al. (2012) believed lottery-based studies have considerably high levels of internal validity because most of the measured student achievement differences are the result of participating in a charter (treatment). Betts \& Tang (2011), on the other hand, countered that motivated parents losing the lottery may opt for private schools, thereby creating a downward bias in the control group (traditional public school).

Propensity scoring matching seeks to overcome issues related to external validity by matching charter school students with non-charter students who have similar estimated chances of attending a charter school (Betts \& Tang, 2011). However, because this approach cannot account for a number of unobservable variables that may influence student performance, this research design is seen as being subject to selection bias.

CREDO, the Center for Research on Education Outcomes at Stanford University, has produced a number of charter school performance studies using a matching method 
similar to propensity score matching called the virtual control record (VCR) approach (Cremata et al., 2013). The VCR approach creates a "virtual twin" for each charter school student represented in the study. In theory, this "virtual twin" should be identical to charter school student in every way other than attending a charter school. The reliability of this approach, however, has been questioned because it is only capable of matching $85 \%$ of all charter school students with a VCR peer, and the excluded $15 \%$ are reported to have an average performance score 0.43 standard deviations lower than the average score of those students included in the model (Maul \& McClelland, 2013; Miron \& Applegate, 2009).

Intuitively, it would seem that the excluded students would create an upward bias in the performance of charter schools measured by this approach. However, the VCR research design has also been criticized for creating a downward bias in the performance of the charter school peer (Hoxby, 2009). This performance bias is claimed to be the result of creating a TSP peer student that is not actually an individual student but an average of a group of students with similar characteristics as the charter school peer. Creating a TPS student peer that is in reality an average of a group of TPS students reduces the measurement error for the TPS peer to nearly zero. This in turn creates a overestimation for the measurement error for the charter school student peer and 
consequently creates a downward bias on the performance results of the charter school student because "the measurement error will be much smaller for the group average observations than for the observations of individual charter school students" (2009, p. 3). Finally, many of the results in the CREDO study are statistically significant at the 95\% confidence level. When the results are translated into days of additional schooling, the magnitude is as high as $\mathbf{5 6}$ days of additional instruction (CREDO, 2105; Cremata et al., 2013). However, many of the effect sizes, while statistically significant, are well below the "criteria of effectiveness" threshold of 0.2 standard deviations (Pogrow, 2015, p. 11). 
Table 1. Transformation of Learning Gains ${ }^{\circ}$

\begin{tabular}{|c|c|}
\hline $\begin{array}{c}\text { Growth } \\
\text { (in standard deviations) }\end{array}$ & $\begin{array}{c}\text { Gain } \\
\text { (in days of learning) }\end{array}$ \\
\hline 0.00 & 0.0 \\
\hline 0.01 & 7.2 \\
\hline 0.05 & 36.0 \\
\hline 0.10 & 72.0 \\
\hline 0.15 & 108.0 \\
\hline 0.20 & 144.0 \\
\hline 0.25 & 180.0 \\
\hline 0.30 & 216.0 \\
\hline
\end{tabular}

Table 1. Transformation of Learning Gains

Furthermore, the CREDO studies do not explicitly state how the conversions from effect size to additional days of learning were computed. A chart listing the effect size to additional days of learning conversions are illustrated in Table 1. 
Being mindful of the limitations of each approach, the following passages will present a synthesis of the findings from a number of charter school achievement studies. As stated above, the 2013 CREDO study (Cremata et al., 2013) and the 2015 CREDO study on urban charter schools both have their inherent limitations and their critics. However, due to the unprecedented access CREDO has to vast stores of school achievement data (CREDO, 2105), their studies' results will feature prominently in this section of the literature review because they offer the most comprehensive series of charter school performance research available. The main purpose of the following section of this review is to discuss the research describing the impact charter schools have on the reading and mathematics achievement of URM and ELL students and children living in poverty.

Overall, the findings from most empirical charter school achievement studies indicate that charter school performance is mixed relative to traditional public schools (Buddin \& Zimmer, 2005; Bulkley \& Fisler, 2003; Cremata et al., 2013; Hill et al., 2006; Toma \& Zimmer, 2012; Winters, 2012; Zimmer \& Buddin, 2006b; Zimmer et al., 2012). These conclusions are supported by the meta-analysis of Betts and Tang (2011), who found that "charter schools are in some cases outperforming traditional public schools in terms of students' reading and math achievement, and in other cases performing similarly 
or worse" (2011, p. 55). However, a disaggregation of the student level data reveals a more nuanced picture of charter school achievement.

Overall, the CREDO National Charter School Study 2013 (Cremata et al., 2013) found that charter schools have a positive impact Black students in reading equivalent to 14 additional days of instruction but no significant impact on Black students in mathematics. For Hispanic students, those attending charters showed slightly lower growth in reading and mathematics than their traditional public school peers. On the other hand, charters were found to have a positive impact on the math and reading achievement of ELL and special education students.

Furthermore, where charter schools appear to have their greatest impact is on the achievement of students living in poverty. As a whole, charter school students in poverty showed increases in mathematics achievement equivalent to 22 days of additional learning and 14 additional days in reading compared to their traditional public school peers (Cremata et al., 2013). Moreover, charter schools were found to have an even greater positive impact on both the reading and math scores of ELLs and Blacks in Poverty (Cremata et al., 2013). Whereas ELL charter school students gained the equivalent of an additional 43 days of learning in reading and an additional 36 days of learning in math, ELL students in poverty gained 50 days in reading and 43 days in math 
compared to their TPS peers (Cremata et al., 2013). Black charter school students in poverty gained an additional 29 days in reading and 36 days in math. These results are supported by a number of regional studies on charter school achievement. In Texas, Zimmer and Buddin (2005) found that "charter schools that focus on at-risk students provided slightly more 'value added' than conventional public schools, while non-at-risk charters provided slightly less value added than conventional schools" (2005, p. 355). In their study of charter school achievement in 13 states, Clark, Gleason, Tuttle, \& Silverberg (2015) concluded that these patterns support the notion that charter schools serving more disadvantaged students are more effective than those charters that serve more advantaged students. On the other hand, these patterns could also be indicative of an environment where the traditional public schools available to more advantaged students are stronger than those available to more disadvantaged students, leading to greater opportunities for charter schools to positively impact the achievement of more disadvantaged student populations (2015, p. 432).

A follow up to the CREDO National Charter School Study 2013 (Cremata et al., 2013) was performed to determine what effect charter schools could have on the academic growth of students living in urban areas. This study (CREDO, 2105) investigated charter school data from 41 urban communities. The Urban Charter School 
Study Report on 41 Regions 2105 (CREDO, 2105) findings concluded, "There are more regions where urban charters students outpace their TPS counterparts than regions where charter students lag behind. Twenty-six urban regions have noticeably better learning gains in a year's time compared to 11 regions whose results lag behind their local yearly TPS gains in math. For reading, students in 23 regions outpace the learning gains of their TPS peers while in 10 regions their learning gains are smaller" ( p. 11).

Similar to the trends discovered in the National Charter School Study 2013 (Cremata et al., 2013), the Urban Charter School Study Report on 41 Regions 2105 (CREDO, 2105) found that urban charters achieve their best results serving students with multiple risk factors. "Across all urban regions, Black students in poverty receive the equivalent of 59 days of additional learning in math and 44 days of additional learning in reading compared to their peers in TPS. Hispanic students in poverty experience the equivalent of 48 days of additional learning in math and 25 days of additional learning in reading in charter schools relative to their peers in TPS" (p. 18). These results coincide with the Zimmer and Buddin (2006b) study of two California urban districts in which they found, "The positive effects on charters in mathematics is dominated by strong positive effects for Hispanics in charters" (2006b, p. 323). Furthermore, nationally, Angrist, Pathak, and Walters (2011) found evidence that "charter schools serving heavily 
minority, high-poverty student populations in urban areas are more likely to boost achievement than are other sorts of charter school" (2011, p. 4).

When the results for urban charters were disaggregated by school level (CREDO, 2105), elementary and middle-school charters exceeded the results for charter high schools by an additional eight and 41 days of learning, respectively, in math and an additional 24 and 36 days of learning in reading.

Furthermore, the impact of urban charter attendance on student achievement showed significant annually increases between 2008 and 2012. The improvement during that four-year period was 29 additional days of learning in math from, 29 to 58 days, and an increase of 17 additional days of learning in reading from 24 to 41 days. This trend would suggest that within the urban charter school landscape, schools that continue to operate in this environment improve year to year and as underperforming charters close, new charter schools open that are increasingly better able to learn from the successes and mistakes of earlier generations of charter schools.

Finally, the effects of urban charter school attendance were positively correlated with the number of years of charter school enrollment. This trend was "strong enough that by the time a student spends four or more years enrolled in an urban charter school, 
we can expect their annual academic growth to be 108 days greater in math and 72 days greater in reading per year than their peers in TPS" $(2105$, p. 26).

The national charter school performance landscape appears to be somewhat mixed. Nevertheless, a number of studies (Betts \& Tang, 2011; CREDO, 2105; Cremata et al., 2013; Zimmer \& Buddin, 2006a) have found that charter schools can, for specific at-risk student populations, outperform traditional public schools in both math and reading. If the factors related to their success can be uncovered, the findings could offer researchers, policymakers, and educators with a better understanding of the nuanced differences between charter and traditional public schools that may be responsible for mechanism by which charter schools have increased academic achievement of underrepresented minority, ELL and low-income students. 


\section{Chapter Three}

\section{Overall Procedures}

This study used a multi-case study design (Merriam, 1991) with purposive sampling of three high-performing California charter schools. The three schools were selected from the top $10 \%$ of California charter schools as ranked in the 2015 US News \& World Report Annual School Rankings (U.S. News \& World Report, 2015). This ranking system used a three-step process to rank schools based on high school performance and college readiness measures.

The first two steps in the ranking process assessed each school's performance on its respective state high school proficiency test. In California, this was the California High School Exit Exam (CAHSEE). In order to be included in the ranking, a school had to score at least one third of a standard deviation above the state average. Additionally, performance for school's economically disadvantaged students was also assessed to ensure this group of students was also performing above the state average. Schools that passed those thresholds were then assessed on their college readiness index. This measure used the school's AP or IB scores, depending on which program was largest at the school. The college readiness index was computed using the school's AP or IB participation rate and the percentage of students who received an AP score of three (3) or 
higher or an IB score of four (4) or higher. The maximum college readiness index value was 100 , which meant that every 12 th-grade student in a particular school took and passed at least one AP or IB test before or during their senior year (U.S. News \& World Report, 2015).

The data collected for this study included classroom observations, principal and teacher interviews, and document analyses. Principal interviews were used to inquire about teacher recruitment, development, and retention; resource allocation; data driven instruction; parent outreach; and school culture. Teacher interviews were used to inquire about curriculum, instructional practices, school culture, and student expectations. Classroom observations were used to investigate teaching practices, formative assessment strategies, and student expectations. There was a limited amount of document analysis used to determine to the extent to which the characteristics and practices supporting student achievement were recorded in the school artifacts. These documents, when available, were used to triangulate the findings from the principal and teacher interviews.

\section{Sample Selection}

In addition to the sampling criteria described above, the researcher selected a purposive sample of three schools. The purpose of this sampling was to collect a broad 
array of charter schools for the study by selecting one school categorized as a member of a startup network, a second school that was categorized as an independent startup, and a third that was an independent conversion charter school.

The selection process began by sending study invitation letters and emails to the principals of 10 local schools that meet the sampling requirements. From this group, positive responses were received from only two of the schools. One school was a member of startup network of four charter schools managed by a single charter management organization (CMO). The second was an independent charter, which was located in the center of an inner-city neighborhood. Both of these schools were predominately Hispanic and had an underrepresentation of African-American students relative to school's districtwide demographics. Finally, a third school was found outside the local area. This school had a predominately African-American student body and was also a conversion charter. However, this school was overrepresented by African-American students and underrepresented by Hispanic students relative to the district. This school was also not included in the top $10 \%$ of the US News \& World Report rankings for charter schools. However, it was awarded a Bronze Award for its above average performance on the state's high school proficiency exam. The demographics for each school are detailed in Table 2. 


\begin{tabular}{|r|r|r|r|}
\hline & Destiny & Believe In Me & City Charter \\
\hline School Type & Startup & Startup & Conversion \\
\hline Ranking & Bay Area & Oakland & Sac. \\
\hline 2013 API & 857 & 37 & bronze \\
\hline Graduation & $92.7 \%$ & 735 & 780 \\
\hline $\begin{array}{r}\text { Largest } \\
\text { Minority }\end{array}$ & Hispanic & Hispanic & $90.1 \%$ \\
\hline Low-income & $70.9 \%$ & $73.2 \%$ & $73 \%$ Black \\
\hline Enrollment & 455 & 269 & 926 \\
\hline
\end{tabular}

Table 2. School demographics and performance 


\section{Role of the Researcher}

Prior to entering the Educational Leadership Program, the researcher worked for seven years as a math teacher at a number of inner-city charter schools in the San Francisco Bay area. The majority of the students he taught were Hispanic and African American. The majority of them also qualified for free and reduced meals prices (FRMP). One of the schools at which the researcher was previously employed was in the sample for this study.

The sole researcher for this study conducted all the interviews and performed all the classroom observations and document analyses. The researcher also maintained a reflective journal to track emerging themes and reflections about the data collection process. Journal entries occurred weekly at a minimum and were also recorded following each interview or observation. Data memos were used to record detailed information about observations and interviews and assisted in first and second rounds of coding.

\section{Data Collection}

The researcher initially transcribed interview data, which was recorded on an electronic device. However, after three labor-intensive transcriptions, the researcher decided, in consultation with the dissertation chair and committee, to send the remaining 
19 interview audio files to a professional transcription service. The researcher transcribed the three follow-up interviews with each school's college counselor, however, due to the interviews occurring so late in the data collection cycle.

The electronic interview data files were stored on a password-protected electronic file management system. Participant name, location, date and time for all interviews were recorded in the filenames for each interview.

Classroom observations were collected using two classroom observation templates created for this study. A copy of each template is included in the appendices. The first template was designed to allow the researcher to rank the classroom session using three predetermined categories: curriculum, instruction, and technology. A row to collect "other" data was also included in the template. The curriculum category was ranked on a predetermined scale of one (1) to four (4). A one (1) designated a curriculum that was taken directly from a textbook and delivered without any type of modification. A four (4) was used to designate an internally developed curriculum that incorporated one or more of the characteristics of culturally relevant pedagogy or culturally responsive teaching.

Similarly, the instruction category was also ranked one (1) to four (4). A one (1) designated a class in which the instructional practice was limited to direct instruction. A 
four (4) was used to indicate a classroom where a number of different teaching modalities were used in addition to evidence of one or more traits of culturally responsive teaching. The technology category was ranked on a scale of zero (0) to four (4). A rank of zero (0) indicated that technology was not used in any form during the class. A rank of one (1) indicated that there was minimal use of technology, such as a laptop connected to an overhead projector to display a lesson. And a rank of four (4) indicated that classroom technology was an integral part of the lesson and each student had access to a laptop or related device.

The front of the template was arranged in a tabular format to record the rankings and any observational notes for each category. The back of the template had an open space section for the researcher to record diagrams and another section for writing notes, reflections, and additional observations. The second template used a split-page format that allowed the researcher to keep a time-log account of classroom activities on one half of the page and space to record reflections or notes on the other half of the page. Observation data from the two templates was organized and formatted into an Excel Spreadsheet for data analysis. 


\section{Data Analysis}

The interview and observation data were analyzed using hypothesis coding (Miles et al., 2013) for first and second round analysis. Subsequently, pertinent themes were drawn from the coalesced, coded data to generate the study's findings. The codes used for the initial analysis were drawn from the literature related to culturally relevant pedagogy (CRP) (Ladson-Billings, 1995b) and culturally responsive teaching (CRT) (Gay, 2010).

\begin{tabular}{|c|l|}
\hline \multicolumn{2}{|c|}{ Culturally relevant pedagogy and culturally responsive teaching data codes } \\
\hline Code & \multicolumn{1}{c|}{ Description } \\
\hline $\begin{array}{c}\text { High-expectations (with } \\
\text { commitment) }\end{array}$ & $\begin{array}{c}\text { Culturally responsive teachers are socially } \\
\text { and academically empowering by setting high } \\
\text { expectations for all students with a commitment } \\
\text { to every students' success }\end{array}$ \\
\hline $\begin{array}{c}\text { Multidimensional and } \\
\text { Cuging }\end{array}$ & $\begin{array}{l}\text { Culturally responsive teachers are multi- } \\
\text { dimensional because they engage cultural } \\
\text { knowledge, experiences, contributions, and } \\
\text { perspectives }\end{array}$ \\
\hline Holistic & $\begin{array}{l}\text { Culturally responsive teachers are } \\
\text { socially, emotionally, and politically } \\
\text { comprehensive as the seek the educate the whole } \\
\text { child }\end{array}$ \\
\hline $\begin{array}{c}\text { Long-term teaching } \\
\text { perspective }\end{array}$ & $\begin{array}{l}\text { Culturally responsive pedagogues think in } \\
\text { year test long-term success and not just end-of- }\end{array}$ \\
\hline Cultural Competence & $\begin{array}{l}\text { Reshaping the prescribed curriculum to } \\
\text { build on student funds of knowledge. Teachers } \\
\text { honor the home language of the students }\end{array}$ \\
\hline
\end{tabular}

Table 3. CRP and CRT data codes 


\section{Chapter Four}

\section{Overview}

The purpose of this research study was to investigate the characteristics of three high-performing California charter schools serving underrepresented minority and lowincome students. A review of the research, related to charter school performance, indicated that, overall, charter school achievement was mixed relative to that of traditional public schools (TPS). Many charters schools performed on par with their TPS peers, a small percentage outperformed TPS and a slightly larger percentage of charters under-performed.

However, a number of research studies (CREDO, 2105; Cremata et al., 2013; Zimmer \& Buddin, 2006b) found exceptions to these academic performance patterns. The most recent of these studies, The Urban charter school study on 41 regions 2015 (CREDO, 2015), found that urban charter schools were effective at increasing the math and reading achievement of urban minority and ELL students living in poverty beyond that of TPS. Zimmer \& Buddin, (2006b) found similar results in their study of two California urban charter schools. In an effort to help explain these results, this study sought to answer the following research question: What are the performance 
characteristics of high-performing California charter schools serving underrepresented minority and low-income students?

In order to investigate the performance of three high-performing urban California charter schools, this research study used an interpretive, comparative, case study design (Merriam, 1991). The data analyzed, for this study, included classroom observations, and teacher and principal interviews. The data was analyzed using hypothesis coding (Miles et al., 2013) using codes derived from operationalizing the tenets underlying both culturally relevant pedagogy (Ladson-Billings, 1995) and culturally responsive teaching (Gay, 2010).

Three common themes emerged from the analysis as primary characteristics supporting student achievement across the three schools. Each school had a culture of high expectations that was reinforced by a number of academic support programs and strategies. The teachers and administrators also displayed a strong commitment to help students succeed. A lead content teacher or team of teachers internally developed the majority of the curricula taught at the schools. It was often designed with very high levels of rigor and included scaffolds at accommodate students with varying levels of prior knowledge and skills. The instructional practices used by many of the teachers were engaging and multi-dimensional. These practices involved the use of multiple teaching 
modalities and typically incorporated some type of collaborative learning approach into every lesson

The following passages provide a detailed and rich description of each of the three schools' culture and classrooms, using a narrative style based on portraiture (Lawrence-Lightfoot, 2008). This will be followed by an initial discussion of the common characteristics discovered across all three schools and a review of the variations in curriculum, instructional practices, found at each of the schools.

The following excerpt, taken from the interview with Principal Estrada, at Destiny Public School is emblematic the high expectations he and his staff had for their students. High-expectations with a commitment to support the achievement success of every student, was a major finding across all three schools in this study.

During the interview, he also mentioned a number of other issues that were indicative of his social justice approach to leadership.

\section{School \#1: Destiny Public School (DPS)}

I tell my kids, they are all destined for greatness very often. That is like a common phrase that I use. Because I feel like that is what most upper-middle class people in positions of power feel like. That they are destined for great things and they just live their lives that way. And so I want all our students to believe that as well. I believe education is a great way to achieve greatness. (DPS principal, Mr. Estrada, 09/25/15) 


\section{The Destiny Public School Culture}

Sitting in the middle of the Destiny Public School (DPS) campus on a warm autumn afternoon, I get the feeling that I at a small, suburban liberal-arts college. But I am not. I am sitting at a small table in the middle of the incredibly clean high school campus of Destiny Public School. As I scan the immediate area, I cannot find one piece of litter anywhere. What I see are worn concrete paths leading from one circular complex of classrooms to the next. Towards the back of the campus is the two-year old Destiny Center, or $D C$, as most affectionately call it. The building came about as a part of a recent school redesign project. The purpose of the redesign was to create Destiny Public School 2.0 , or DPS 2.0 as they called it. The intent was to create a learning environment that could prepare all of its students for success in a four-year university. The redesign went well beyond the building of a new facility. The pedagogical, technological, and curricular foundations of the school also were revised to help increase student achievement.

Principal Estrada described the design process by which DPS 2.0 was created as one of co-creating a vision for the new school.

When we had about $80 \%$ or $90 \%$ of our teachers coming back and we were able to co-create the vision that was about two years ago. ... We did a lot of design 
work about leveraging technology and rethinking what teaching is. I'm excited that even in the course of this year might get back to where we are co-creating a vision for the school. (DPS principal, Mr. Estrada, 09/25/15)

This passage is emblematic of Principal Estrada's leadership philosophy, which in many respects is very closely related to the transformational model (Leithwood \& Jantzi, 2006). He actively sought ways to include multiple stakeholder groups in creating the vision for the school through consensus-building and collaboration. The process, as he explained, was very dependent upon the level of teacher turnover at any given time.

I think it depends upon the year. I think there are some years where PD (professional development) was built around co-creating with teachers. And we also have a student design team that has been involved in like creating the students' visions and goals of the school. We've never done a good job of engaging parents in that process. That is something that we'd like to get better at. I think that is something our parents are ready for now and we also now have a situation where most of our teachers are staying on from one year to the next. (DPS principal, Mr. Estrada, 09/25/15)

This passage, in many respects, is evident of a leadership style and school culture where the school's success is the result of input from administrators, teachers, and even students contributing to a vision and set of goals that as lead to increased student achievement.

As I sit at the bench, I am passed by a group of students, all of whom are carrying Chromebooks, which are tucked under their arms like metallic footballs. They walk past 
me engaged in a discussion about a recent quiz they all seem to have done well on. These students appear enthusiastic about schoolwork and, from the sound of it, take pride in their success.

Like many other of the high-performing charters in the Northern California ("EdData Website," 2016), DPS is predominantly Hispanic (see Table 1), a trend that has been increasing in the past few years. According to the 2013-2104 demographic data for the DPS ("Ed-Data Website," 2016), the DPS student body was $60.1 \%$ Hispanic. This is actually only $0.1 \%$ above the district average. However, the disproportionalities exist in the African-American and Filipino categories. In 2013-2014, the DPS student body was $6.8 \%$ Black compared with the district average of $11.9 \%$. At DPS, $11.3 \%$ of its students are Filipino, while district average, for this group, was $6.8 \%$.

While no one could say for sure what effect these disparities had on the school's diversity or performance, the trend had not gone unnoticed by the faculty and administration.

Something we did this year that was based on the research was to take a look at our African-American population, which in our school is really small... So we've done some particular work to try and increase our African-American population. And this year's freshman class did have a much larger number than it did the year before. And we made a point, this year, to try and group as many AfricanAmericans as we can in one advisory so it wasn't like one African-American 
student in an advisory all by themselves with a group of students that didn't share the same background which could make them feel marginalized across the campus...And we partnered them with teachers that we felt could support that group as well. (DPS 9th grade counselor, Ms. Eager, 03/03/16)

It is this type of data-driven attention to detail that has helped DPS become one the highest performing charter schools in California. And when I walked around the campus, it is obvious that most DPS students radiated level of pride and self-confidence that not was present at most other high schools.

The self-confidence that I observed in many of the students as they shook my hand or offered directions was not by accident. It was the result of a school culture that is very well-thought out and supported by school norms that seem to be performed almost automatically. It was explained to me by the principal that the ritual handshake, which occurs at the beginning of every class as the teacher greets each student, is purposefully done to help students develop confidence in their interactions with adults. He feels this skill will become more important once they get to college and no longer have advisors, teachers, and parents to advocate on their behalf. This long-term perspective that DPS takes in the holistic development of each student that has played a significant role in the school's success and is also one of the tenets of culturally relevant pedagogy. Principal Estrada gave the following example: 
In like interacting with strangers or visitors, they are like, "hi my name is José nice to meet you" and they're like "wow your kids are very poised" and by this time most of them have been shaking an adults hand close to 3000 times. I can't tell you how many times we have had adults say wow I've never had a teenager shake my hand like that before. So by then our kids are juniors or seniors, they're really very, confident. (DPS principal, Mr. Estrada, 09/25/15)

Principal Estrada explained that together with teachers, students, and even parents they have created a school culture where all students are expected to graduate prepared for college. They have supported this expectation by creating a cohort advisory model designed to create a sense of community and a place where students can create meaningful and supportive relationships with teachers. Additionally, many of the school's norms were designed to help students develop a sense of self-confidence, which was evident throughout the school. This school culture supported a classroom environment where I often observed teachers holding all their students to, what I would describe as, very highest expectations.

\section{The Destiny Public School Classroom}

Before entering the classroom, one of the first things noticed was the orderly manner in which the students lined up to shake the teacher's hand as they entered the room. There was very little of the usual horseplay that is the norm at many high schools. Standing aside and watching this orderly procession of students, I couldn't help but get 
the feeling that many of these students would soon enter the conference rooms of Silicon Valley high-tech firms in the very same manner. There was something about their demeanor that said, "We're here to get some work done!"

As they entered the classroom, each student opened out his Chromebook and began the "Launch." The "Launch" is a brief formative assessment activity that every teacher gives in the first three to five minutes of class. As Principal Estrada describes it, the "Launch" serves two purposes. First, it sets the tone for the class by giving the student a discrete chunk of work that he is responsible for completing as soon as the bell rings. At DPS, students are expected to be in their seats and working from the minute the bell rings. Second, the "Launch" allows teachers to quickly, formatively assess their students' prior knowledge before beginning day's activities. This type of formative assessment is very much aligned with the principle of culturally responsive teaching (Gay, 2010), which encourages teachers to use each student's current body of knowledge as a basis for teaching new content. In all but one of the classes observed at DPS, the teacher administered a "Launch" within the first three to five minutes of class.

The "Launch" is bookended by the equally brief "exit ticket," which many teachers administer using a widely available software program that was developed by a former DPS math teacher. That teacher is now responsible for technology development 
for the entire four-school network. The only classroom exception to the "Launch" policy could be found in Ms. Hill's "Academic literacy and leadership" class.

Ms. Hill's "Academic literacy and leadership" class was the first class observed at DPS. This class is one of the two major support classes the school provides for student working below grade level. The other is the "Academic Numeracy" class.

We have some things that we have historically done to help students improve. For example, the Academic literacy and leadership course is designed to help students believe that they can be good readers and they do a lot of silent reading time there. Many of those students have increased their reading by two to three grade levels in that class. We also have our academic numeracy class, which is a very differentiated, self-paced class. We get about two and a half years from our students that are significantly far behind in growth. (DPS principal, Mr. Estrada, $09 / 25 / 15$ )

What I observed in the Academic literacy and leadership class supported Principal Estrada's description. Just before the bell rang, students were already sitting in their seats with their silent reading books opened and engaged in reading. After 15 minutes of silent reading, the teacher asked for three volunteers to talk about the books they were reading. Since the students had all chosen their own books based on interests and reading level, almost every student raised their hand for the opportunity to discuss their book. The teacher called on three randomly selected students and each them was gave a short summary about the developments in their book. Their discussion was remarkably rich for 
students designated as being "below and far-below" grade level. They used terms like "main character," "protagonist," and "plot." Their discussions were animated to the point of laughter as each of the three student took turns describing how their books were progressing. These students did not act like students who had been tested as reading and writing two to three years below grade-level. They seemed so confident, and even when they made mistakes and used the wrong word, they promptly followed it with a "my bad, I meant to say...." This does not happen by accident. During our interview, Ms. Hills reported:

I do a lot of work in this class on voice and being able to do public speaking in both poetry and presentation skills with research projects. I'd say a lot of them come in pretty shy from middle school and a little scared to share their voices but they're in front of the classroom doing presentations week-two solo. So they start to get over that fear pretty easily... I am such an advocate that their voice is their tool to help change themselves and the world around them and that if you aren't able to speak up for yourself, no one is going to do the work for you. (DPS literacy and leadership teacher, Ms. Hill, 09/11/15)

This excerpt in many ways reflects the theory of critical consciousness, which is a key tenet of culturally relevant pedagogy. As I sat in her class, I noticed that Ms. Hill offered her students a number of different activities that allowed them to critically analyze themselves and their place in the world. The main class activity for that day was a poetry recital in which the second half of the class individually recited their poems to 
the entire class. The poems, written as a homework assignment, were entitled, "I am from."

The students were given a great deal of latitude to describe where they come from. One student identified himself as being from a long line of Mayan warriors whose descendants had migrated to California for a better life. Another student described in rich detail the neighborhood that she lived in and the customs and norms that made her part of town a community of first, second, and third generation Mexican immigrants. After each poem, the teacher asked the students to write a "shout-out" for the presenter. Throughout the recital, the entire class appeared to remain actively engaged in this multi-dimensional activity (Gay, 2010).

After the last student presented, Ms. Hill asked the class for five shout-outs for each of the presenters. The feedback was all positive and kept the class engaged. As an exit ticket, Ms. Hill had the students discuss with their groups, "How would you like to improve as a poet?"

What was most meaningful about this formative assessment was the language Ms. Hill used with her students. By asking them to talk about how they would like to improve as a poet, I believe she did two things. First she had them engage in self-reflection of their performance and determine the corrective action needed to improve. This skill of 
critical self-reflection will be relevant for these students throughout their lives. Second, by using the term "poet" instead of, perhaps, the phrase, "write better poetry," she had the students identify as a poet and not simply as a student writing a poem for a literacy class. This concept of having students developing scholarly identities was a significant component of the DPS pedagogy. Oftentimes, I heard teachers refer to their students as mathematicians, scientists, and artists.

The school culture at DPS is one of high expectations for all students combined with a number of supports to help students meet those beliefs. Supports come in the form of teacher commitment to their students and broad range of behavioral norms that are expected from both students and teachers. The DPS classroom is a safe place were students are pushed, oftentimes, beyond their own preconceived limits of their abilities. It is place where high-performance is the norm and teachers and student appear to work collaboratively to meet or exceed expectations.

\section{School \#2: Believe In Me Academy (BIM)}

"These kids don't need rescuing; they don't need a savior. What they need is someone who believes in them." (BIM math teacher and department chair, Mr. O'Toole, $12 / 04 / 15)$ 
One of the first teacher interviews was with a veteran math teacher named $\mathrm{Mr}$.

O'Toole. He offered his view about what he thought was, at root, BIM's success by first describing why, in his opinion, many inner-city charters are not successful.

I think too many of these schools are founded by people who find their value in "we're gonna go in here and save these poor unfortunate black and brown children." Well great, except that you are now thinking about these kids as poor and unfortunate as opposed to freakin' brilliant... A common influence that comes into the school is, "I'm here to rescue these poor, impoverished children." It's like a cancer in those schools. And it comes into some charters but not into others. And if there is a problem that's it. These kids don't need rescuing; they don't need a savior. What they need is someone who believes in them" (BIM math teacher and department chair, Mr. O’Toole, 12/04/15)

This excerpt from my interview with Mr. O'Toole very succinctly describes the

foundation of BIM's success. All around the school, from the front office, to the

playground, to the classroom, I got the distinct impression that all the adults there

believed in their "kids" and they were there to support them on their path to college.

\section{The Believe In Me Academy Culture}

On my first day of observations at the Believe In Me Academy (BIM), I felt like the school's campus was, in many ways, an oasis from the chaos that existed just outside the school walls. From the outside, the school appeared to be an archetypal, inner-city 
Catholic school. I was told that the school's campus previously housed a Catholic school that was operated by the Catholic Church that sat on the front corner of the campus.

However, one look at the adjacent corner told me that this was also a very challenging neighborhood. As I entered the campus, I noticed group of about five to six African-American males standing on the corner. They all wore the standard street uniform of baggy white tee-shirts; baggy, sagging jeans; and pearl white sneakers or black work boots. The fact that it was 11:30 am and they were all "hanging" out on the corner lead to me believe that this group was a small sample of the city's chronically underemployed African-American male population. When I was about to leave the campus about three hours later, the school was on lockdown because the Oakland police were searching for a suspect in a recent nearby armed robbery.

Inside the walls, it seemed like I was a world away from the challenges that existed outside. Tall evergreen trees rose above the back of the classrooms and the Oakland hills could be seen in the background. In many respects, it almost felt like a small private or Catholic school setting. The campus was made up of a number of slatetile roofed, adobe-like classrooms from the extinct Catholic school. These classrooms were supplemented by a number of modular units that housed the math and English departments. In between the classrooms was a large, 10,000 square-foot courtyard that 
served as a basketball court, playground, and gymnasium. It was filled with the 270 or so students who attended the small charter school.

The students, like much of the surrounding neighborhoods, were predominantly Hispanic with a small percentage of African Americans. During my initial meeting with the principal, we discussed the apparent underrepresentation of African-American students in the local charter schools. The best reason he could give me for the disproportionate demographics of his school was that many of the parents heard about the school via "word of mouth" from other parents whose children attended or graduated from the school. We agreed that it would make for an interesting follow up study and we should try and revisit the question at a later date.

When discussing the parents who chose to send their children to BIM, he also mentioned what he believed to be an alignment between BIM's disciplinary philosophy and the parents' expectations.

On a fundamental level, a lot of our families come to us because you have a certain constituency in the city that appreciates and is philosophically aligned with a little bit more of a firm discipline policy than you might find at some of the community schools but not at most at comprehensive public schools. They are either not willing or able to implement it. And even if it's not philosophical, it's just "I want my kid to be safe during the school day," we hear that a lot from our parents (BIM principal, Mr. Champion, 11/06/15) 
Principal Champion was referring to the school's no-nonsense approach to discipline. It is what many teachers described as a firm assertive discipline program coupled with a restorative justice component. It was designed to create a safe and structured environment where students could learn and feel protected. One teacher stated that the emphasis on behavior and discipline was more stringent and consistent for the ninth and tenth graders than with the upper-classman. As a result, she felt that most of the disciplinary issues the students brought from other schools were mitigated by the time she saw them in her 11th and 12th grade English classes.

Yeah. I think for the ninth graders and the tenth graders the rules are very firm... I think that with the upper classmen we still are somewhat, but we don't see as many behavioral problems... I think it's because ninth graders are pushing boundaries and they need a bit more structure. ... I actually think that because we're so strict with smaller things and we enforce them that the thought of being blatantly disrespectful seems so out of the realm of possibility. (BIM teacher, Ms. Dennis, 11/06/15)

Ms. Dennis is referring to the process whereby incoming ninth graders inculcated with the school's behavioral expectation needed to support a safe and focused learning environment. There is also a coordinated effort, by the administration and all the ninth grade teachers, to communicate the school vision and mission of having every student accepted into a University. 


\section{The Believe In Me Academy Classroom}

Most teachers greeted the incoming students in one form or another. In Ms. Tanner's eleventh grade English class, students were greeted with a firm business-like handshake and a friendly, "good morning Marisol", addressing each student by her first name. In Mr. O'Toole's ninth grade Algebra I class: students entered the room; stood by beside their assigned seats; and waited for the teacher to greet them with a stern, "good morning class". They all responded in unison, "good morning Mr. O'Toole" and then took their seats. It was apparent that teachers were given a certain amount of autonomy in how they greeted their student at the beginning of class. Nevertheless, every teacher I observed greeted their students in one form or another, before beginning the day's lesson.

A certain measure of teacher autonomy was also evident in the classroom procedures used by individual teachers. While most teachers began the day's lesson with a brief warm-up activity, of some sort, a number of them took a different approach. Ms. Underwood began her Pre-Calculus class with an "open" quiz. Students were allowed to use their notebooks and get help from each other on these "open" quizzes, which, I was told, she gave regularly. They could not, however, use notes on the "closed" quizzes. The 
students appeared very engaged and a number of them actually seemed to enjoy working together on a math quiz.

Mr. Barriento began his art class with a 15-minute, direct instruction lecture in which he reviewed his ten-page handout on "vanishing point" sketches. Throughout the lecture, he modeled how to create a "vanishing point" landscape. Many of the students in this class were also in the previous period's Pre-Calculus class and were a little more unruly that they were with Ms. Underwood. This class was held during their next to last instructional period of the day and they appeared to be a bit more restless than before. However, there never showed any type of disrespectful behavior towards the teacher. Once the teacher finished the lecture and instructed them to create their sketches, every student in the class worked in an engaging and focused manner, on their sketches. A number of the students called Mr. Barriento to their desk for support or guidance.

The only class that appeared to be a bit unruly and off-task was Mr. Maxwell's Algebra 2 class. The students completed most of the assigned work, however, there were a number of side conversations regularly occurred throughout the class. The teacher seemed unfazed about the disruptive behavior and proceeded to follow his lesson plan even though a number of students were off-task and did not complete their work. The teacher circulated around the class supporting student who asked for help as well as those 
who were off-task. Finally, he assigned the Chromebooks and had the students complete an activity using Kahn Academy, in manner similar to the approach the veteran math teacher, Mr. O'Toole, ended his class. After this class, I was scheduled to interview the principal and mentioned that Mr. Maxwell seemed to have some challenges with classroom management. Mr. Championed informed that they had hired Mr. Maxwell at the last minute to fill the vacant position and that this was his first teaching assignment. In retrospect, considering that Mr. Maxwell had only been teaching for nine-weeks, he exhibited a number of the characteristics associated with Culturally Responsive Teaching. I will discuss the details of his instructional practices in greater detail, later in this chapter.

Overall, the classrooms at BIM were orderly and engaging. Teachers were allowed a certain level of autonomy with regards to the curriculum, instructional practices and use of technology. There were definite signs of innovation regarding the use of technology. However, many of the initiatives were in the trail stages and the Chemistry and Biology teachers were still investigating a definitive conclusion about the effectiveness of tools such as Comprend.io and Peardeack. On the other hand, Kahn Academy appeared to be an integral part of the math curriculum and teachers in the science department were also using it to a lesser extent. For the most part, the BIM 
classroom was provided a well-managed environment where teachers could offer students a good deal of individual support while they themselves felt supported themselves by the administration. I think the twelfth-grade English teacher, Ms. Dennis, summarized the culture and classrooms at the BIM nicely when she said:

It's the type of place where we don't really need to worry about major behavioral issues in the classroom. I've always felt like even in my first year when I was totally new and not sure of what to do, that I was backed up by administration... and just that this is a safe place that learning is going to be done, and that we're going to hold them to a high standard both academically and behaviorally. (BIM teacher, Ms. Dennis, 11/06/15)

\section{School \#3: City Charter High School (CCHS)}

"Our students try harder... poverty is a big issue and there's a lack of male role

models. They want a change in their lives." (CCHS Counselor, Mr. Niks 03/06/16)

I think that when you come from backgrounds where you know what's wrong, you have had struggles, your own personal struggles, struggles in the family, you know poverty is a big issue and there's a lack of male role models. That motivates a lot of our students to try harder to make a change, to make things different. You know they come difficult backgrounds. They want a change in their lives. (CCHS Counselor, Mr. Niks 03/06/16)

The first thing noticed when approaching the CCHS campus is the enormity of it

all. The campus and related grounds take up over four city blocks. From the outside, it 
appears to be a traditional public school with a football field and basketball courts. That's because it was once the only high school the city. Established in the late 1800's, the school moved to its current location in the 1920s. At its peak, the campus it accommodated over 4,000 students. Then, in the mid-1930s a second city high school was built and the school's student body was split in half.

By the mid-1990s the City High School was in the bottom five percent state-wide and less than half of its seniors graduated. The school was on the brink of being place in state receivership. Then, a hometown boy and retired professional athlete, Lamar Kensington (pseudonym) delivered a proposal to convert City High School into an independent charter school managed by his local, community-development, and nonprofit organization. The proposal met some initial resistance, from the teachers and parents.

The teachers were concerned that the conversion, to an independent charter, could jeopardize their positions. And parents were fearful this change was the first volley in a barrage to gentrify their predominately African-American neighborhood. After a long and contentious period of negotiation, City High School opened as City Charter High School in the early 2000 s. 
Since the conversion, the school has improved in nearly every measurable category. However, it has struggled in recent years to make AYP. Nevertheless, according to the most recent data available ("Ed-Data Website," 2016), the school has shown a considerable improvement in its results. Over $50 \%$ of its African-American and over $60 \%$ of its Hispanic students scored proficient or above in both math and English/language arts on standardized tests. The schools graduation rate is above $90 \%$, with $93 \%$ of those graduates completing the course requirements for University of California/California State University (UC/CSU) admissions. And finally, City Charter High was recognized by U.S. News and World Report in its 2015 Best High Schools in California Ranking (U.S. News \& World Report, 2015) with a bronze medal, for its graduation rate.

\section{The City Charter Culture}

When entering the main hall leading to the administrative offices, once again the enormity of the school is evident, as well as its history. From the hall's ceiling rafters, hang a photo-chronology of the schools demographics. The picture, entitled "1932Students," shows three White teenage males standing arm-in-arm wearing "letterman's sweaters" and bowties. The "1931 Aeronautics Club" picture shows approximately 20 or 
so white teenage males and one male who appears to be of Asian descent sitting alongside an early 20th-century biplane.

The "1964 Guitar Club" photo and those thereafter show an increasingly diverse student body made up African-Americans, Hispanics, and an occasional Asian or White student. The "1969 Students" photo is comprised of three African-American teenage males sporting Afros and black-leather jackets reminiscent of the Black Panthers. From that photo on are more representations of the school increasingly African-American student body. This student body also very closely reflects the changing demographics of the nearby predominately middle-class African-American community.

I noticed that the students at CCHS appeared more prone to physical horse-play than at the other two schools. When I first observed this behavior, I initially assumed it may have been due to a lack of discipline. However, after observing a number of classes, I realized that this behavior rarely made its way into the classroom. When I began to watch and listen more closely to these interactions, I realized that these students were not only catching with their friends and discussing aspects of their personal lives, they were also, at times, discussing academic related topics as well. Their interactions may have been a bit more animated and exhibited a bit more verve than those I observed at the 
other schools but they were just as meaningful and relevant with respect to the student experience at CCHS.

The school leader, Ms. Primera, was a recent addition to the school. This is her first year as principal, at City Charter. Many of the teachers spoke about the high teacher and administrative turnover at the school. They also believed that were it not for a committed, small, core group of returning teachers and administrators, the school would not be able to maintain its current level of performance. Mr. Vincent spoke about challenges with high staff turnover, when we discussed whether or not his department had created any type of articulation plans across the grade levels to help increase achievement for those students entering freshman year performing below grade level.

... the turnover rate amongst teachers is so high. Then when we do get new teachers here, I think that we've relied a lot on Teach For America teachers which is not necessarily a bad thing, but that means you have a lot of people who are trying to find their footing as a first year teacher. If it weren't for a core group of committed teachers who stay on, there would be no place for institutional memory to live. (CCHS Teacher, Mr. Vincent 01/20/16)

Examples of the committed core group of teachers, he mentioned, were available to see throughout the school. It was often evident in their interactions with students and the level of achievement they demanded, that the high expectations, listed in the school's "5 Pillars" was more than just a part of the school's motto. Many of the teachers 
exhibited high expectations for their students. Along with these high expectations, the faculty and administration also developed processes to ensure students at all levels were provided with the supports they needed to be successful. Ms. Dunleavy, a recent addition to the school, spoke about these supports during our interview:

Yeah. There's definitely high expectations and support and built-in mechanisms to facilitate that. So for example, we had grade level meetings where they gave us lists of everybody who was not passing, and the expectation was that we were going to make contact with all of those parents to do what we need to do so that kids can get back on track and pass their classes instead of okay, well kids aren't going to pass. Kids don't pass kind of thing. That wasn't the expectation at all and it wasn't the expectation that we just make something magical happen so that they pass. It was partner with parents and do what we need to do to light fire under kids so that they take care of what they need to do. (CCHS Teacher, Ms. Dunleavy 12/18/15)

In addition to the high expectations teachers and the administration have for the students, I was told that the students also expected a lot from their teachers as well. This was most apparent for new teachers who transferred to CCHS, after working at less demanding institution.

Totally. Yeah. I mean part of my challenge this year is I have been a really great teacher in my previous situation. But coming here and having to adjust to the challenge of the newness, there is not the wiggle room, the stuff that I could've gotten away with at my old school to kind of ease that transition to a challenging new assignment is not here. It's not here even from the kids. The kids have high expectations of their teachers and communicate those, checking in on like when 
the quiz is graded and what grade did they get, and kids have no problem like telling us what is going on? (CCHS Teacher, Ms. Dunleavy 12/18/15)

\section{The City Charter Classroom}

Most the classrooms at CCHS appeared to be well-managed and engaging. However, there were also a few examples of new or marginally effective teachers that I witnessed as well. In one of the math classes I observed, I was told the teacher was a long term loan from another department. He did not appear to be very well versed in the content of the course and mistakenly told a number of students their answers were incorrect because they did not exactly match the answers in teacher's edition of the textbook. For example, one student said the correct answer to a problem was "angle CBA," but the teacher told him that his answer was incorrect and that the correct answer was "angle ABC," as stated in the teacher's edition. However, both statements were the correct answer to the problem. Throughout the class students stood up and walked around the classroom. At one point, a student stood and walked out of the room without asking permission.

I later learned that the school had experienced high teacher turnover the previous year and a number of classes were being taught by long-term substitute teachers. 
During a subsequent visit, I had the opportunity to visit another math class. It was the antithesis, to the math class I had previously observed. As the students enter the Ms. Santos first period, math class I couldn't help but notice the comparative lack of formality as the students enter the class. She greeted each of her students with somewhat mechanical "fist-bump" and a very welcoming good morning. Most students responded in kind: "fist bump", "good morning Ms. Santos". Some were a bit more enthusiastic, adding an extra, "Booyah" to the greeting or shouting, "good morning teach!!" The relative lack of perceived formality, to the classroom entrance ritual, was supplanted by an observable atmosphere of warmth and camaraderie between the teacher and many of her students.

As the class began, the teacher assigned four problems from a worksheet as warm-up and began her rounds of checking homework. I noticed a group of three or four girls sitting in the back corner of the class having a conversation about something other than the assigned activity. The teachers seemed to be aware of this behavior but instead focused on checking homework.

The rest of the class was somewhat uneventful. The majority of the instruction, for the first thirty-minutes was teacher-led. The teacher circulated throughout the room, writing on a handheld electronic tablet and stylus that projected annotations on a screen 
in the front of the classroom. A number of students enthusiastically raised their hands to answer questions. About thirty-minutes into the class, the group of off-task girls began to focus on the assigned classwork and appeared to have little trouble completing the worksheet, even though they have spent the majority of the class talking amongst each other.

The next classroom observed was an AP class taught by Mr. Vincent. The class was held in an old performing arts theater located outside the main building. When entering the room, the incredibly small class size of six students made to feel even smaller by the vastness of the theater turned classroom is noticeable. The class has already begun by the time entered, and the teacher had a "quick-write" activity displayed on the screen using an overhead projector. The atmosphere feels very collegial. The teacher ended the activity by playing and audio recording of the poem read by a narrator with a very deep, rich, James Earl Jones pitched voice. The subsequent discussion about the poem included all six students engaged in what felt like the type of literary circle one would expect to find in an adult book club. Students cited examples from the poem to support their arguments and appeared to speak in full, complete sentences without much prompting from the teacher. 
Overall, the classrooms procedures at City Charter High School (CCHS), did not have the uniformity of Destiny High or BIM-Academy. I am not sure if this was by design to accommodate the backgrounds of the student body or the result of simply having a large number of new teachers who were still getting the feel of the school, its students, and its procedures. Nonetheless, as I sat in the classrooms and walked through the halls, I got the strong sense that there was a level of caring and respect exhibited by the administration and teachers that felt unusually high for such a large inner-city high school.

\section{The Major Themes}

This study investigated the performance of three high-performing charter schools serving minority and low-income students. The purpose was to determine what characteristics may be responsible for each school's exceptional academic performance and which of those characteristic the three schools had in common. As the result of a number of classroom observations, and staff interviews, three themes emerged from the data collected and analyzed for this study. First, all teachers and administrators had high expectations for their students. These high expectations, a tenet of both culturally relevant pedagogy and culturally responsive teaching, were supported by a number of school policies and programs put in place to ensure all students had an equal opportunity 
to succeed. Second, the overwhelming majority of the curricula used in the three schools were created internally, to meet the needs of the students. Additionally, a number of teachers spoke about creating rigorous, culturally responsive curricula that leveraged their students' prior knowledge. Third, these curricula were delivered via instructional practices that were often aligned with tenets of culturally responsive teaching in that they were multi-dimensional and were observed as being engaging to the majority of the schools' students. The curricula often included scaffolds and accommodations to support the development of struggling students while challenging those students performing at the highest levels in each class.

\section{High Expectations with Support}

At all three schools, the administration and faculty supported their high expectations for students with three common strategies. First, each school had a collegegoing culture that was illustrated in the college-prep and advanced placement focus of the courses offered at each school. This college-going culture was reinforced by explicit messaging about the importance of getting accepted into and graduating from a four-year college. Second, the college-counselors considered it part of their responsibility to impart some of their cultural capital to their students, in order to help them navigate the college selection and application processes. Third, each school used some version of a four-year 
cohort advisory model. This allowed students four years develop supportive and meaningful relationships with their teachers.

\section{College Going Culture with Commitment and Support}

All the schools investigated in this study were described as college preparatory high schools. The expectation that every student would graduate prepared for college, was a part of each school's mission. Across the schools, there was constant messaging that, "you can make it to college regardless of your circumstances." At City Charter High School (CCHS), this message was visible on the Wall of Fame, a 40,000 square-foot open space in between the main hall and the wings of the classrooms. Three of the walls were covered with pennants from each of the colleges to which a CCHS graduate had been accepted. Under each pennant, was row after row of one-inch by three-inch slips of paper, with the name of CCHS graduates who had been accepted to that university. The pennants had names of four-year universities from all across the country, including such highly selective institutions as: MIT, New York University, Stanford, and UC Berkeley. A number of the Historically Black Colleges and Universities (HBSU) were represented as well. The largest number of acceptances was from the local CSU campus and there was an equally impressive number acceptances from the local UC campus. 
This school-wide culture of college-readiness is more than just a wall covered with college pennants, with slogan, "Yes you can!" It is really grounded in groups of committed teachers and administrator who have bought into the mission of the school. This point was very well expressed by Ms. Pimera, the school principal, when she described the difference between her previous school and CCHS: I can't tell you how many times staff members at my previous site would talk about how not everybody wants to go to college. I used to always say, "But that's not our decision to make. We have to give them choices."

I'm now in a situation where the vision and the mission is all about getting all of our kids to college. There's just a huge shift, which in my mind meant there have to be people connected to this work who are choosing to work there because of the vision and the mission, not because they're sitting in a spot because they got tenure and they're not going anywhere. (CCHS. Principal Primera, 12/02/15)

Like the principals at the other schools in this study, the principal of CCHS was drawn to the school because its mission to prepare all of its students for a four-year college. However, all the schools in this study also served a student population comprised mostly of traditionally underperforming students. Therefore, the need for additional supports, to achieve the mission, was paramount. For schools like Destiny Public Schools (DPS), the supports came in the form of ninth-grade, academic development courses like Ms. Alvarez' Academic Numeracy and Ms. Hill's Academic Literacy and Leadership 
courses. Courses that were created to help students achieve up three school-years of addition growth in the period of one school-year. Additionally, in keeping with the holistic approach to teaching, many teachers believed their responsibilities went beyond simply teaching the academic content. They also believed that part of their mission was to educate the entire student and to support his development as a human being.

At CCHS, second year U.S. History teacher, Ms. Cloverdale described her curriculum as being very rigorous and providing a solid foundation for the demands of college. Her curriculum has and instructional practices demand a great deal of critical thinking and writing from her students. She almost affectionately described the support she provides students as being invested in her students' success and their lives.

Academically, my expectations are pretty rigorous, and they get that from the getgo because they have homework every night. I grade it tediously...my curriculum is pretty rigorous with high expectations. So, yeah, teachers, our college counselor, and also just the general environment here at CCHS is pretty supportive. Teachers are expected to stay in contact with parents. They're expected to use data to help inform curriculum. When you're hired to this school, you're expected to be more invested in the students' success and their lives which I think goes a long way to getting them into college. (Ms. Cloverdale, CCHS, $12 / 18 / 15)$

At Destiny Public Schools, expectations for teachers are also set very high. Principal Estrada explained that one of the advantages of leading a charter school is the level of flexibility he has with human capital management, which he might not have were 
he working in a TPS. The high expectations that he has for his teachers is undergirded by the requirement that they consider every minute of instructional time precious and use that time to help their students prepare for success in college. The way he explains it, little details like shaking students' hands, correcting students' posture, and using academic language is all part of helping students develop to the point where these behaviors become automatic.

Well, one part of our school is that you have complete control over who you hire. And that allows you to make sure you don't have people in the building that don't high expectations for all her kids. And I know if I were working at a public company or a public school that will be a lot harder to do. I think that since we expect all our kids to go to college they should be treated as scholars but I think that there is some variance in how that is manifested here.

I think the way we get teachers to do that is to give them feedback. I think we did a lot of work in the last year around going to the source like teachers talking to other teachers about what they notice. (Principal Estrada, DPS, 09/25/15)

The feedback he was referring to was the school's informal and formal peer review processes. Teachers are encouraged to visit others' classrooms and observe best practices as well as give each other constructive feedback on what they observed. This is all part of an integrated strategy illustrated in a document called "Technology and Time 2.0" that allows teachers to engage in high yield instructional practices. These will be discussed in more detail in a later section of this chapter. Nevertheless, the primary goal 
of these high-yield instructional practices is to help students develop critical thinking and problem-solving skills needed to succeed in college.

On the other hand, the smaller BIM receives students from a number of different middle-schools in a district serving over 10,000 middle-school students, and each student comes to the school with a unique set of skills and challenges. While BIM teachers pride themselves on having a very rigorous curriculum, many of the students would possibly not succeed if it weren't for the wide array of academic supports provided for them.

For ninth graders, the supports begin well before the first day of school. During the summer, all the incoming ninth graders participate in a four-week summer bridge program call Summer Success Camp. During this camp, all students are given both math and English language arts diagnostics to determine each incoming student level of prior knowledge in math and English. This assessment data is used to provide some content support for each student, but its main purpose is to assign students to homogenous math classes based on skill-level.

Once the school year begins, ninth graders who are at risk of failing one or more classes are assigned to ASP, which stands for academic support program. ASP is scheduled every day from 4:20 pm until 5:00 pm. The ASP is staffed with paid tutors who are all students at one of two local universities. A credentialed teacher or an 
administrator manages the sessions. Most days there are up to 40 of the school's 80 or so freshman attending ASP.

The academic support does taper off as students' progress into the tenth grade. For all students, there is an academic support program called "P7", which stands for period seven. P7 scheduled 3:35 pm to 4:15 pm Monday through Friday. Each teacher is required to offer two "P7" sessions each week, one for his content courses and one for his advisory. Students can be assigned to P7" by a teacher, administrator, or parent, or a student can voluntarily attend. I was told that a number of student advocate for themselves and voluntarily attend at least one "P7" each week.

Each school has high expectations for its students as expressed in their respective mission statements. However, since their students enter ninth grade with varying levels of academic performance the need for additional supports is paramount. For Destiny Public School the academic support comes in the form of the ninth grade academic numeracy and academic literacy classes. These classes are designed to accelerate academic achievement of students attending them by as much as three grade levels in one year. At CCHS, Ms. Constantine's "Reading 9" provides a similar support for ninth graders struggling with reading and English language arts but there was no specific math support class for ninth graders. Ms. Lipchitz, the CCHS lead math teacher, taught a 10th grade 
Algebra I class that appeared to be similar in many ways to Destiny's Academic Numeracy class. They both used a mastery-based pedagogical approach that allowed students to progress form one topic to the next, completing and passing formative assessments. They both used adult teachers' aides to support struggling students, but the level of differentiation was much more sophisticated in the class at Destiny.

BIM's method of supporting ninth grade students involved tracking students into homogenous math classes so that the level of support could be modified to the students in each class. The students were assigned to the math classes based on the diagnostic they completed during the Summer Success Camp. Moreover, as I was told by a number of teachers, the tracking of students into math classes created an implicit tracking system that resonated throughout the students' other classes based on the logistics of scheduling the other classes around math.

Because math is tracked, it's the tail that wags the dog, which means that there are some math classes that carve a whole cohort of higher skilled students. (BIM, Ms. Echolat, 12/17/15)

Ms. Echolat leads the Reading Center at BIM. The Reading Center is just one of a number of academic supports offered to students in need. In addition to the " $P 7$ " and ASP, there is also the Learning Lab, which is led by an experienced math teacher. All ninth grade students were required to attend the Learning Lab where they received 
additional support with mathematics. They were also required to write blog posts that were available for all their teachers to read. The blog posts were about any problems students were having such as specific problems in a class or issues they are dealing with at home.

Each school had their own autonomous approach to providing academic support for struggling students. There were some common strategies but each school had created its own system designed to leverage the human and financial resources available. However, where all three schools appeared to have a common support structure was in the area of college counseling.

\section{College Counseling and Cultural Capital}

When discussing each school's success, during the teacher and principal interviews, a number of respondents from each school reported how instrumental the college counselors were to each school's high college acceptance rates. The initial data collection plan for the study did not include counselor interviews. However, after analyzing interview transcripts college counseling emerged as a theme for a number of codes associated with high expectations with support. As a result, a set of counselor interview questions was created using the teacher interview instrument as a starting point. 
During the interviews with teachers, a number of them praised the work their respective college counselors performed that seemed to go above and beyond their expected duties. This sentiment was expressed most deeply at CCHS. Ms. Cloverdale summed it up very succinctly when asked about some of the key drivers for the school's high graduation and college acceptance rates. In addition to the rigorous curricula and the supportive, committed teachers, she also attributed much of the school's success to their college counselor.

I think, from my perspective, just having a great college counselor, Mr. Niks, who just goes above and beyond for these students is one of the keys to our success. (Ms. Cloverdale, CCHS, 12/18/15)

Her fellow CCHS social studies teacher, Mr. Innis, also reported his belief that the work of the college counselor, Mr. Niks, in large part was responsible for the school's high graduation and college acceptance rates.

Yeah. The graduation rate is fine. I think we're really good at that because we have great counselors and we have a college counselor in the school, Mr. Niks who's absolutely amazing. He is the reason we have the success that we have with high school graduation and acceptance into four-year institutions. (Mr. Innis, CCHS, 12/18/15)

CCHS math teacher, Ms. Lipchitz pointed out that the reason the college counseling was such a key component of the schools' success was, in part, due to the 
socio-economic background of many CCHS students. With over 73\% of their students coming from low-income families, the majority of its students were first-generation college students. Very often, when discussing the complicating factors involved with supporting low socio-economic students, the lens is most often focused on those factors related to the economic implications of living in poverty. Schools consequently focus on the financial implications that may affect low-income students in preparing for a fouryear institution. This may cause schools to focus in on items such as application and test fees, the cost of school visits, and concerns about the cost of attending college.

Ms. Lipchitz commented about the need to support their students' lack of cultural and social capital as well. Being the first in their families to attend college, the average CCHS student may not have access to many of the college counseling resources uppermiddle class students get at home, from their parents, neighbors, and peers. The needs of CCHS students go beyond just giving reminders about when to complete applications and take tests. Many of these students also need a great deal of support making sure that they complete the requirements for applying to certain colleges as well as determining which schools are the best fit for their academic backgrounds and career aspirations.

Therefore, the role of the college counselor at CCHS is as much about counseling and guiding students along the pathway to college as it is about sharing the cultural 
capital that he has accumulated as college graduate and as a third generation college student.

I mean we have a college counselor. I know a lot of schools don't have that. $100 \%$ of his job is working with our seniors to make sure that they've all taken the SAT and ACT and helping them register for those things. When I was ready to take the SAT it was like "Hey, mom, dad, what do I do to sign up for this?" I had people at home to help me with those types of things. A lot of our kids don't.

So he takes it upon himself to make sure that all have taken those and that those scores are getting reported to the colleges they want them to be. He's checking their graduation requirements on a regular basis and saying, "You need to be applying to this school because you got a 3.0 or higher. You're interested in this." So he knows the colleges in the area inside and outside. He knows the UCs and the CSUs and he knows all the ins and outs of getting kids in. So having someone like that on your campus is huge for our kids. (Ms. Lipchitz, CCHS, 12/18/15)

At CCHS, the college counselor played a crucial role in supporting first generation college students as they scrambled to meet the never ending series of deadlines related to applying to four-year post-secondary institutions. The work of the college counselors at Destiny and BIM were also equally as important to each school's success. However, at the smaller BIM, the lone school counselor, Ms. Macias, claimed that her success was more of a team effort. Without the support of teachers, administrators, and parents, her job would impossible for one person to handle. The tasks associated with the academic counseling for all 290 students and managing the college application process and coordinating campus visits for each year's senior class is a 
daunting process. So Ms. Macias relied on more of a 360-degree approach to supporting the school's upperclassmen.

Ms. Macias mentioned a number of times the importance of parents in supporting student success. She described how she has been able to partner with the school's parents and use them as a vital link in the college preparation process even though many of them are not college graduates. The parents had access to the students during the non-hours and kept them accountable for meeting the college application related deadlines. Ms. Macias used her cultural capital as a college graduate and college counselor to make sure they were taking and passing the right course and applying to the right schools. Together, this combination resulted in more than $90 \%$ of BIM's graduating seniors getting college accepted into a four-year college.

BIM is clear example of how a small community charter high school can still provide first generation college students with the support they need to get into college. The key to BIM's success was partnering with the parents, which in a way holds the students accountable for meeting the college admissions deadline, while providing them the support and guidance that more affluent students receive at home.

Destiny Public Schools fell somewhere in the middle of BIM and CCHS. Their counseling department counselor consisted of two full-time counselors who were 
assigned half of the student body based on last name. Ms. Eager was assigned to all students whose last names started with "A-L" and for Mr. Maestro, the students with last names starting with "M-Z". Two counseling interns supported these two full-time counselors and college counselor, Dr. Daniella Bolivar, headed the entire department. Many of the teachers interviewed at DPS, like their counterparts at BIM and CCHS, also believed the counselor played a critical role in the school's success. At DPS, that success translated into a $97 \%$ college acceptance rate, which is an impressive number. But as Principal Estrada pointed out, "That's still 3\% short of your goal to get 100\%."

Similar to both BIM and CCHS, all students were required to complete the A-G requirements in order to graduate. DPS also did not accept a " $D$ " as a passing grade in a class, because credits from those class would be not be accepted by a UC or CSU. According to Ms. Eager, the counselors make sure students stay on the path to college from the first day they walk on campus until well after graduation. Because most the DPS's students are first-generation college students, the school's support structure is designed to offer them a great deal of guidance throughout every step of the college application and admission process.

Our graduation requirements are the A-G requirements. So every one of our graduates is eligible to apply to a CSU or UC. Colleges won't take "D"s for credit 
so we don't allow our students to pass with a "D". We set up the path so that it much barricaded. And that can be very helpful. And because we are small, we can provide a lot of individualized support to make sure they actually complete each step because we know many of them are first generation and they can't go home ask mom or ask dad, "what test do I take". We have to kind of fill that role and because we are small, we can do that. (Ms. Eager, DPS counselor, 03/03/16)

Ms. Eager was referring to the same forms of cultural capital that CCHS's Ms. Lipschitz spoke about. In many ways, the high school counselors at DPS also shared their cultural capital with their students to help them successfully prepare for and apply to college. Interestingly, they both mentioned the items related to the placement test required for college admissions. However, Ms. Eager was also aware that getting the students into college only was half the challenge and that a number of their students were not completing college. Though the exact number was not known, it was a concern and an issue they planned to investigate further.

In order to help students persist through college, the school had not only increased its focus on helping students develop more persistence and "grit," but they had also taken concrete steps to increase the odds that their students would persist through college. The first step was to make sure students were applying to colleges that were a good fit for them. The counselors helped each student create list of colleges they believed were a good fit for his personal needs and program interests. 
...this past week, Laura and I contacted every single senior and asked, "Did you fill out your FASFA!!! Did you fill out your FAFSA?" because if they don't then they don't get aid and that is huge reason why they come home. We realize that that is only one piece. So we are really conscience about helping them build that list of where they are going to apply so we can make sure they're going to a school that's going to support them. And they're going to appreciate who they are. Because I can send them off the any university but the question is, will that be right for them or will that college have program they're going to enjoy? Will they be able to support them and their situation? We can only do so much while they are here. And when they leave, we just want to make sure we're sending them off to the right places. (Ms. Eager, DPS counselor, 03/03/16)

All three schools had college counselor who was committed to helping their students get accepted into a four-year college. For most of their students, who were firstgeneration college students that meant having counselors willing to offer support in the form of the types of cultural capital they had received from their parents when preparing for college. They also spoke about the importance of partnering with parents. While many of the parents themselves had never gone to college, their support in holding the students accountable was a crucial part of the equation. As DPS counselor, Mr. Maestro put it:

And which is why so much of our support services include outreach to parents and workshops and informational meetings. It's constant. And that's one of the things that are built into our protocols because we know how important that is. Because we can't miss that piece. (Mr. Maestro, DPS counselor, 03/03/16) 


\section{Four-Year Cohort Advisory, Student Support and Development Model}

At DPS, the student advisory system has been at core of the school since its inception. Over the years, its advisory evolved into a meaningful support system for the student and a place where they learned many of the socio-emotional skills the administration believed were an important part of preparing students not just for college, but for life as a well-rounded socially-conscious citizen. This holistic view of educating the entire student is one of the six dimensions of culturally responsive teaching (Gay, 2010), and it was often discussed as one of DPS's core values.

I remember when a lot of the one counselor's job was mainly like scheduling and some of the more logistically stuff and now that we got a few more, they really focus on like the social emotional things now over there, they do advisory now. They run a curriculum for advisory and they also do all the emotional stuff that we talk about in advisory. (Mr. Jones, DPS, 12/15/15)

I also think that the administration is looking at the child as a whole and not just as a student. They're looking at them as a human being, all of us are really. But obviously, they are the ones preparing them. And the counselors, oh my gosh, the advisory lessens -- senior advisory this year and the amount of work that they do to help them get ready for college, mentally and emotionally, it's amazing. (Ms. Gonzales, DPS, 2/08/16)

Mr. Jones and Ms. Gonzales, both long-term teachers at DPS, stated that the school's efforts to support the socio-emotional development of students were not left up 
to the individual perspectives of each teacher. The counselor created grade-level curricula, which the teachers used in their advisories to help student develop their socioemotional skills. But there was more to the advisory models. Each of the schools also used the four-year cohort aspect of the advisory system to help provide some of the support students would need to deal with academic and personal challenges of going to college. For the students at DPS, the four-year path began just prior to day one of freshman year.

Every year, every freshman class starts off with a retreat where they bond with their advisory, they bond with the 20 students that they'll be together with everyday 30 minutes until they graduate three years later. So they bond with their advisory and then they do some sort of breaking out of your shell, taking a leadership role, responsibility type of activities and then they come back and then they are ready to go. (Ms. Timbiku, DPS, 2/08/16)

What Ms. Timbiku was referring to was the four-day freshman retreat that DPS holds every summer at a different college campus. For four days each fall, all the freshman and their adviser gather together for an intensive introduction to the school, its rules, and the members of each advisory. During this retreat, the students engage in all sorts of activities designed to help develop relationships with the members of their advisory, including the adviser. This retreat is in some ways an abbreviated version of BIM's Summer Success Camp. 
The main focuses of Summer Success Camp are on assessment and diagnostics. However, some time is spent introducing the incoming freshman students to their adviser and members of their advisory cohort. Once the first day of school begins, the adviser is the primary point of contact for all the students in the school. As mentioned, the single counselor at BIM relies on the teachers to serve as a two-way channel of communication. Without this teacher-counselor relationship, it is doubtful the school could have achieved its past success.

The advisory system, we mentioned support, the adviser is really the frontline of student support. This is just a need. I think it's a safe generalization that urban kids really benefit from that adviser piece. So we've seen a lot of the charters implement it. (Principal Champion, BIM, 11/06/15)

CCHS is also one of the charter schools that has chosen to adopt the advisory model. While many of the teachers spoke about the efficacy of their four-year cohort advisory model, a number of teachers and the principal discussed the need to improve the effectiveness of their system.

Advisory is a concept that from day one, our founder was, "That has to happen." Every student needs to have a relationship with the staff member, feel special, have a place that they can go to that's their family or their community on campus, so we have it at the end of the day, 25 minutes every day. I already have a lot of ideas on how I want to switch that for next year, but for now, that's what we've got. (Principal Primera, CCHS, 12/2/15) 
The advisory program is probably another thing that we're working on making stronger. The idea is that you have your kids starting freshman year and you stay with them through their senior year. This is only my second year so I just have my kids for two years. (Ms. Lipchitz, CCHS, 12/18/15)

Again, I've only been here for two years. I know that advisory has been successful in the past. That's when advisory was in the morning. I think that's just about it. Because when I see my students, I see them at 3:10, they're tired. They've had a really long day. The last thing they want to do is research colleges or practice for the ACT, doing the things that are really, really advantageous for them but they're checked out. Saying that, I think our advisory curriculum is really good. We've just got to make the advisory a morning class again. (Ms. Cloverdale, CCHS, $12 / 18 / 15)$

Overall, all three schools showed evidence of having high expectations for all students. This was usually expressed in each school's mission statement, which involved some language about preparing all students for college. Additionally, many of the teachers described their students' skills as being average or below-average upon entering the school; however, they believed that all students could succeed given the appropriate support.

At all three schools, a common support mechanism was some form of a four-year advisory program. The advisories at all three schools appeared to have three common purposes. First was they provided a safe, protected space for the students to develop relationships with each other and their adviser. This also allowed the adviser to be, as Principal Champion described her, "the first line of support." Second, it was in the 
advisories that students were given much of the information and resources needed successfully apply to college. Third, the curriculum for the upperclassman advisories were created by a college counselor and focused on all the college related activities those students needed to get accepted into a four-year college.

At BIM and DPS, the counseling staff developed the grade-level lesson plans for the advisories. For freshman and sophomore students, the advisory curriculum was focused on the school norms and included some lessons related to the development of non-cognitive skills such as persistence, grit, and self-regulation. At the smaller BIM, the teachers worked jointly in grade-level groups to develop the advisory curricula for each grade. Overall, it appeared that the advisory was a key characteristic underlying each school's success and provided many of the students, especially those who entered with skills below grade-level, the opportunity to access the school's curriculum in a way that would have otherwise not been possible.

\section{Internally Developed, Culturally Relevant Curriculum}

Throughout each of the three schools, the majority of the curricula used was developed internally. In some cases, it was produced by a lone teacher working in her specific content area, and in others, the curriculum was created by a collaborating group of teachers. Regardless of the process used to create the curricula, the goal was always to 
better support the needs of the students. Many teachers spoke about creating a very rigorous curriculum for their classes to challenge the higher performing students while including a number of scaffolds to support students needing additional support to access the lessons. This practice is very much aligned with the tenet of culturally responsive teaching referred to as "high expectations with commitment" and supports. By creating rigorous curricula with scaffolds that provide multiple entry points for students at all levels, teachers are manifesting their high-expectation for students in their lessons. Examples of this practice were evident in many of the discussions I had with teachers after the observations and during the structured interviews.

My Algebra curriculum specifically is I'd say two years removed from Engage New York. So I used it heavily my first year in regards to creating my sample set of problems, but an Engage New York lesson is so long I would probably take a quarter of it because the Engage New York curriculum is just way too far above where my students are at. It folds in way too many sub-skills to the extent that I can't just use it at face value. So I need to scaffold it or I need to change the problem the way in which the problems are asked or what have you so that they are at a level where my students can be successful. (Ms. Alvarez, DPS, 1/12/16)

In this excerpt, Ms. Alvarez describes how she modified an existing open-source curriculum to build on her students' existing funds of knowledge. This process could be described as the type of cultural competence that is a marker of culturally responsive teacher. 
The Engage New York curriculum that Ms. Alvarez referred to is an open source curriculum created by the New York State Department of Education. It is made available, free of charge, in MS Word and PDF formats. A CCHS math teacher, Ms. Santos, used a curriculum she created for her pre-calculus class that was also based on the Engage New York framework. She also commented that the pacing of the lessons was a bit too fast for her students, and also that she had to modify the lessons to make them accessible for her students, by reducing the number of sub-topics covered in a lesson.

However, the practice of adopting another state's curriculum and modifying it to meet the needs of students appears to be an exception. Most of the teachers spoke about developing their own curricula by gathering items from a number of different sources, including textbooks, printed worksheets, and online resources. This process often involved selecting content aligned with the Common Core State Standards (CCSS) that also seemed appropriate for their classes while honoring the culture and backgrounds of their students. BIM science teacher Ms. Ellsworth spoke about her curriculum development process as something of a scavenger hunt. However, her primary objective was always to create a curriculum suitable for her student that challenged them to reach higher levels of achievement. 
I think there is tons of stuff for every single topic out there. It's a matter of selecting which one is going to be appropriate for their reading level, their listening level, their familiarity with the topic, their ability to understand it because of the language and so forth, its appropriateness in terms of whether it's accurate, what it's covering. That's the first step is just vetting it.

Beyond that, in terms of modification, it depends on what the content it. If it's reading, usually I'm not going to modify it further.... it depends on the resource, but usually, I don't have to do as much modification there. It might be questions that I change, or especially with labs, I might have to change the materials. (BIM, Ms. Ellsworth, 12/04/15)

Ms. Ellsworth's process for finding appropriate curricular resources for her students was pretty common across all the schools. CCHS principal, Ms. Primera, mentioned that the additional workload associated with developing curricula was one of the major sources of burnout at her school. She created a curricula development program where one teacher is given an additional "prep" period to create all the lessons for a particular subject. The lone CCHS AP U.S. History, Mr. Innis, spoke about working with a consortium of local AP History teachers form neighboring schools to share the workload of creating his rigorous AP History lesson. He spoke about the ability to use his fellow AP History teachers, many of whom he met during his credentialing program, as a benchmark for his students' achievement. Since a number of his peers worked at more affluent suburban high schools, he spoke about gauging his students' progress by using common assessments with his consortium. 
Mr. Innis also brought up a common theme regarding curriculum, which a number of teachers spoke about, and that was feeling passionate or getting a sense of ownership from creating his own lessons.

Yeah. I think about that when I thought about leaving. It's like, "Am I going to go into a school that's going to say, 'No, you can't teach this. You can't teach that. There's already this curriculum in place. You teach this."'... I'd struggle with that because I'm super passionate about the curriculum that I have now. And trying to teach someone else's curriculum, I'd struggle to find the same passion. (CCHS, Mr. Innis, 01/20/16)

This sentiment of feeling passionate about a curriculum that a teacher created was expressed by a number of the teachers I observed.

At Destiny Public Schools (DPS), AP History teacher Ms. Gaines spoke about engaging multi-media curriculum as something she felt very passionate about teaching. Her lessons used video recordings of teens rapping about the amendments to the constitution while the students sang along. A number of her lessons used music and video as tools to help engage students in the lessons. Additionally, she infused a number of culturally-relevant topics into her lessons, like the black lives matter movement. Ms. Gaines engaged her class in a discussion about why it was more difficult for members of the black lives matter movement to exercise the right to free speech than it was some white supremacist groups like the KKK. Using her lesson called "Your Favorite 
Amendment," students were required to pick their "favorite" constitutional amendment and then research online resources for examples of groups who were able to exercise that amendment and counter-examples of where other groups right the exercise the same amendment was denied or curtailed. This discussion about the first amendment and white supremacist groups ultimately worked its way into a heated debate about the unfair distribution of political power and social capital in the United States.

I expected to see more themes related to social justice and critical consciousness infused in the curricula created by these autonomous charter school teachers. However, only a few examples of this were found and mostly at Destiny Public Schools (DPS). In Ms. Hill's Academic Literacy class where students read their poems of self-identification, issues of social justice were an integral part of the curriculum. Her approach to engaging students with a culturally-responsive, multi-dimensional curriculum was centered on having students discover their own voice and identity through reading and writing.

...it has really been kind of my ideas in how I want to shape it knowing that the themes of the classes, how to build reading, writing and leadership and through kind of a social justice lens with that. So the beginning unit of the year is like reader's identity and literacy identity and who you are and leaders in history and how they have used literacy to become leaders. So that first unit of the year, they study Malcolm X and how many times I'm supposed to read in jail and they study Sherman Alexie, a very popular writer. (DPS, Ms. Hill, 1/12/16) 
Ms. Hill also spoke about including forms of mindfulness training into her curriculum as a way to help students better manage the stress of school and find balance in their lives.

Specifically, they are learning how to meditate and we're doing daily meditation over the next month in something that will probably extend for the rest of the year and I think that is a piece of this high rigor charter schools and a lot of high schools that have really rigorous curriculums and college prep of how do students balance their mental health especially that junior and senior year. (DPS, Ms. Hill, $1 / 12 / 16)$

This innovative aspect of Ms. Hill's curriculum was, of course, focused on helping students develop the emotional or spiritual tools to cope with the demands of working in a rigorous academic environment. Culturally responsive teachers (Gay, 2010) are considered holistic in that they educate the whole child: socially, emotionally, politically, and, in this case, spiritually. During her interview, Ms. Hill did stress the fact that mindfulness was form of meditation based on the principles of Buddhism. However, it was considered secular because it did not promote a philosophy of meditation that could be considered religious.

Not all of the teachers believed that explicitly including aspects of social justice into their curriculum was necessary. BIM Math teacher, Mr. O'Toole, believed in a "back to basics" approach to teaching and developed a curriculum that was mainly comprised of 
worksheets and that utilized Kahn Academy as a practice and diagnostic tool. He was emphatic in his belief that it was important to simply get the students to read, write, and perform mathematics at a level sufficient to ensure their success in college. All that other "horse manure" just got in the way and created students who relied on rhetoric more that intellectual capacity.

That's all bullshit. First of all, these kids are from east Oakland. And I'm gonna talk to them about racism. Really, like they don't know about it. They don't experience it. How about this, you want to end the cycle, get yourself educated. Get a nice job, buy your mom a house, okay. Problem solved. You can't do anything about it till you become educated enough to become a powerful man or woman to change the world around you. (BIM, Mr. O'Toole, 12/04/15)

Mr. O'Toole explicitly spoke about social justice in the form of using education to improve the socio-economic status of his students. This excerpt is emblematic of the cultural competency component of culturally relevant pedagogy. However, Mr. O'Toole's belief is that the path ending the cycles of poverty and racism that impact many of our inner city students is through a college education, not a curriculum designed to discuss those issues in class. His no-nonsense approach to teaching mathematics, which is based on the use of what I would describe as very challenging worksheets to help students build mathematical problem solving skills and Kahn Academy to 
formatively assess student progress is evidence of his support and commitment to the high-expectations he has for his students.

Surprisingly, the only school that thoroughly integrated the use of technology into all of the curricula was DPS. Every teacher in the school that I observed had created their curriculums so that they could be accessed online using Google Classroom. These teachers also required students to submit assignments and take many formative assessments online. As part of their redesign work, DPS 2.0 developed a technology plan that allows them to use technology to facilitate the transfer of knowledge and support collaboration. They also created a document called Time and Technology, which discussed the school philosophy on the use of technology and the guidelines supporting that philosophy. DPS principal, Mr. Estrada, pointed out that if for some reason the school lost power or access to the internet, they could still teach an effective class, but it simply would not be as efficient as it would have been otherwise.

Based on my original propositions for this study, I expected that technology would have been a crucial component in the success of the all the schools. However, BIM and CCHS proved that a charter school does not need make huge investments in technology to be successful at increasing student achievement. BIM had Chromebooks, and they were shared across all the subject areas. A few BIM teachers stated their 
perception that the math department seemed to have priority access to the Chromebook cart.

The majority of the teachers at the three schools used culturally relevant curricula that they created internally to meet the needs of their students. These curriculums were the work of an individual or groups of teachers at the school and in one case resulted from the collaboration of a number of AP History teachers at three different schools. Many of the teachers spoke about creating rigorous curricula that offered a number of scaffolds and supports to create multiple entry points for students with a broad array of prior knowledge. This aspect of the curricula was aligned with a culturally responsive teaching's high-expectations with commitment and culturally relevant pedagogy's cultural competency. Additionally, a number of teachers explicitly included social justice topics into their lessons to make the content more engaging for students. Again, this practice did not occur as often as I had expected and one teacher expressed opposition to including such topics in his lessons. Finally, while varying levels of technology were available at each of the respective schools, Destiny Public Schools (DPS), had a one-toone technology program where all teachers delivered their lessons online.

Overall, the common curricular thread across the three schools appeared to be the use of rigorous internally-developed lessons that included scaffolds to support students at 
all levels. These curricula were reflective of the tenet of high-expectations, which is a key component of culturally responsive teaching and was evident throughout each of the schools. However, these lessons would not have been very effective at increasing student achievement unless they were paired with equally rigorous and engaging culturally responsive instructional practices.

\section{Differentiated, Culturally Responsive Instructional Practices}

In my discussion of the classroom instructional practices, I will focus not only on the teaching modality (teacher-led, small-group, or whole class discussion) used by teachers to deliver their curricula, but also on the level of student engagement observed during the lesson. The need for this two-dimensional approach to observing and analyzing classroom instructional practices became apparent during two of the initial classroom observations for this study. Early on, I observed two math teachers deliver the same curriculum, using the similar teaching modalities but achieving disparate levels of student engagement. It was apparent that the first teacher, though less experienced, was able to achieve a higher level teacher engagement than the more experienced teacher. The less-experienced, more effective teacher had apparently created a classroom environment, through her instructional practices and interpersonal relationships, where students appeared to feel safe, respected, and empowered to achieve. This sense of empowerment 
observed in her class was in many respects a reflection of a culturally relevant pedagogical marker referred to as cultural competence. From that point forward, I began to observe classrooms with an eye to both the instructional practices as well as student engagement.

Additionally, these discussions about instructional practices and perceptions of student engagement will also include some mention of teacher assessment practices, as they are closely related to classroom instruction. Many of the teachers and principals spoke about the use of data-driven instructional practices. While this practice appeared to be more prevalent in two of the schools, teacher and principals at all three schools spoke about the importance of using assessment data to drive classroom instruction. The school where this practice was most evident was DPS.

So I think the highest leverage things teachers can do is pull small groups based on the data. Have one-on-one conversations about perseverance. To create academic mindsets and facilitate problem-solving and all those things. I don't think there is easy tech replacement for all those instructional practices. But there are a lot of tech replacements for direct instruction, testing, peer feedback. Like all these things that can happen with the computer you're freeing up teaching to do things that are more important. (Principal Estrada, DPS, 9/21/15)

As part of the DPS redesign projects, teachers were surveyed about what they thought were their most impactful instructional practices and which practices had the least return on student achievement. As a result, DPS created a document call Time and 
Technology. This document describes some of the strategies teachers at DPS can use involving technology to facilitate high-value instructional practices such as small-group instruction and one-on-one support. Another way teachers at DPS used instructional technology was to identify high-performing students and to facilitate their continued advancement by way of self-directed learning. This was primarily possible because all DPS teachers posted their lessons online where they were readily available to students who wanted to work at a faster pace or simply preview upcoming lessons.

When I observed Ms. Alvarez' ninth grade Academic Numeracy class, I saw a class of 45 students working in one of three distinct zones of the classroom. In the front of the class, Ms. Alvarez was work with a groups of eleven underperforming. The first part of this small-group lesson involved having the student use Google Docs to see their most recent quiz score. I assume this was so that they could see the data that was being used place them into the group. Next, she began a review of the material that she had decided to re-teach to these students based on the quiz results. The students appeared very engaged in the lesson and throughout the entire class their only one minor disruption was from one student in the small-group setting.

While Ms. Alvarez was working with the small group of 11 students in the front of the class, there were approximately 25 other students working in pairs or groups of 
three. They were seated at tables along the side and back walls of the room. Three student-teachers, who were also junior or senior AP Calculus or Statistics students, were assisting them. The students working in small groups appeared mostly on task. The student-teachers circulated throughout these groups offering them support, when needed. When conservations from these pairs became a little raucous, the teacher politely asked them to use their "quiet voices" when speaking with their partners. Throughout the entire class she only had to make this request twice.

In the middle of the room were approximately 10 to 12 students sitting at individual desks working on their Chromebooks wearing phones. Ms. Alvarez explained that these students were engaged in self-directed learning, working ahead of the rest of the class, at their own pace. Since most of the lectures for her class were also posted online, these students could work, self-directed at their own pace and were later brought back into the whole class when they began a new lesson.

Throughout the entire class, students seemed to use many of the behavioral skills they learned in their freshman orientation that were reinforced in the advisory. These skills included self-control, persistence, "quiet voices," and collaboration.

So I split my class up into three different groups. I think of my lowest students, my bottom $20 \%$ that struggle with a lot of their foundational skills...They're 
lacking that number sense. And so the bottom $20 \%$, I have it differentiated as an instructional model where I give them a lot more direct instruction when it comes down to the skills so that they can access more content in an independent fashion. And then the other two thirds of the class, I focus a lot of the instruction on how many scaffolds ... I don't want to give scaffolds to people who don't need it. (Ms. Alvarez, DPS, 01/12/16)

Ms. Alvarez' instructional practices involved the use of assessment data to constantly support her students' needs. However, much of what she does would not be possible without the use of technology. Also, the amount of student engagement required to operate what is essentially three classes at once seemed to also be supported by much of the character development work that occurred in the freshman and sophomore advisories. What was not reflected in the interview excerpt was the sense of community Ms. Alvarez created within her classroom. As students in her small-group section mastered a skill, she was then identified to the members of the small-group as an expert in that area. Students were directed to ask her for help when they had a question about that particular skill. In this complex, high-functioning math class, a number of characteristics converged to create a learning environment that allowed underperforming students to advance two to three years in the course of one year. The first was a school culture of high expectations with a commitment to supporting the success of all students. Second was the use of an internally developed culturally relevant curriculum that was 
designed for use in a blended-learning environment. And finally, there were multidimensional and engaging culturally responsive instructional practices used by the teacher to facilitate the learning of three different levels of students in one class.

Overall, Principal Estrada summed up DPS's instructional practices and what the researcher observed in Ms. Alvarez' class very succinctly in the following passage:

Giving multiple pathways to understanding things that kids can access through technology is key. So we use things like Guru to push personalized independent learning. If we can do that so kids can learn faster, teachers can be, like okay we have $90 \%$ of our students engaged in learning on their computers so I can pull five kids that are not doing well and that I know because they're doing formative assessment that the technology has provided me a list that I can then draw these kids out and do a small group instruction. (DPA principal, Mr. Estrada, 09/25/15)

This example of a high-performing remedial math class at DPS provides a stark contrast to an equally high-performing 10th grade Algebra class at CCHS. Ms. Lipchitz came to CCHS two years ago, after teaching math in another state for 15 years. She brought along with her, an Algebra curriculum that she had created over the past few years and asked if she could use at CCHS to help struggling who had either failed Algebra in ninth grade or who had not taken it yet.

Ms. Lipchitz also, like Ms. Alvarez, used a mastery-based curriculum that required students to pass a number of formative assessments before moving on to the next topic. However, that was where the similarities ended. The only technology available in 
her classroom was a laptop and an electronic tablet with stylus, which were projected on a screen. While Ms. Alvarez' class was predominately Hispanic, with a mix of males and females, Ms. Lipchitz class was all male and, to all appearances, almost exclusively African-American.

The class began with the teacher displaying a timer from her laptop onto the screen and she asked the students to complete a warm-up activity. Initially, the students seemed very engaged in the activity. As I walked around to see how they were doing, most appeared to have the correct answers. Once the timer ended and the teacher called on volunteers, they seemed to lose some of their earlier enthusiasm for the work. It was almost as if she had interrupted them from playing a game or something else they would have found interesting. She seemed to get very little response from most of the students and ended up answering the majority of the questions herself.

Next, was whole-class activity that involved the teacher displaying a linearequation on the board and asking the students to solve it on their individual whiteboard. Many of the students seemed to find this activity interesting and appeared to compete with each other to see who could get the correct answer the quickest. Correct answers were followed with an emphatic, "Yes!" and incorrect answers were often accompanied by, "all man." It took a while for me to realize that Ms. Lipchitz also required her 
students to give their answers in complete sentences. Instead of simply saying, "six," they were required to respond, "The answer is six" or "The value of ' $x$ ' is six."

Next, she had her teaching assistant take a group of five students to the computer lab to work on missing "power assignments," which were formative assessment quizzes, while she had the remaining students work on a test review for the upcoming unit exam. She allowed them to work individually or in pairs. Only two students took the opportunity to work together. The remaining students all sat at their individual desks and worked independently. Once again, they all appeared to be very engaged in the assignment. When I later asked her how she made decisions about switching teaching modalities, she replied:

It just depends on the class and depends on what we're teaching. Usually the first time through something I do a lot of direct instruction. Really, my direct instruction a lot of times is the kids might have marker boards out and be working with me. It's never me just talking and they're just sitting there. I do a lot of modeling how to do something, kind of the "I show and then you do" idea. The following day it might be, if we're kind of reviewing that topic or doing a second day on it, it might be in small groups. (CCHS, Ms. Lipchitz, 12/18/15)

A few minutes later, one student came back into the class stating proudly that he had passed his "power assignments" and was ready to work on the review for the exam. Once the students finished their test review packets, they were allowed to play a board game at the back of the room that involved a pair of dice and some wood blocks or any of 
the other math related games. She later explained to me that the dice game required the students to determine the probability of getting a certain number on the pair of dice; however, she had never explained the game to them as a probability related activity. She just told them the rules of the game and allowed them to figure out how to win. By the end of class at least seven or eight students, mostly African-American males, were totally absorbed in playing the game right up the bell.

From the beginning of class, it was obvious that Ms. Lipchitz had a friendly and professional relationship with her students. Throughout the entire period, she only had to correct a student's behavior one time. Approximately 10 minutes after she assigned the test review, one of the students got up from his desk and walked over to another student and began playing around with him. When Ms. Lipchitz asked him to go back to his seat and finish the review, he replied, "I'm done." It seemed that her students were constantly in need of something to work on keep them engaged. She told him to pick one of the math games and take it back to his seat. The situation was immediately resolved. Not once did she raise her or appear to get angry with him.

It was also apparent that she had created a competitive atmosphere in the class, where the students seemed to enjoy competing against each other to see who could the 
correct answer or finish first. I asked her how she differentiated instructional practices for those students who were working at a faster pace than the rest.

I think that's where you have to look for opportunities either for them to help others or find them something more challenging to work on. For a lot of them, that is something they've not been asked to do before because they're used to being the one who needs helps, not the one who is able to help. So I ask them to tutor others I think it's one way to keep them kind of engaged and then there are the games. I keep a lot of math games on hand for them. (CCHS, Ms. Lipchitz, $12 / 18 / 15)$

My observation of Ms. Lipchitz' class led me to the conclusion that she was utilizing a number of the tenets of culturally relevant pedagogy and culturally responsive teaching in her instructional practices. She showed a high level of cultural competence in an awareness of her students' need to remain constantly challenged in order to remain engaged, as well the competitive nature of her students. Ms. Lipchitz is also a women's basketball coach. She understood the communication styles of her students and did not become defensive when their tones were somewhat defiant, but she also demanded that they use complete sentences when answering questions. And finally, she created a sense of community by helping her students build classroom relationships based on competition but also by helping each other. The most surprising finding of this classroom observation, however, came during the after-class debrief. When I asked her if she was aware that her classroom practices had many of the hallmarks of culturally relevant pedagogy, she 
replied that while she had heard of culturally relevant pedagogy, she did not really know exactly what it was. She explained that the way she ran her class was "just good teaching" that met the needs of her students.

At BIM, I had the opportunity to unknowingly observer a first-year teacher who had been teaching for less than four months. His case is interesting because of what seemed to be a lack of control, over some of the students in the class, was his approach to culturally relevant pedagogy. Mr. Maxwell began his third period Algebra II class, in the usual manner at BIM, with a warm-up. For the warm-up activity, Mr. Maxwell displayed the image of a graph on the screen and asked the students to write a story about the graph at it would relate to the monthly profits of a local gym. This exercise was relevant in that it referenced a situation that all of the students seemed to have had experience with. The students seemed engaged in the activity and quickly wrote their answers on their worksheets. Once the timer ended and Mr. Maxwell asked for volunteers to share their answers, a number of students began engaging in side conversations. This behavior did not appear to disrupt Mr. Maxwell and he continued with lesson. He made the simple request of "eyes up" a number of times to get everyone's attention. One of the students told a particularly interesting and very detailed story about the graph. It was obvious that 
many of the students found the activity interesting even though a number of students were off-task, having side conversations.

Next, Mr. Maxwell distributed the Chromebooks and had the students begin a Khan Academy activity (Khan Academy, 2016). Many of the students who were previously off-task began working with their partners to answer questions or watch a video lesson related to the content. After about 20 minutes, the same students began to have conversations unrelated to the activity as Mr. Maxwell circulated through the class and assisted students who had called on him for help. Instead of asking the two pairs of students who were talking to get back to work, he instead began acknowledging the students who were making progress on the activity. He explained that he expected all students in the class to finish the assignment, however he recognized those students who had completed the task early and had moved on to the next lesson.

While Mr. Maxwell appeared to struggle with keeping the entire class on task throughout the period, he never lost control of the class. Many of his instructional practices were similar to what I had earlier witnessed in Mr. O'Toole's math class. Being a new teacher, Mr. Maxwell had yet to create those working interpersonal relationships with his students, but he began the process by acknowledging and praising the students who were being successful while not alienating those students who were off task for 
much of the class and did not complete the assignment. However, when I reviewed my observation notes, I was able to identify elements of his lesson plan and instructional practices that were aligned with culturally relevant pedagogy and culturally responsive teaching even if his execution of them needed more practical experience in order to create an effective lesson in safe and ordering classroom environment.

Overall, the instructional practices across the three schools varied greatly as did the level of experience of the teachers. Nevertheless, just about every teacher observed displayed some level of cultural competency in his interactions with his class. Only once did I see a teacher who was implicitly disrespectful to students. The students were totally un-engaged and the teacher taught the entire lesson directly from a textbook. He also occasionally gave students incorrect answers or told students whose answers were correct that they were wrong. I was told this teacher was sports coach who was on loan to the department to fill a position that had recently been vacated by a teacher who left twomonths into the semester. I did not include this classroom observation in any of the analysis because it appeared to be a total outlier from the rest of the classrooms that I observed at the three schools.

Across the three schools, the teachers used instructional practices that were engaged students very often by tapping into their prior knowledge and experiences. These 
practices were holistic and took a long-term perspective to teaching that allowed teachers to use their classroom to support their students' socio-emotional development by reinforcing many of the skills that were taught advisory. Teachers also offered their students opportunities to support each other and to create a communities of learners in the classroom. In a number of cases, teachers created safe and structured environments where students could analyze and discuss issues regarding race, class, and inequality. 


\section{Chapter Five}

\section{Overview}

This study examined the performance characteristics of three urban charter schools and was grounded by the research question, what are the primary performance characteristics of high-performing California charter schools serving minority and lowincome students? Two of the schools investigated in the study were selected from the top ten percent of a national high-school ranking (U.S. News \& World Report, 2015). The third school, was awarded a bronze medal for its high-school graduation rates. Additionally, all three schools served a majority of students, classified as low-income, based on their free and reduced meal price status (see table 1).

Overall, the findings revealed three major themes: (a) high-expectations with commitment to supporting the success of every student; (b) internally developed, culturally relevant curricula with scaffolds and supports; and (c) multi-dimensional and engaging culturally responsive instructional practices. All three of these characteristics appeared to be interrelated. The high expectations that the staff had for their student could not have been realized without rigorous curricula, aligned with Common Core State Standards (CCSS) and the Next Generation Science Standards (NGSS). These curricula were internally developed to meet the needs of the students. The curricula 
would have been to no avail were it not for the culturally relevant instructional practices that were multi-dimensional and engaging. The success of these instructional practices was predicated on the socio-emotional development and support that the students received via the advisory support programs. All three schools used a four-year cohort advisory model in which the first two years of the program focused on socio-emotional and non-cognitive skill development as well as academic support. The junior and senior years of advisory were mostly dominated by topics related to selecting and applying to appropriate four-year post-secondary institutions. Additionally, it was in the advisory that students and teachers developed the interpersonal relationships that provided the foundation for creating curricula and instructional practices that allowed students to realize the high academic expectations that the teachers and administrators had for them.

These three characteristics revealed the nuanced ways in which each school adapted their supports, curricula, and instructional practices to the contexts in which they operated. These adaptations were most apparent in the areas of supports and curriculum. Across all three schools, the frontline of support was the advisory. Each school adapted its advisory structure and lessons to the needs of its students and the resource of the school. While the structures may have varied across the three schools, the studentteachers relational aspects of the models were consistent across the schools. 
Similar variations were evident in the curricula used at each of the three schools. The DPS and BIM, due to their greater access to technology, developed more curricula that supported a blended-learning approach. Whereas, at CCHS whose technological infrastructure was still emerging, the curricula were mostly confined to pen and paper lessons.

Presented in this chapter are an interpretation of the study's findings and recommendations for practice in the context of the research question, an analysis of the data, the current literature, and theoretical frameworks. Discussed next are the limitations of the study in relation to the methodology and then arguments for the equity implications of the findings. Finally, this section closes with recommendations for further research and conclusions.

\section{Interpretation of Findings}

The purpose of this study was to investigate three high-performing urban California charter high schools to determine what characteristic supported their students' achievement. Much of popular debate about charters schools has been centered around arguments about their efficacy and achievement (Betts \& Tang, 2011) and accusations about questionable practices and general lack of accountability (Bifulco \& Ladd, 2007; Lacireno-Paquet et al., 2002; Yeh, 2013). The intent of this study was to make a 
significant contribution to the body of research on charter schools by exploring the characteristics of the types of charter schools that have been shown to achieve greatest comparative outcomes, those serving urban, low-income, minority students (CREDO, 2105; Winters, 2012; Zimmer \& Buddin, 2006b). This study's findings could help inform educational leaders, researchers, and policymakers about the attributes of charters schools that have been academically successful with some of our most underserved student populations (Darling-Hammond, 2010).

The primary characteristic supporting student achievement across the three schools involved some manifestation of high expectations with commitment. This characteristic was something of an unexpected result based on the current literature about charter school performance (Epple, Romano, \& Zimmer, 2015; Maas \& Lake, 2015; Zimmer \& Buddin, 2007). On the other hand, this finding was very much in line with the theoretical frameworks guiding this study, culturally relevant pedagogy (Ladson-Billings, $1995 \mathrm{~b})$ and culturally responsive teaching (Gay, 2010). The three schools all had structures in place that supported the high expectations for students in a manner that validated and celebrated their students' cultures. In addition, there was a basic assumption among most teachers that every student could achieve academic success. 
The academic supports at each school came in a number of forms. However, the primary structure for student academic support and socio-emotional development, at each school was a four-year cohort advisory system. The advisory was held each day for 25-30 minutes. In the advisory, the teacher would review each student's grades at least once a week. In this respect, the advisory and the advising teacher were the frontline of academic support for each student. On other days, there was some type of lesson plan covered. The curriculum was created by the school and college counselors at the larger DPS and CCHS and in grade-level teacher groups at the smaller BIM. In freshman and sophomore classes, the lessons were mainly focused on socio-emotional development and helping students assimilate into the school culture. In junior and senior years, the curriculum was focused on helping students select and apply to an appropriate college. At all the schools, the college counselor created the curricula for the upperclassman years.

It was in the advisory that teachers and students developed the fluid interpersonal relationships, described as a marker of culturally relevant pedagogy. Oftentimes, the lesson plans for advisory covered topics related to the students' home culture. These types of lesson engaged both the teacher and her students in meaningful discussion that fostered closer interpersonal relationships. These relationships laid the groundwork for creating various programs and curricula designed to support the students' academic 
socio-emotional development. These strategies were part of a comprehensive agenda designed to holistically educate the entire child and create a sense of interconnectedness between the students and each other, and their advising teachers. This community of learners was evident, in varying degrees across the three schools.

As the teachers developed these meaningful and supportive relationships, they were able leverage their increased cultural competence to craft their pedagogy. This culturally relevant pedagogy was rooted in the backgrounds, prior knowledge, and cultural beliefs of the students. The first step in this pedagogical process involved constructing internally developed, culturally relevant curricula. With an intimate understanding of their students' backgrounds, teachers at all three school created rigorous curricula for their content classes that were emblematic of their school's highexpectations. The teachers told the researcher that these curricula were always aligned with the relevant content standards and were rigorous enough to challenge the highest performing students in the class while being accessible to remainder of the class through the use of scaffolds and other integrated instructional supports. Though designed to challenge the most advanced students, the included scaffolds manifested the culturally responsive belief that all students can succeed academically, given the proper support. The content of these lessons occasionally addressed relevant social issues such as 
immigration reform and black lives matter. The inclusion of such topics was an indication of the teachers' cultural competence, and it also provided students the opportunity to develop critical consciousness and socio-political awareness as they discussed and debated these sometimes sensitive social issues in a safe and protected space.

At two of the three schools, teachers leveraged their access to laptop computers to create engaging lessons that would not have been possible without the use of technology. This supports the proposition that charter schools are more likely to innovate in their efforts to support student achievement (Epple et al., 2015). This characteristic was also another of the requirements discussed in Albert Shanker's original charter school proposal (1988). Proposals were required to address "how the curriculum would support the use of multiple instructional strategies which included integration of audio, video, dance, music..." (1988, p. 99).

At the highest ranked school, teachers developed their entire curriculum to be used on the Chromebooks that every student carried with them, throughout the day. Many of these teachers required their students to submit their assignments and take formative assessments online. Additionally, students were also allowed the opportunity to engage in self-directed learning, which was facilitated by their access to the curriculum in an online environment. This use of technology as a way to facilitate the sharing of knowledge was 
seen as key factor in the school's success. At the larger conversion charter school, CCHS, where access to laptop computers was somewhat limited, teachers were able to develop engaging curricula that involved pen and paper lessons. They also shared the limited number of laptops available in manners that many teachers reported to seem fair and equitable. During the researcher's interview with the school principal, she stated the school expected to soon receive a large technology grant that would be used to create a one-to-one technology platform for the school.

Next, teachers at each of the school engaged in what could best be described as culturally relevant instructional practices that were supportive and differentiated. Across the three schools, teachers appeared to leverage their knowledge of their students' backgrounds, prior knowledge, and home culture to deliver lessons that were, for the most part, effective and engaging. There were a few exceptions; however, those were mostly newer, inexperienced, or generally low performing teachers. Even many of the newer teachers with less than three years of experience were observed using instructional practices that were effectively engaging. In the vast majority of the classrooms observed, teachers used some form of cooperative learning (Ladson-Billings, 1995). These collaborative instructional practices took the form of peer-tutoring, think-pair-share, group activities, and online collaboration via Google Docs. 
Some of the most Impressive instructional practices were observed at Destiny Public Schools (DPS). In many DPS classrooms, teachers automated what they considered low-leverage instructional practices, such as direct-instruction, test-taking, and peer-feedback, into lessons and activities that students could access online via their Chromebooks. Teachers then used a large portion of their instructional time working with struggling students individually and in small groups.

At City Charter High School (CCHS) and Believe In Me Academy (BIM), teachers engaged in equally effective instructional practices that were less differentiated but provided scaffolds that were integrated throughout the curriculum to support students' access to the course content. At BIM, teachers regularly used technology to allow students to collaborate, access online tutorials such as Khan Academy and No Red Ink, and access the internet for research purposes. CCHS teachers also used engaged in similar online instructional activates but on a much more limited basis due their lack of technological resources.

Whether the environment was technology-based, blended classroom, or more of a traditional classroom setting, teachers at all three schools used a range of instructional practices that were appropriate and engaging. These instructional practices exhibited fair levels of cultural competence on the part of the teachers. This cultural competence was, I 
believe, the result of the relationships that teachers built with their students in the advisories. It was the teachers' and administrators' intimate knowledge of their students' cultural backgrounds and prior knowledge that supported the high academic achievement of the schools' students.

In summary, it was apparent that at the foundation of each school's success was their own version of a four-year cohort advisory model, which supported a culture of high-expectations. The reason this support is oftentimes unique to charter schools is due to the some of the restrictions on student contact hour, stipulated in many traditional public school collective bargaining agreements (CBA) (Torres \& Oluwole, 2015). Since none of the schools investigated in this study were covered by CBA, they are allowed to incorporate 25- to 30-minute advisory sessions into each day's class schedule, while still allowing teachers to teach four to five periods a day, without incurring additional instructional costs.

\section{Educational Equity Implications}

This study focused on finding the characteristics of high-performing California charter schools serving minority and low-income students. Its theoretical framework was based on a number of the tenets of culturally relevant pedagogy (Ladson-Billings, 1995) and culturally responsive teaching (Gay, 2010). This focus was chosen because charter 
schools have become increasingly more responsible for educating a larger portion of our nation's low-income and minority students, and they are also more highly concentrated in our inner city regions (Cremata et al., 2013). Additionally, prior research indicated that charters schools were more effective at increasing the academic achievement of lowincome and minority students compared to traditional public schools (CREDO, 2105; Zimmer \& Buddin, 2006b) .

This situation is also very relevant within California. The Golden State has the second highest concentration (8\%) of public school students attending charter schools, in the nation (California Charter Schools Association, 2106). However, due to its size, California has the highest number of charter schools $(1,230)$ serving the largest number of charter school students $(500,000)$ in the country. This combination underscores the implications for research related to the effectiveness of charter schools serving California's low-income and minority students.

It is hoped that the findings from this study could help inform California school districts and charter school authorizers about some of the characteristics that could support the creation of more high-performing charter schools for low-income students. This would, in turn, create more high-quality school choice options for low-income parents. Such a trend could ultimately democratize our public school system to the point 
where low-income families would have as many high-quality school choice options as their middle- and upper-class counterparts.

\section{Recommendations for Practice}

As stated above, at the core of each school's success was a culture of highexpectations supported by the implementation of a four-year cohort advisory program. While I have mainly spoken about this program from a structural perspective, it is important to understand that the relational aspect of this program where I believe it has its greatest benefits. The advisory program is designed to serve as the first line of academic and emotional support for students. However, this support function would not have been very effective if students and teacher could not have developed meaningful and supportive interpersonal relationships with each other. In many respects, the lessons designed for use in the advisory fostered the growth of these relationship by offering students and teachers opportunities to discuss relevant social and cultural issues and topics.

Next, each of the teachers interviewed for this study spoke about the need to create curricula that supported the developmental needs of the students. Many of the teachers spoke about the amount of time and effort it took to modify textbook lessons for this purpose. While not as common as expected, teachers occasionally integrated current 
social issues and political topics into their curricula to engage students in a way that was indicative of the teachers' cultural competence. At other times, the lessons were comprised of basic-skills worksheets designed to help support the needs of students whose prior knowledge lacked certain foundational skills, such as numeracy or academic vocabulary.

Finally, the instructional practices used to deliver the curricula varied across the three schools and reflected the cultural diversity of each one. However, the instructional practices at all three schools included some form of collaborative learning such as peertutoring or group-activities. Additionally, teachers at each school appeared to have adapted their instructional practices to the demeanor of their students. At DPS, where the students had a more reserved and mature comportment, the classroom instructional practices were regimented and students were expected to adhere to clearly prescribed code of conduct. At CCHS, where the student body appeared much more animated, teachers seemed to have adapted their instructional practices in a way that engaged students, and allowed them to still keep some measure of order in the classes without alienating students for exhibiting behavior that could have been construed as disruptive or defiant. These culturally responsive and engaging instructional practices were likely the 
result of the relationships teachers and students developed with each other in their respective advisories.

\section{Limitations}

Due to the qualitative nature of the research methodology and the lack of random sampling, the results of this study are not generalizable beyond the three schools investigated. The purposive sampling method (Fraenkel, Wallen, \& Hyun, 2014) used to collect a sample of three charter schools with a broad range of characteristics was not performed in a random fashion. Therefore, the three schools comprising the sample cannot be regarded as an unbiased representation of the California charter school population as a whole. Consequently, the researcher cannot make statistical inferences about the findings from this study. The reader, however, may make theoretical inferences from the results, based upon rich descriptions of each of the schools provided in the beginning of chapter four.

\section{Recommendations for Further Study}

A challenge that occurred when searching for a sample of appropriate schools was finding a California, high-performing charter school that was proportionately represented with African-American students. Only one school in the local area meeting the case 
criteria was proportionately represented with African-American students. The others were over-represented with either Hispanic or Filipino students and under-represented with African-Americans, based upon the demographics of the districts in which they were authorized. A recommendation for future research would be to determine if there is a statistically significant underrepresentation of African-American students in California's highest performing charter schools. And if so, what is causing the disproportionality?

\section{Reflections on the Research Process}

Most importantly, keeping my dissertation committee apprised of my progress throughout the data analysis provided me with a system for questioning my assumptions. Many of these assumptions were the result of researcher bias and position. Having worked in a number of charter schools, I made a number of assumptions and proposition that were not supported by the literature review and many of them turned out to be incorrect or inconclusive. For instance, based on my experience of working in a wellfinanced charter school, I assumed that all three schools would have been much more reliant on technology and blended-learning. This was only true at DPS and somewhat true at BIM. Furthermore, regularly communicating with them, the members of my committee helped sharpen the focus of the theoretical lens, for the study, which ultimately lead to a number of breakthroughs in data collection and analysis. 
Secondly, the process of recruiting a sample of schools for the study was started too late in the spring semester prior to the academic year. As a result, I was forced to expand my search criteria to schools beyond the top $10 \%$ in order to find the third school for the study sample. This school, however, broadened the range of school characteristics in the sample and provided the study with a school whose student population was comprised of a majority of African-Americans.

Finally, by following up on the recurring code, college-counseling, which repeatedly came up in a number of the teacher interviews, I subsequently interviewed each of the school's college counselors and uncovered a major source of data for one the study's primary findings. The counselor interviews were not a part of the original data collection plan

\section{Conclusion}

This purpose of this research study was to investigate the characteristics of three high-performing urban California charter schools serving low-income and minority students. Ultimately, three themes emerged from an analysis of the data. The first theme was a school culture of high expectations with a commitment to support the success of every student. This characteristic, which is a tenet of culturally responsive teaching, was evident in the college-going culture that permeated each of the school campuses. The 
student supports were rooted in the four-year, cohort advisory systems that each school adapted to its student population and available resources. This key component of the charter schools support system, would have been restricted if the schools' teachers had been represented by a collective bargaining agreement similar to those in place at most California traditional public schools (Torres \& Oluwole, 2015). The advisory was the place where students developed supportive relationships with their fellow classmates and their advising teacher.

These relationships provided a foundation for the development of the socioemotional skills that would help the students succeed academically. They also provided the teachers the opportunity to develop the cultural competence (Ladson-Billings, 1995b) necessary to create rigorous culturally relevant curricula with appropriate supports for their students. This cultural competence also supported the crafting of multi-dimensional and engaging instructional practices (Gay, 2010), rooted in the belief that all student can succeed academically when provided appropriate supports. Together, these three characteristic comprise what could best be described as culturally relevant charter school pedagogy. 


\section{REFERENCES}

Angrist, J. D., Pathak, P. A., \& Walters, C. R. (2011). Explaining charter school effectiveness (Working Paper No. 17332). National Bureau of Economic Research. Retrieved from http://0-www.nber.org.opac.sfsu.edu/papers/w 17332

Betts, J. R., \& Tang, Y. E. (2011). The effect of charter schools on student achievement: A meta-analysis of the literature. Center on Reinventing Public Education. Retrieved from http://eric.ed.gov/?id=ED526353

Bifulco, R., \& Ladd, H. F. (2007). School choice, racial segregation, and test-score gaps: Evidence from North Carolina's charter school program. Journal of Policy Analysis and Management, 26(1), 31-56. http://doi.org/10.1002/pam.20226

Budde, R. (1988). Education by charter: Restructuring school districts. Key to long-term continuing improvement in american education. Retrieved from http://eric.ed.gov/?id=ED295298

Buddin, R., \& Zimmer, R. (2005). Student achievement in charter schools: A complex picture. Journal of Policy Analysis and Management, 24(2), 351-371. http://doi.org/10.1002/pam.20093 
Bulkley, K., \& Fisler, J. (2003). A decade of charter schools: From theory to practice. Educational Policy, 17(3), 317-342. http://doi.org/10.1177/0895904803017003002

California Charter Schools Association. (2106, March). California charter schools by the numbers. Retrieved December 27, 2014, from http://www.calcharters.org/understanding/numbers/

Clark, M. A., Gleason, P. M., Tuttle, C. C., \& Silverberg, M. K. (2015). Do charter schools improve student achievement? Educational Evaluation and Policy Analysis, 37(4), 419-436. http://doi.org/10.3102/0162373714558292

CREDO. (2105, March). Urban charter school study report on 41 regions 2105. Retrieved February 14, 2016, from http://urbancharters.stanford.edu/download/Urban\%20Charter\%20School\%20Stu dy\%20Report\%20on\%2041\%20Regions.pdf

Cremata, E., Davis, D., Dickey, L., Lawyer, K., Negassi, Y., Raymond, M., \& Woodworth, J. (2013). National charter school study 2013. CREDO. Retrieved from http://credo. stanford. edu/documents/NCSS

Darling-Hammond, L. (2010). The flat world and education: How America's commitment to equity will determine our future. New York, NY: Teachers College Press. 
Ed-Data Website. (2016). Retrieved March 13, 2016, from http://www.eddata.k12.ca.us/App_Resx/EdDataClassic/fsTwoPanel.aspx?\#!bottom=/_layouts/E

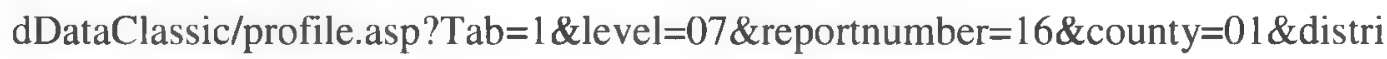
ct=61 192\&school=0108670\#studentsbyraceethnicity

Epple, D., Romano, R., \& Zimmer, R. (2015). Charter schools: A survey of research on their characteristics and effectiveness (No. w21256). National Bureau of Economic Research. Retrieved from http://www.nber.org.jpllnet.sfsu.edu/papers/w21256

Fraenkel, J., Wallen, N., \& Hyun, H. (2014). How to design and evaluate research in education (9 edition). New York: McGraw-Hill Education.

Gay, G. (2002). Preparing for culturally responsive teaching. Journal of Teacher Education, 53(2), 106-16.

Gay, G. (2010). Culturally responsive teaching: Theory, research, and practice. Teachers College Press. Retrieved from https://books.google.com/books?hl=en\&lr=\&id=rYspC7CzowC\&oi=fnd\&pg=PR7\&ots=Elapixe4yE\&sig=lwMT_cNMdIgdbRgHU4CeFQ D1U5E 
Hill, P. T., Angel, L., \& Christensen, J. (2006). Charter school achievement studies. Education Finance and Policy, 1(1), 139-150.

Hoxby, C. M. (2009). A statistical mistake in the CREDO study of charter schools. Retrieved June, 8, 2010.

Kahlenberg, R., \& Potter, H. (2015). What charter schools can teach us about teacher voice. Teachers College Record. Retrieved from http://tcf.org/work/education/detail/what-charter-schools-can-teach-us-aboutteacher-voice

Khan Academy. (2016). Algebra II | Khan Academy. Retrieved April 11, 2016, from https://www.khanacademy.org/math/algebra2

Klar, H. W., \& Brewer, C. A. (2013). Successful leadership in high-needs schools: An examination of core leadership practices enacted in challenging contexts.

Educational Administration Quarterly, 0013161X13482577. http://doi.org/10.1177/0013161X13482577

Kolderie, T. (2005). Ray Budde and the origins of the "Charter Concept." Education Evolving, Center for Policy Studies and Hamline University.

Lacireno-Paquet, N., Holyoke, T. T., Moser, M., \& Henig, J. R. (2002). Creaming versus cropping: Charter school enrollment practices in response to market incentives. 
Educational Evaluation and Policy Analysis, 24(2), 145-158.

http://doi.org/10.3102/01623737024002145

Ladson-Billings, G. (1995). But that's just good teaching! The case for culturally relevant pedagogy. Theory Into Practice, 34(3), 159-165.

http://doi.org/10.1080/00405849509543675

Ladson-Billings, G. (1995). Toward a theory of culturally relevant pedagogy. American Educational Research Journal, 32(3), 465-491. http://doi.org/10.3102/00028312032003465

Ladson-Billings, G. (2006). Yes, but how do we do it? Practicing culturally relevant pedagogy. White Teachers/diverse Classrooms: A Guide to Building Inclusive Schools, Promoting High Expectations, and Eliminating Racism, 29-42.

Ladson-Billings, G. (2009). The Dreamkeepers: Successful Teachers of African American Children (2 edition). San Francisco, Calif: Jossey-Bass.

Lawrence-Lightfoot, S. (2008). The Good High School: Portraits Of Character And Culture. Basic Books.

Leithwood, K., \& Jantzi, D. (2006). Transformational school leadership for large-scale reform: Effects on students, teachers, and their classroom practices. School 
Effectiveness and School Improvement, 17(2), 201-227.

http://doi.org/10.1080/09243450600565829

Maas, T., \& Lake, R. (2015). Effective charter and traditional school characteristics: Aligning findings for informed policy making. Journal of School Choice. Retrieved from http://0www.tandfonline.com.opac.sfsu.edu/doi/abs/10.1080/15582159.2015.1028311

Maul, A., \& McClelland, A. (2013). Review of national charter school study 2013. Retrieved from http://greatlakescenter.org/docs/Think_Twice/TT_Maul_CREDO2013.pdf

Merriam, S. B. (1991). Case study research in education: A qualitative approach (1 edition). San Francisco: Jossey-Bass.

Miles, M. B., Huberman, A. M., \& Saldaña, J. (2013). Qualitative data analysis: A methods sourcebook (Third Edition edition). Thousand Oaks, California: SAGE Publications, Inc.

Miron, G., \& Applegate, B. (2009). Review of "Multiple Choice: Charter School Performance in 16 States." Education and the Public Interest Center. Retrieved from http://eric.ed.gov/?id=ED530094 
National Center for Education Statistics. (2015). The NCES charter school fast facts.

Retrieved February 17, 2016, from https://nces.ed.gov/fastfacts/display.asp?id=30

Pogrow, S. (2015). Authentic quantitative analysis for education leadership decisionmaking and edd dissertations: A practical, intuitive, and intelligible approach. National Council of Professors of Educational Administration.

Reed, S., \& Rose, H. (2015). Charter school spending and saving in california. Journal of School Choice, 9(3), 407-445. http://doi.org/10.1080/15582159.2015.1061392

Renzulli, L. A., \& Evans, L. (2005). School choice, charter schools, and white flight. Social Problems, 52(3), 398-418. http://doi.org/10.1525/sp.2005.52.3.398

Shanker, A. (1988). Restructuring our schools. Peabody Journal of Education, 65(3), 88100.

Stulberg, L. M., \& Weinberg, S. L. (Eds.). (2011). Diversity in American higher education: Toward a more comprehensive approach. New York, NY: Routledge.

Toma, E., \& Zimmer, R. (2012). Two decades of charter schools: Expectations, reality, and the future. Economics of Education Review, 31(2), 209-212. http://doi.org/10.1016/j.econedurev.2011.10.001

Torres, A. C., \& Oluwole, J. (2015). Teacher satisfaction and turnover in charter schools: Examining the variations and possibilities for collective bargaining in state laws. 
Journal of School Choice. Retrieved from http://0-

www.tandfonline.com.opac.sfsu.edu/doi/abs/10.1080/15582159.2015.1079468

U.S. Department of Education. (2014, April). Charter school enrollment. Retrieved December 26, 2014, from http://nces.ed.gov/programs/coe/indicator_cgb.asp

U.S. News \& World Report. (2015). U.S. News \& World Report best charter schools in California. Retrieved from http://www.usnews.com/education/best-highschools/california/rankings

Wei, X., Patel, D., \& Young, V. M. (2014). Opening the "black box": Organizational differences between charter schools and traditional public schools. Education Policy Analysis Archives, 22(0), 3. http://doi.org/10.14507/epaa.v22n3.2014

Winters, M. A. (2012). Measuring the effect of charter schools on public school student achievement in an urban environment: Evidence from New York City. Economics of Education Review, 31(2), 293-301. http://doi.org/10.1016/j.econedurev.2011.08.014

Yeh, S. S. (2013). A re-analysis of the effects of KIPP and the Harlem Promise Academies. Teachers College Record, 115(4). Retrieved from http://www.tcrecord.org/DefaultFiles/SendFileToPublic.asp?ft=pdf\&FilePath=c: 


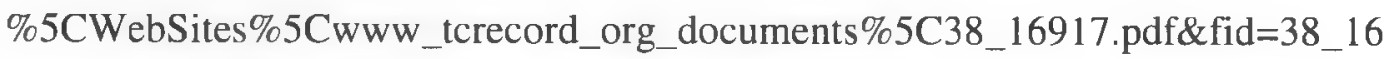
917\&aid=2\&RID=16917\&pf=Content.asp?ContentID=16917

Zimmer, R., \& Buddin, R. (2006a). Charter school outcomes in California. National Conference on Charter School Research, Vanderbilt University.

Zimmer, R., \& Buddin, R. (2006b). Charter school performance in two large urban districts. Journal of Urban Economics, 60(2), 307-326. http://doi.org/10.1016/j.jue.2006.03.003

Zimmer, R., \& Buddin, R. (2007). Getting inside the black box: Examining how the operation of charter schools affects performance. Peabody Journal of Education, 82(2-3), 231-273. http://doi.org/10.1080/01619560701312954

Zimmer, R., Buddin, R. J., Chau, D., Gill, B., Guarino, C., Hamilton, L., ... Brewer, D. (1999). Charter school operations and performance: New evidence from California. Rand Corporation.

Zimmer, R., Gill, B., Booker, K., Lavertu, S., \& Witte, J. (2012). Examining charter student achievement effects across seven states. Economics of Education Review, 31(2), 213-224. http://doi.org/10.1016/j.econedurev.2011.05.005 


\section{Appendices}

\section{Appendix A}

IRB approval letter 07/23/2015

protocol@sfsu edu

Jul 23

Dear Timothy Weekes,

Our office has finished an initial pre-review of your research study titled, "What are the Key Performance Characteristics of High-Performing Charter Schools in Northern California." Given the nature of your questions, our office has concluded that your research can be reviewed as Exempt, pending a change in your research procedures. Our office is proposing that you change your data collection method from focus groups to one on one interviews. By changing this procedure the risk associated with your protocol can be greatly mitigated. If you wish to move forward with the focus group interviews please let our office know so that we can continue our review but please note that this will entail a more thorough review of your study.

If you have any questions or concerns, please feel free to contact our office.

Regards,

ORSP - Human and Animal Protections

San Francisco State University 
Appendix B

Counselor interview questions

\section{Counselor interview questions (30mins.)}

\section{How would you describe your students' skills?}

2. What do you think is most responsible for your school's success?

\section{Curriculum}

- What is the purpose of the curriculum you that you provide teachers for advisory?

- Where does the curriculum come from?

- How involved were you in the process selecting or creating it?

- Are you modifying the curriculum, in anyway, to meet the needs of the students?

- Does the curriculum include any character or non-cognitive skill development (such as motivation, perseverance, and self-control, and classroom norms/behaviors)

- How much is the use of technology included in the curriculum 
Appendix C

Teacher interview questions

Teacher interview questions (30-40mins.)

How would you describe your students' skills? How about the skills of the students overall at the school?

What do you think is most responsible for your school's success? Curriculum

- Where does the curriculum come from?

- How involved were you in the process selecting it?

- To what extent are you modifying the curriculum to meet the needs of your students?

\section{Instruction}

- How are decision made to differentiate instruction?

- How do you make decisions about teaching modality? Direct instruction, smallgroup, think-pair-share, Self-directed.

- Describe your philosophy regarding formal and informal assessment

- What is your primary objective when it comes to teaching students characterdevelopment (non-content related, classroom norms and behaviors)

\section{Technology}

How do you use technology in your practice? 


\section{Appendix D}

\section{Principal interview questions}

Charter school principal interview questions fall 2015

1. How would you describe your educational leadership philosophy?

2. What ideas, concepts, strategies have worked well or not so well at the school? What have you done to address those that have not gone so well?
a. Well
b. Not so well

3. What drew you to working at a charter school?

4. Do you believe all teachers in the school have high expectations for all students? If so, how have you been able to get all teachers to embrace this attitude?

5. What role has technology played in the school's success? 
Appendix E

Classroom observation template

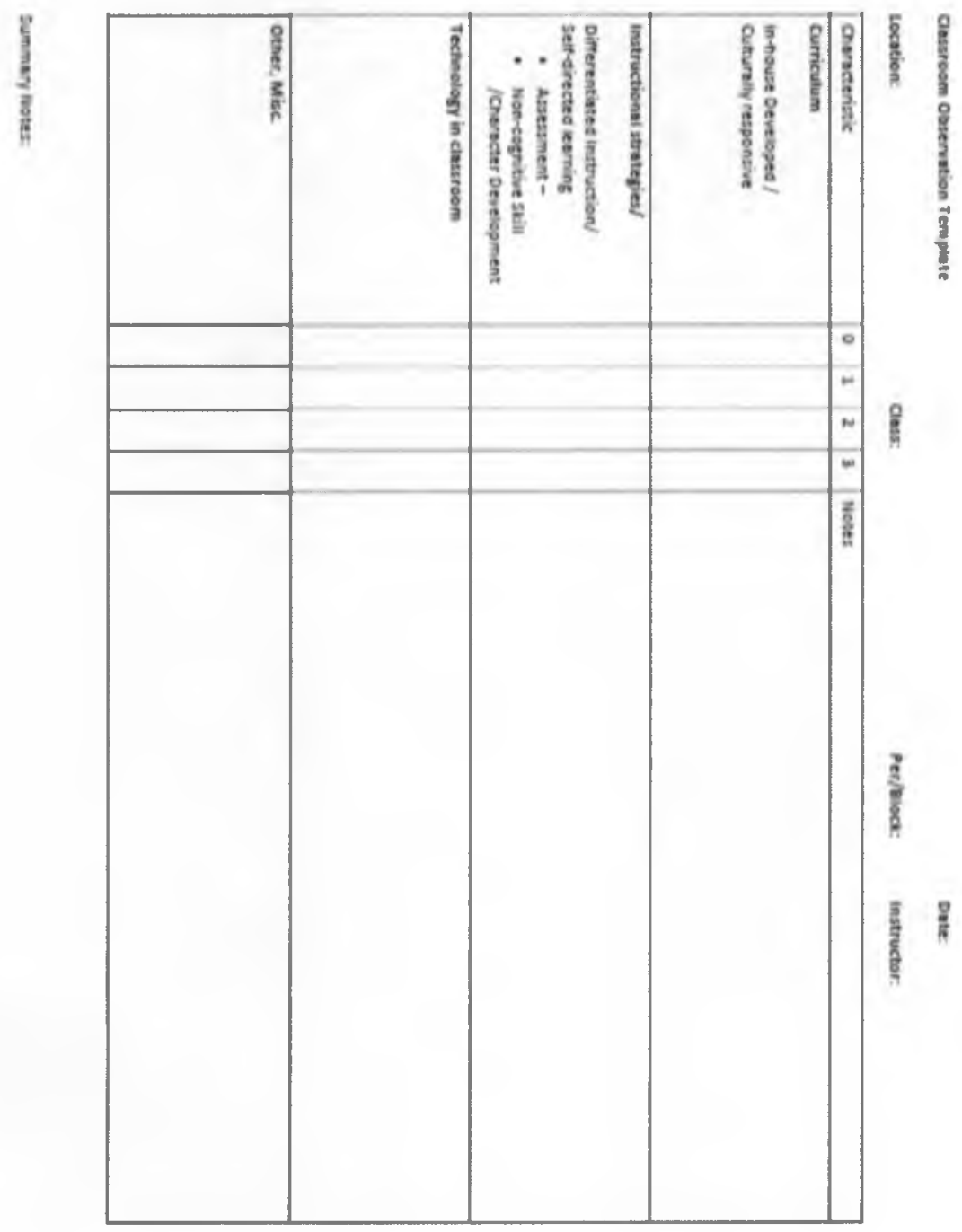




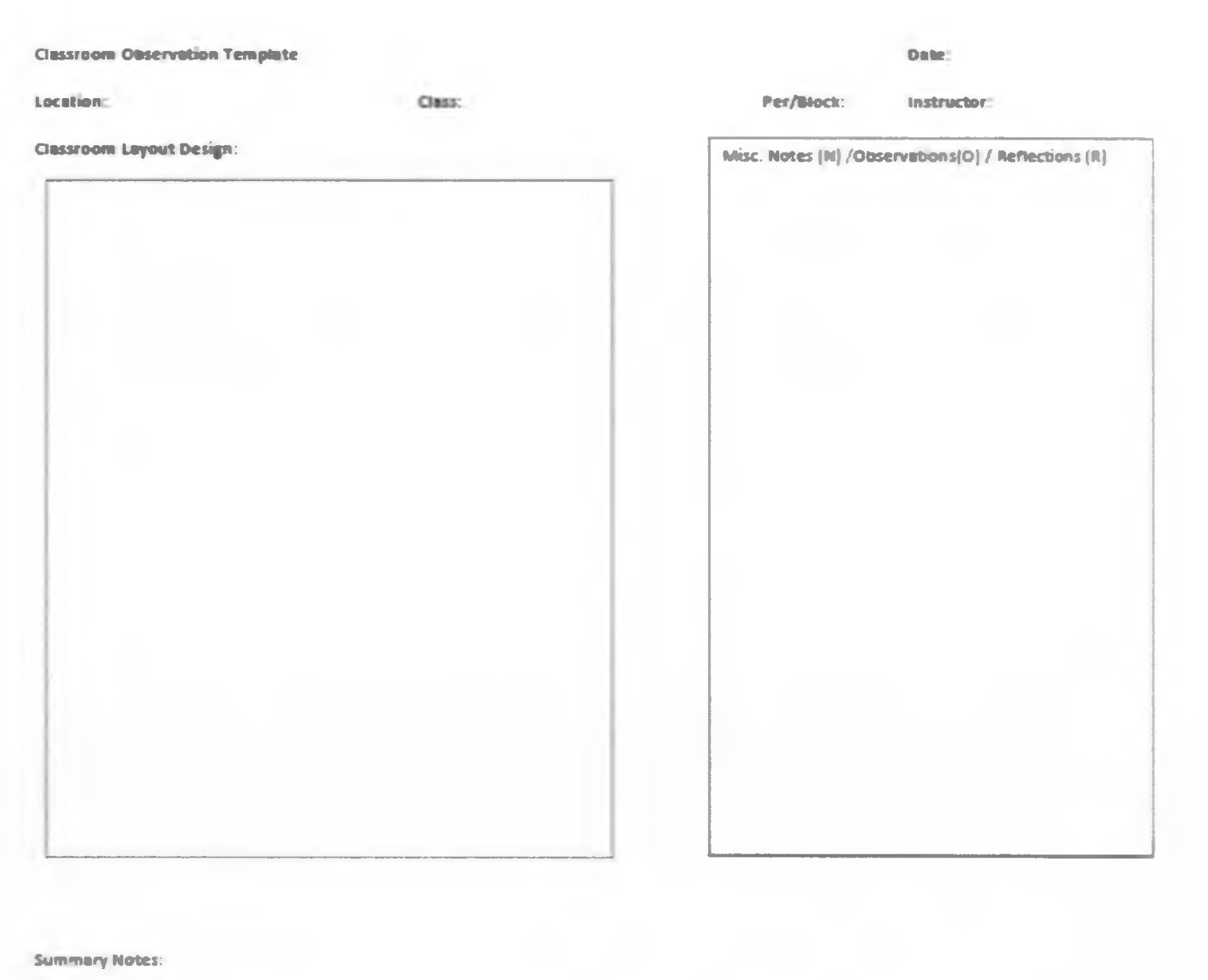


Appendix F

Split page observation template

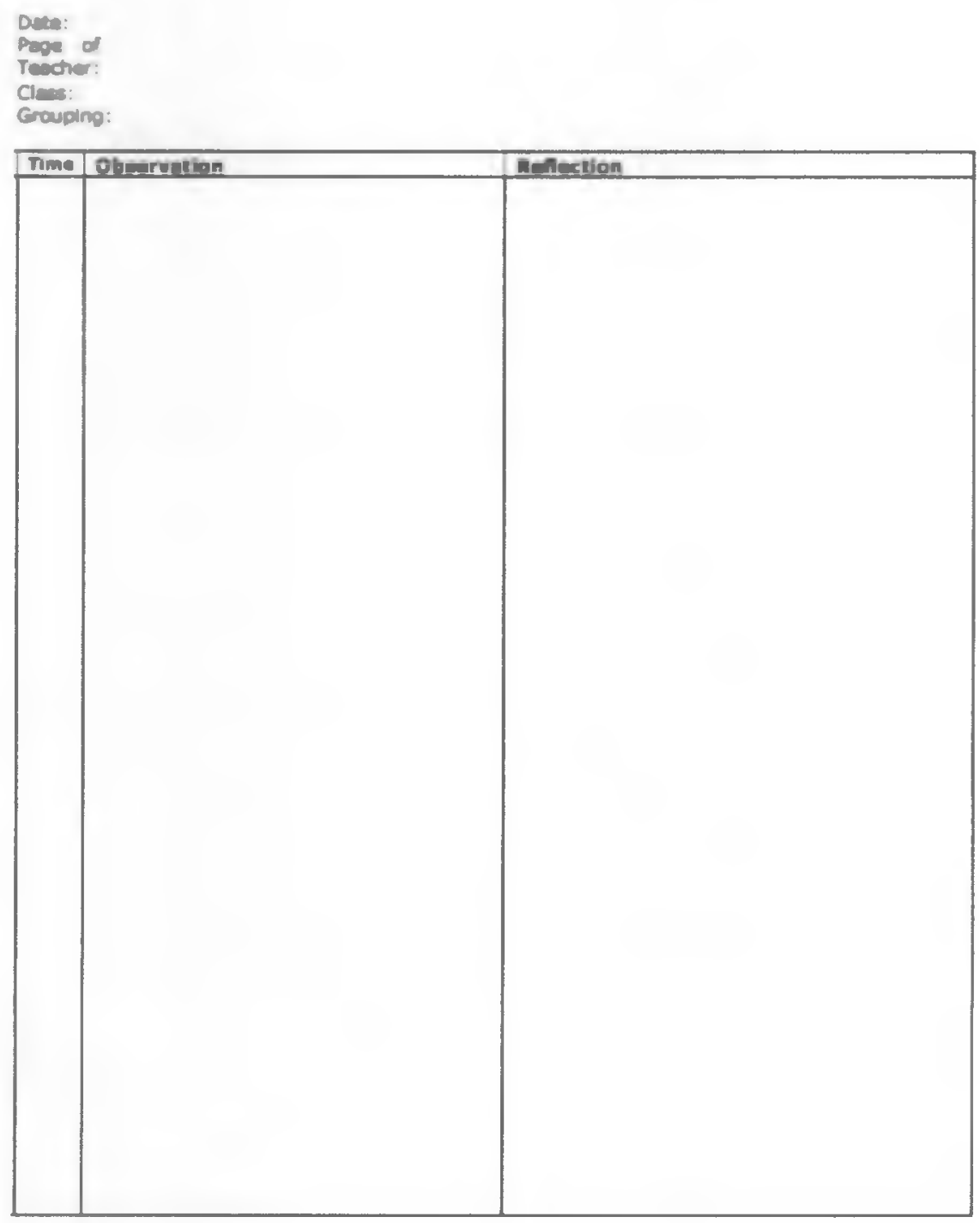


Appendix G

Principal invitation letter

\section{Study of high-performing charter schools in California}

Project Information Statement/Letter of Invitation to School Principals

My name is Timothy $\mathrm{L}$. Weekes, and I am a doctoral candidate in the Educational Leadership Program at San Francisco State University (SFSU). I am conducting educational research under the supervision of Dr. Jamal Cooks. The purpose of this study is to uncover specific characteristics supporting your charter school's exceptional performance. I invite you to consider taking part in this research as it may prove to be a valuable resource for a large audience of educational leaders and researchers. Furthermore, this research study will meet the requirements of the Institutional Review Board (IRB) for San Francisco State University assuring you there will be minimal risk of harm to any of your school's participants. And if selected, your school will receive a $\$ 50$ gift card from a retailer of your choice, at the completion of the study.

Aim and Significance of the Research

The proposed study will focus on high-performing charter schools that serve a substantial percentage of under-represented minority students. This research is significant because it will highlight information about the key characteristics that may contribute to under-represented minority students' academic success and provide insight into the role school principals play in leading high-performing charter schools that serve these students.

Benefits of the Research to Schools

The findings from this study will be made available to educational leaders and researchers interested charter school performance and the achievement gap. Additionally, the 
results of this study could also help inform providers of teacher and administrator credentialing programs. A summary of the findings will also be provided to all the schools participating in the study.

Research Plan and Method

Data collected for the study will include: interviews, focus groups, classroom observations and document analysis. Most of the data for this study will be collected in fall 2015 but we may request a few follow up visits in spring 2016.

All data collected will be treated as confidential and neither the school nor any individual will be identifiable in any written reports. Participants may withdraw from the study at any time without penalty.

Invitation to Participate

If you are interested in participating in this study please send a signed consent letter on your school's letterhead to the following address:

Timothy L. Weekes

Or scan a signed copy and email it to: timw@.sfsu.edu

If you have any questions, please feel free to email or call me. My phone number is: $510-$ 504

\section{School Involvement}

Once we receive your consent to participate in the study, we will schedule a time for an introductory meeting. At this meeting, we will arrange for a number of visits to your school site, during the coming school-year to collect data for this study. 


\section{Appendix $\mathrm{H}$}

\section{Teacher interview transcript}

[0:00:00]

Interviewer: So we're starting today. This is January the 12 th with Ms. Alvarez.

So first thing is the first question is about student skills and your description of them. So I say, how would you describe-and the main thing we're trying to get is some of the strategies you're using to reach students and be successful with them as far as curriculum and instruction and practices.

Respondent: Are we thinking -- so this question describes student skills kind of like when they start? A little bit more at the beginning or where they are now?

Interviewer: I would take however you want to describe it. So first of all, we're seeing your students, so the ones you work with currently, how would you describe their skills?

Respondent: Okay. I would say, I guess I would talk about kind of where they start. So I would say that they are below average, below the average Algebra 1 freshman. And any student who was about near average or above average is placed in the Algebra 2 as a freshman. So I also do the placement test in some of those so that's the only reason I know that data. But the students, generally speaking, come in low on their foundational algebra skills and the other piece of that is that their skills are generally low in their student skills as well so their ability to show notes or organize their work or communicate their answers on paper or out loud. It's pretty low. So sometimes it's difficult to find out whether their content skills are low or the students skills are so low that they struggle to have a relational frame to put those into. So that's kind of where they start.

Interviewer: And how about, let's see-I know you did talk about your students' skills and communication skills. How about maybe their social, emotional, non- 
cognitive skills, like persistence and self-control, things like that? How would you describe that?

Respondent: I would say that they definitely come in lacking those skills. Specifically, they have very low confidence in their ability to do math and so a lot of what we do in the freshman year are both between Algebra 1 and AcNum is about building their confidence and changing the statement of "I hate math" to "I can learn math." So they don't have to love it by the end of the year but our goal is definitely how do we get it so that they understand it. They can learn it regardless.

Interviewer: How do you get there?

Respondent: It starts by a lot of early wins. So the pedagogy of having them win early often, and we do that specifically through very robust data systems. So exit could be one of them or even if it's like Khan Academy or it's using Google forms that have the Flubaroo add-on to it, which is another way of essentially taking a quiz that gives you immediate feedback. But we do a lot of work around how do we make sure that the students have immediate feedback so that they see the effort that they're putting in actually translates to knowledge. That would be step one.

Interviewer: And even the early wins, would you consider them to still be rigorous achievements?

Respondent: They shouldn't be. It's a concept of winning first, having that feeling of being successful for the first time. That can then dramatically change the mindset and give us access to, okay, so now this is difficult, like here are two resources, here's a video and here's a practice set before you actually get to see if you know what you know.

[00:05:00]

Interviewer: Going back, one thing you said -- so in the beginning you said that a lot of students come in below average for Algebra 1 when they are freshman, and you said that they are average. They're placed in Algebra 1 or Algebra 2? 
Respondent: Algebra 2.

Interviewer: Algebra 2, if they are average for Algebra 1?

Respondent: I push a lot of kids up and they're doing just fine in Algebra 2. It's actually really impressive.

Interviewer: So it means they've already taken Algebra 1 ?

Respondent: They've taken Algebra 1 as an 8th grader and they passed it.

Interviewer: Which students get put into AcNum?

Respondent: Every single student who's in Algebra 1 is put into AcNum as well as some students, who based on their placement test, their Algebra skills are actually fine but their numeracy could use some support so that they can be as successful as possible.

Interviewer: Okay. So students take AcNum and Algebra 1 together or it is back to back or at the same time?

Respondent: It's not necessarily back to back but they're not at the same time, so there are separate courses. There's an Algebra 1 course and there's an academic numeracy course. I have it first period AcNum and fourth period Algebra 1. It's possible or vice versa.

Interviewer: Okay. Now this might be a redundant question because you probably see just about every student that comes to the school, but how would you describe the skills of the students overall at the school, just in general?

Respondent: Overall, I do see every single one of them. I think by the time they are juniors, they have extremely strong student skills. So the concept of persistence, the grit, the growth mindset of "I can learn anything if I work hard" I think is really set in by the time they're juniors. And then, I believe by the time they are seniors that I would say about $80 \%$ or $90 \%$ of them are ready for college level math, and I obviously don't have a 
data point to back that up but I feel like based on the numbers that I remember from the past, that that would be about accurate.

Interviewer: So overall, $80 \%$ to $90 \%$ are ready for college level math. Do you believe that overall students that graduate, do you feel they're all ready or capable of going to college?

Respondent: Absolutely.

Interviewer: Do you think there's ever any students that come here that just aren't capable of going to a college or that's not possible?

Respondent: I don't believe that and I think as a school, we don't believe that. What actually end up happening are not as different but our belief is when they come in as 9 th Graders, that every single student, regardless of your demographic or prior knowledge, can be successful in college. It's just what the path looks like to get there.

Interviewer: I just think maybe some prior knowledge, some schools might say, they easily frame it with the not...

Interviewer: So do you know how they say it like, well not all students need to go to college and I think underneath that there's this thing like some students justthey're so far behind that we take too much but no matter how far behind the student is when they come here, they pretty much-not pretty much -- they can be prepared to go to college?

Respondent: Yeah. That's our belief.

Interviewer: Okay. And what did they do to support students that come in really, really far behind?

Respondent: There're a couple structures. One of them is the AcNum, Academic Numeracy Program, which backfills 2nd through 8th Grade math. So it's meant up to bulk up that foundation and it's a self-paced course and so some students 
might finish the nine units-I think it's nine units now, the nine units in three quarters and some might finish it in a year and a half but that's one thing. Another thing is the Academic Leadership Class, which Diana teaches. It mirrors the - it doesn't mirror but it supports the development of literacy and leadership out of freshmen.

Interviewer: So AcNum is more of a yearlong course?

Respondent: It can be now. So at the end of this year, if a student still has two units that they haven't finished, then next year they will finish Academic Numeracy during their flex periods and whenever they're done, then they get the credit for the class.

Interviewer: All right. So it's more like a mastery orientation?

Respondent: It is mastery orientation.

Interviewer: That's good. Okay. I'm going to go to the next question which kind of goes from this, the next one. So the school definitely is in the top $10 \%$ or so and easily in the top $10 \%$ of the charter schools in the state, I think probably in the top 5\%. So what do you think is responsible for that success and why the school's in the top $10 \%$ and not the top 5\%?

Respondent: I think it's like our really strong belief that all students can learn and be successful and go to college. It's the core heart of what drives us. The second piece of that is that I believe that we are extremely data driven and innovative for students. And so an approach that we take is not seeking technology for technology base, like for technology's sake is what I meant to say. And so a lot of our technology solutions are more like this is a really great teacher practice. How do we leverage technology to make it more efficient or provide an extra feedback loop to students? So we really look for technology to mold around us rather than like this is a really great program. It looks really cool and really engaging. We actually don't care about the engagement as much as we care about what is the teaching best practice? What does that do for students? How does it empower them to be lifelong learners? I think that's just at the baseline of... 
Interviewer: And do you have any example of that?

Respondent: You know, so you take all the LearningList approach, right? So-

Interviewer: Learning what?

Respondent: LearningList, like a LearningList which is now -- we're now in partnership with Gooru to actually build out the technology piece that is LearningList but LearningList within their core started because we believe that a teacher does not needit's so if you take the flipped model classroom, right? The flipped model is they go home, they watch a video, they come to class, and they do the practice. But the concept to that is that the kids are able to learn content without a teacher just describing it to 30 students at once. By changing the media in which a student learns content enables the teacher to differentiate in a more powerful way.

So we don't necessarily believe in the flipped model per se but a LearningList would be about giving students resources, making sure they understand what those resources are, what they align to, and then having the assessment at the end of that that is coded in a way that a teacher can really efficiently analyze that data, pull small groups and intervene rather than I'm going to teach all 30 of you at once and there's still going to be a set of population of you that don't get it and need the re-teaching so instead changing time and space of a teacher and a student's role.

Interviewer: I want to go back to that belief thing but I know that you do that practice but do you think how widespread would you say that is throughout the school?

Respondent: The practice itself is really widespread so the idea of enabling students to learn contents on their own rather than a teacher lecturing to them, that concept it widespread at the school.

\section{Interviewer: Sort of self-directed?}

Respondent: Right. A little bit more of a self-directed approach that has some sort of assessment attached to it so that a teacher can then remediate and do some other instruction. And so where we're kind of going is where-so right now, that is how a lot 
of people deliver their classes and where we're going is strengthening our teachers' capacity to have small group instruction during that time.

So now it's like how do you set up the dynamic of the class so that both things can be happening at the same time? That's kind of like where we are in the process. It's like we believe all students can learn things on their own. We need to be able to assess what they actually know so that we can intervene. Now, how do we make both live at the same time? At the school level where we're at, on my classroom level, what I'm piloting and figuring out is what needs to happen for that.

[0:15:00]

Interviewer: So going back to the strong belief is that a lot of schools have that even as part of their, not the mission statement but in their-

Respondent: Core values?

Interviewer: Yeah, core values, like high expectations for all students but of course not all charter schools are successful or even close to the top $10 \%$. What do you think it is about this school that the strong beliefs in the students are part of this school's success? But how are they able to translate that to actual academic outcomes?

Respondent: Right. I think the data piece that I said right after that, that's it because we could say that every single teacher does it but unless we're actually collecting and analyzing data that supports or does not support that then we don't know. And so we're extremely data driven and so we're constantly collecting and analyzing our own data so that we know this is the expectation or this is my central question like if we go to a class. So this is my essential question. This is the data that I have to support that the kids really know what those like in answers, how much strong, rigorous answer to that essential question.

And so everything that we do is very rooted in like the data like on a teacher by teacher basis, not like the school does a data analysis ever so often. It's like teachers do data analysis on at least weekly basis of where their students are at meeting their expectations. I think the other piece of that is just making sure that we have strong 
norms that are not just communicated to students but believed by students. So having them feel invested like the community and making sure that they feel invested in this community is another piece of it that we probably shouldn't ignore.

Interviewer: And there's something too how they actually do it because if I look around the students right now, most of these kids around here look like they're focusing on their work and they're not really messing around. Of course, they're teenagers so there're probably some but if you were just to go five miles from here to one of the regular public schools where they say, "Hey, we really believe in our students and we have high expectations and stick them in this room," they probably wouldn't be on task as these guys. So how are these kids able to stay on task and do what you're expecting whereas this doesn't happen in other schools?

Respondent: That's a great question. I've been here for a while and I feel like it comes a lot down to the horizontal alignment of teachers. And so we have a really strong culture of the 9th Grade teachers or the 10th Grade teachers, 11 th or 12th and so having very consistent and equally executed behaviors, expectations, norms by every one of the 9th Grade teachers or every one of the 10th Grade teachers I think is a strong part of starting that conversation where it's like, "This is what we expect of you and every single one of your teachers is going to expect that from you in the same exact way, at the same time, every single day and not waiver." The teams are really invested in whatever those are because they created them and they're not top down. It's very much bottom up what have you.

Interviewer: And the teams would be the grade level teams?

Respondent: Grade level teams, yeah. So I think that's like-if you were to talk about where it starts, that would be where it starts because then you can start to shift mindsets because you have these very baseline expectations or baseline like how do you call on people or how do you tell someone to speak up or how do you-that are very nitpicky but every single 9th grade teacher, someone is speaking quietly says the voice. That's all they say, they just say "voice" and the student knows to stop, rewind and restart in a louder voice. By the time they're 10 th Graders, now the students are saying that to each other. So they're sitting in a class and they can't hear someone, they say "voice" and 
that student knows even if it's coming from across the room in one of their peers to stop, rewind, restart and say it in a louder voice.

Interviewer: Okay. That's good. I think we got about 12 minutes and we'll get to curriculum. Do you think these skills carry on to help the students be successful in college?

Respondent: Yeah. I mean, all of it has to do with-everything that we ask of students are the things that we actually ask of ourselves as professional adults. And so a lot of the language that you might read or see and our staff norms or our staff values, we ask of the students as well. And so, I think that's another thing that we just kind of ground ourselves in like, what does it take to be a human being in this world and we don't try and fluff things up to something that -- or leave something out because we feel it's not as important.

$[0: 20: 00]$ students?

Interviewer: All right. So staff norms kind of get translated to practices with

Respondent: Yeah. I would say to student norms. And that way it just helps and become a-if that's what we expect of ourselves as professionals and that we are all college graduates and it's just the trickledown effect.

Interviewer: Then we get to curriculum. So I'm not going to make any assumptions and I'll just ask. So the curriculum you use, where does it come from?

Respondent: Okay, broad question. Here we go. So baseline I would say was we started from Engage New York. However-

Interviewer: Is that a company or school?

Respondent: Engage New York is curriculum that was created by I'm guessing the New York Ed team and it's used by all of the State of New York. It's free and online. It is all in PDF form and Word format. We chose to go with Engage New York as a way 
of getting to know the Common Core math standards and having a baseline that the network of four schools, like all Math teachers could start to get on the same page about what does it really mean, like what do the Common Core standards really mean? And that was our way of doing professional development around the new standards.

My Algebra curriculum specifically is I'd say two years removed from Engage New York. So I used it heavily my first year in regards to creating my sample set of - and Engage New York lesson is so long I would probably take a quarter of it because the Engage New York curriculum is just way too far above where my students are at. It folds in way too many sub-skills to the extent that I can't just use it at face value. So I need to scaffold it or I need to change the problem the way in which the problems are asked or what have you so that they are at a level where my students can be successful. So my first year using it, I probably used about a quarter of each lesson and now the only things that really remain are maybe like a couple of problems. We don't use any of the Engage New York exams. We write our own exams.

Interviewer: Okay. So this is different than the curriculum that you see like three or four years ago or this is where it came from?

Respondent: Unfortunately, yes.

Interviewer: It's-?

Respondent: Different.

Interviewer: Oh, so it's completely different? So the whole Algebra spine that was there-

Respondent: So the Algebra Common Spine from three years ago, I still use and I'm like the lead Algebra teacher and the networks of people -- a lot of people follow me however it's not ascribed that they follow me. And so I use a lot of the content that I created for that common spine for my videos or my practices. They're like the independent learning skills. That way it frees me up to have more time to do the connection to the real world piece or the connection to have or create models or the-I see teaching math as like these are the hard skills and this is how those skills connect to 
the broader picture of problem solving and the world. So I use the Algebra Common Spine from way back when for the hard skills so that I create stuff for the-

Interviewer: And you still kind of include the Engage New York curriculum in with that?

Respondent: Like I said, the Engage New York literally was just used as a baseline of what does it mean to teach common format. Like what is the language that we need to be using, what is the difference between CST, the California State Standards, and now the Common Core math standards? What is the difference? What does it look like? That's really what we use Engage New York for. I would say that I don't use Engage New York itself. I use it as like-oh, this is the way we need to ask sum of the equations. This is really what it means to master the standard and then I create content that helps me get to that standard.

[0:25:00]

Interviewer: So it's almost like Engage New York is sort of like setting the-I guess milestones to meet further standards pretty much?

Respondent: Yeah.

Interviewer: But you're not actually using the curriculum that they created in the classroom?

Respondent: No. I think the other Algebra 2 teachers are maybe using it more directly and I think that's because it's less modeling. The Algebra 1's specific curriculum is like modeling heavy which is a skill that is not at all in the CST standards.

Interviewer: And then you said you modify definitely by using what was in the Common -- is it the Spine or Common Spine?

Respondent: Spine.

Interviewer: And then you were definitely involved in selecting the curriculum? 
Respondent: Yes.

Interviewer: The lead teacher?

Respondent: Yeah.

Interviewer: Okay. So we get to instruction. So how do you make decisions about differentiating instruction for students?

Respondent: How do I make decisions to differentiate instruction? So I really think about the student in regards to what are their skill deficits and so that's really how I differentiate. So I split my class up into three different groups. I think of my lowest students, my bottom $20 \%$ that struggle with a lot of their foundational skills that struggle with number sense, like basic number sense like why numbers go together. And a great example is two divided by four is two. They don't see that two divided by four is one half. They're lacking that number sense. And so the bottom $20 \%$, I have it differentiated as instruction model towards and so I give them a lot more direct instruction when it comes down to the skills so that they can access more content in an independent fashion. So I do that a lot in the beginning of the year.

And then the other two thirds of the class, I focus a lot of the instruction on how many scaffolds do I need to give them in order to get them to an Engage New York Level question. So that differentiation changes every single day and for every single group based on their prior knowledge. And then the idea being that the top 30\%, I'm giving significantly less scaffolds to. So maybe I' $m$ just giving them three questions: what do you know? What can we try? Did that work? And helping them facilitate their thinking process through something versus the next group I might be like what do you know? And it's more like scaffolding so it's like 30 seconds, what do you know? Share things out, collaborate, come to consensus then what can we try in helping them draw the connections between things. So really about like, I don't want to give scaffolds to people who don't get it.

Interviewer: Correct. And something you said through questioning in grouping, that one specifically about scaffolds and a lot of teachers use the term scaffold but they 
have different application to scaffoldings. So how would you specifically say what are some of the scaffolds? You just mentioned I guess questioning?

Respondent: Yeah. It's absolutely like questioning what are the different scaffolds? So it's what the level of questioning. So the big broader and central question and then the scaffolding would be like so then do we need to help them make those connections between prior knowledge and the essential question? And how many of those questions do I really need to ask? So it's really questioning. I guess working would be the other one. And the other one would be delivery-content delivery model would be the third one.

So I'd say about two-thirds of my students solely learn how to solve an equation from me solely learn how to do that from there. I give them an assessment. I may be filling the gaps, the most common mistakes, those kinds of things. And then the other one-third of the class learns how to solve an equation from me, watches the video and does like EDpuzzle scaffold supports there, and that's the practice model but they first learn it from me.

[0:30:00]

Interviewer: But that video would probably be for the highest performing third in the class?

Respondent: Yeah. So I would use the same video for everyone. It's just- - no they would be the highest two thirds.

Interviewer: The video only?

Respondent: Video only. Video only assessment, fill in the gaps versus-so imagine two-thirds of the class is learning from the video. They don't need me to tell them what to do. And the lowest one-third is in a small group with me and I'm teaching them the same thing that they're watching on the video.

Interviewer: And what about graphic organizers or things like that for scaffolding? 

organizers.

Respondent: For 9th Graders, I kind of give them all the same graphic

Interviewer: To lead everybody in the class?

Respondent: Yeah and it's specifically because it's 9th Grade and so building the student skill of like how do I organize knowledge, et cetera. Those types of things I really do for the entire class. There's not really much differentiation there.

Interviewer: I haven't asked this one before, I was thinking with math, especially with language, are there any specific scaffolds you use for English language learners or not really?

Respondent: I don't use anything specific. The cool thing about math is we -for the most part, every student in that class struggles and interpreting the text in the same way.

Interviewer: And then the last one would be-so we went through instruction, differentiating, self-directed-you kinda talked about that. Philosophy regarding assessment, formal and informal assessment.

Respondent: Informal assessment should be done nearly every day.

Interviewer: And that would be in the form of?

Respondent: Exit tickets, what I call mastery tasks. So they really don't like cluster contents say like solving equations and asking them it could be a quiz of anyone else's class.

Interviewer: Okay. That's a mastery test.

Respondent: Mastery test but they get immediate feedback on how they did on it and they get multiple attempts on it. So if they get $70 \%$ the first time, then they can take it again, they can make an attempt to the next day or the day after that. 
Interviewer: And these are done online?

Respondent: Yeah.

Interviewer: Do you grade them by hand or they're graded?

Respondent: They're graded by computer.

Interviewer: Okay.

Respondent: And so informal assessments are done every single day and they're done multiple times. And the only formal assessment really is the final exam. That's the only examination that can't be retaken or revised.

Interviewer: The final exam is the only formal-?

Respondent: Only one that cannot be retaken or revised. So the concept being you get multiple attempts at every skill throughout the year.

Interviewer: But there is no chapter test or unit test?

Respondent: There are unit tests but they can retake those.

Interviewer: And that's considered informal?

Respondent: Well, the traditional school system would define that as formal but there goes my philosophy. That can be retaken many times. It's more just like a checkpoint to help them stay on track.

Interviewer: So I guess you're differentiating informal and formal with something that can be retaken over for mastery. It's considered informal? 
Respondent: Yeah. So rather than having the final exam replaced, which I know a lot people do this, the final exam replaces that score, I want them to go back and I want them to try it again to demonstrate growth and knowledge and then-

Interviewer: Okay. Replace what score?

Respondent: Whatever score they got the first time. So if they get $30 \%$ on solving equations in Unit 2, they can go back and retake that and up that to an $80 \%$.

Interviewer: Right and that's before the finals?

Respondent: I want the final exam to be much like what life is, which a onetime attempt is. That is my vertical alignment of that so that's a good freshman.

Interviewer: And then the last thing we're going to get to is you use technology pretty much in the class all the time, videos, all that stuff, and then the last thing would be non-cognitive skill development like persistence, grit. What is the primary objective for teaching that to students?

Respondent: The primary objective would be so that students can acknowledge who they are as a learner and they're able to then adapt their own style to meet the needs of anyone who's trying to teach them. So like my essential question in my class is how do I learn? And just getting them to recognize like, are you someone who replays the video? Are you someone who watches the video and then pauses and writes things down? Getting them to really acknowledge what are the processes that you do when you're learning and are those things that help you or don't help you? And all of that kind of goes towards the concept of perseverance and grit but kind of sees it as like a task, like I rewind the video. That is my example of grit.

[0:35:00] End 


\section{Appendix I}

\section{Teacher demographics}

\begin{tabular}{|c|c|c|c|c|c|c|c|}
\hline & & Dotim Ohen & & & encher Bap. & & \\
\hline & Nabe & nudatern & Subjeat & Thtal & Ar ath scaned & Eatseng & Constastha \\
\hline & Cenderatify & Deseing Mblie Sit & & & & & \\
\hline $\boldsymbol{F}$ & Detua & Me fant- & Niverel & & 4 & mesthage & 1 \\
\hline $\mathrm{t}$ & Osdleng & Mabrill & Englis & $z$ & 2 & Whale: & a \\
\hline 2 & gab & M Vom & Mas & as & 2 & alea & . \\
\hline , & Onter & Mo Finid & Eayfer & 3 & 3 & Milde-fiaturs & 0 \\
\hline 4 & kne & Mb llave & Ineid taafies. & 4 & 2 & Dlate & 0 \\
\hline 3 & $9=$ & Mr ine & Seime & 2 & 3 & An: & 0 \\
\hline 4 & zinnas & It Alvere: & Ma & 7 & 5 & Hiemen: & e \\
\hline y & Kative & N hing & Platios: & 12 & 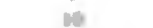 & Des & $\mathrm{B}$ \\
\hline 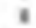 & Frosed & Ma Gunte & leypuses & 10 & $\omega$ & Heran: & e \\
\hline+ & Stib & Sh. $t=$ & Mat & 3 & 2 & An: & 0 \\
\hline 14 & Selate & Me Tenkb & Seiveno & 2. & 1 & Afrite-kmencah & $\mathrm{e}$ \\
\hline 11 & Sen & Me Jabere & Sacie Sculas. & is & 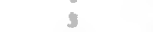 & Alticendenarion & 0 \\
\hline iz & Foremen & u. $\mathrm{Cos}$ & Seriel Seafes: & 5 & 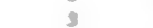 & Afriesednmorkinal & 0 \\
\hline 11 & Dieda & Mo Fogr & Caneshen & 8 & $s$ & able & 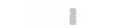 \\
\hline 14 & Imen & Mt Minen & Ceaticher & 2 & 3 & Heren: & i \\
\hline is & Aesele & In heliew & Conather & $s$ & 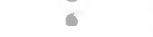 & Heten & 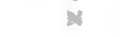 \\
\hline & & 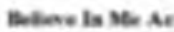 & & & & & \\
\hline $\mathrm{r}$ & Prrese & M Clampian & Fineits & $\mathrm{E}$ & 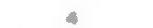 & & I \\
\hline 8 & unomen & Me oriank & nes & : & - & atres & . \\
\hline 2 & Stavin & Mo Twene & Engles & 3 & 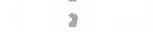 & as: & s. \\
\hline 3 & anes & M Citm 1 & Sertaisheflm & $2 a$ & 夏 & whet & 0 \\
\hline 4 & Decientik & Ne flenth & Selenes & 5 & 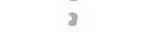 & was & a \\
\hline 5 & nemein & Mo Dabrused & Nes & 2 & 19 & wherating & 0 \\
\hline 6 & neroves & Mt Heriak & Elante. & 3 & 1 & Mincons & 0 \\
\hline 7 & Cart: & Men Darnis & Englet & 4 & 4 & What & 를 \\
\hline 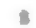 & antb & M ceselns & Setan & 2 & a & ahiofirgus: & 0 \\
\hline 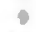 & tasans & Mhe Argatin & Soctaishowm & as & e & ilingenes & 0 \\
\hline 10 & imese & Mr Marest & $M=0$ & o. & ad & whe & 0 \\
\hline it: & Dewere. & Mo Feleial & tench & , & 1 & Whas & t \\
\hline 13 & was & Ma Mesos & Coveneler & $s$ & 3 & Heges & 3 \\
\hline & & concoweste & and & & & & \\
\hline h. & tha sele & Me Primas. & hased & $\bullet$ & 1 & Hirtese & 1 \\
\hline 1 & westos. & Me Vhant & Even & 0 & e & whe & D \\
\hline$z$ & Matlowe & Me Nickisele & un & 1 & 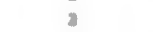 & Alriece-knamon/Niual & 0 \\
\hline$s$ & aoven & Mo Canalute & senelimen & $z$ & 2 & Whe & s \\
\hline 4 & Emo & Ma Sumb & nes & z & $\Delta$ & Migcoulabe & in \\
\hline$s$ & termetes & $\mathrm{MSCM}$ & mernos & 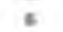 & 4 & ifirense & 0 \\
\hline 6 & Consumer & M Dunlusy & semos & ac & $s$ & whe & D \\
\hline 3 & Homen & Mo lenda & 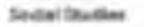 & 2 & 邓 & anes & i \\
\hline e & ing & No Cintetm & serest & $s$ & 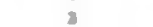 & Wha & s \\
\hline - & Enewe & M. Lochis & ma & $s 7$ & 2 & mea & 룰 \\
\hline te & wims & Me Xine & somens & 2 & 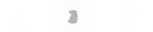 & ales & 0 \\
\hline 11 & vere & Nh Xinas & olve & 1 & 8 & hasn & 0 \\
\hline 12 & Meto & Me Nisks & Contiler & ve & 8 & ane & 1 \\
\hline $\mathbf{3 4}$ & & & & & a & CMereveies Coly & is \\
\hline & & & & & $i$ & latavies Only & 8 \\
\hline & & & & & - & na & 17 \\
\hline & & & & & & 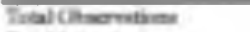 & 33 \\
\hline & & & & & & Dral Itwenter & 23 \\
\hline
\end{tabular}

